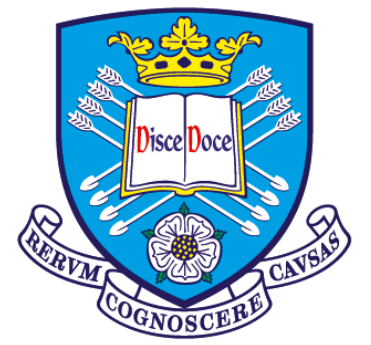

The

University

Of

Sheffield.

Professionalism in the legal profession - can you teach it?

A phenomenographic study of Irish legal education stakeholders' perceptions.

By Rachael Hession

A thesis submitted in partial fulfilment of the requirement for the degree of Doctor of Education

University of Sheffield

School of Education

October 2016 


\section{Acknowledgments}

Thank you to my supervisor, Professor Kathryn Ecclestone, for her constructive feedback, support and endless patience. Thank you also to the Law Society of Ireland for giving me the opportunity to carry out this study. 


\section{Dedication}

To my two boys. 


\begin{abstract}
The Law Society of Ireland is currently the sole provider of legal professional training in Ireland leading to qualification as a solicitor. Its educational policy provides that it must ensure students are prepared for professional practice and instil in them a lifelong commitment to high professional standards and behaviour. Yet, there is concern that professionalism is losing its value.
\end{abstract}

In this context, and following an earlier small scale study which studied the perceptions of the legal education teachers (tutors and training solicitors) only, this thesis explores the teaching of legal professionalism in Ireland using interview data from the principal stakeholders in the legal profession education system including students (the trainee solicitors). The data was analysed phenomenographically in order to determine the extent to which there was variation in perceptions among these stakeholders as to how professionalism is understood and how best to teach or instil the notion.

The findings indicate diverse perceptions among stakeholders that reflect a lack of shared understanding of both professionalism and how to teach it. The study critically discusses the findings in light of relevant literature. It explores questions about how any variance might affect the quality of teaching of professionalism, what social and cultural factors are at play and how, if necessary, variations in perception might be addressed. The study concludes that a co-ordinated approach to understanding and fostering professionalism will help bridge this gap in perceptions. This should raise professional standards and could, potentially, address the concerns of the profession.

The study outlines recommendations for professional education and suggestions for future studies. 


\section{TABLE OF CONTENTS}

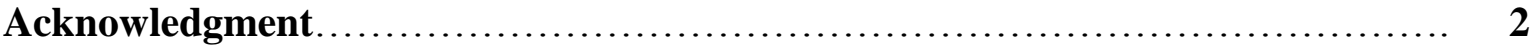

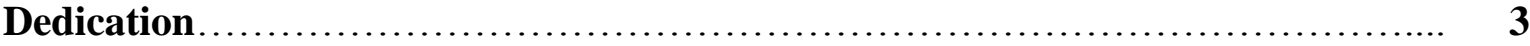

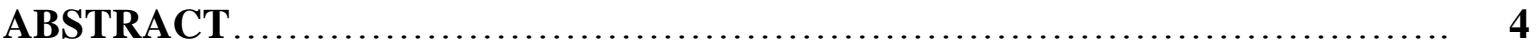

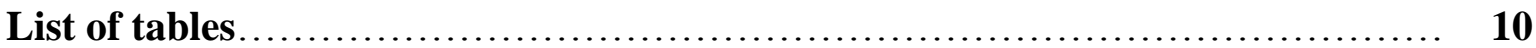

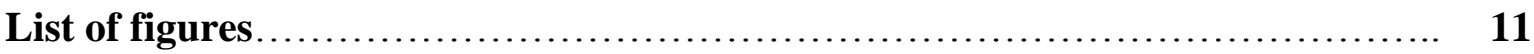

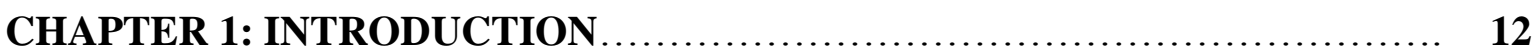

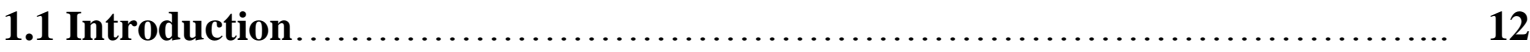

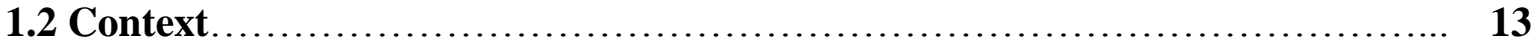

1.2.1 Professionalism in crisis ................................................ 13

1.2.2 Crisis of trust and the rise of rule-based professionalism...................... 13

1.2.3 Irish context/the Legal Services Regulation Act $2015 \ldots \ldots \ldots \ldots \ldots \ldots \ldots \ldots \ldots \ldots \ldots$

1.2.4 Social control and the control of knowledge............................... 16

1.2.5 Commercialisation of the profession...................................... 17

1.2.6 Professional legal education in a new era................................. 18

1.2.6.1 Professional Education .................................................. 18

1.2.6.2 Commodification of professional education............................... 18

1.2.7 The Law Society Professional Practice Course............................. 19

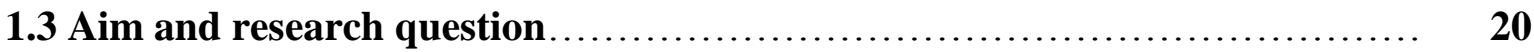

1.4 Rationale for Research/Claim to knowledge............................ 22

1.5 Structure of the study .............................................. 22

CHAPTER 2: LITERATURE REVIEW ................................. 24

2.1 Introduction $\ldots \ldots \ldots \ldots \ldots \ldots \ldots \ldots \ldots \ldots \ldots \ldots \ldots \ldots \ldots \ldots \ldots \ldots \ldots \ldots \ldots \ldots \ldots \ldots \ldots, \quad 24$

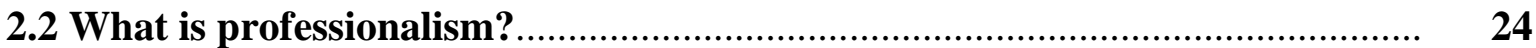

2.2.1 A Profession......................................................... 25

2.2.2 Regulatory, representative and professional bodies........................ 25

2.2.3 Legal Academics...................................................... 27

2.2.4 Personal conscience............................................... $\quad 30$

2.2.5 Medical Profession's understanding of professionalism.................... 30

2.2.6 Cultural influence on understanding of professionalism................................... 31

2.2.7 Social Contract..................................................... 32

2.2.8 Shift from the traditional............................................. 34

2.2.9 Rule-based professionalism......................................... 35 
2.2.10 Defining professionalism and social control.......................... 36

2.3 Workplace learning .................................................. 36

2.3.1 Learning process.................................................. 37

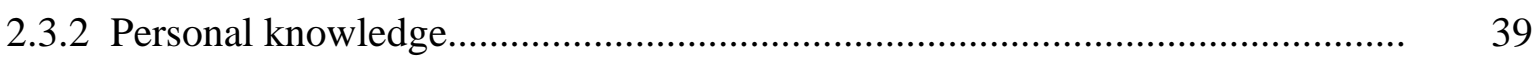

2.3.3 Tacit knowledge................................................... 39

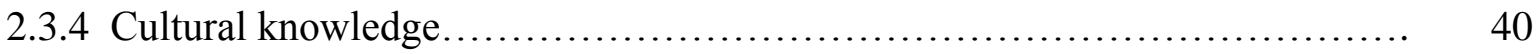

2.3.5 Organisational learning............................................... 41

2.3.6 Situated learning................................................... $\quad 42$

2.3.7 Different but legitimate knowledge................................. 43

2.3.8 Workplace knowledge needs support................................ 44

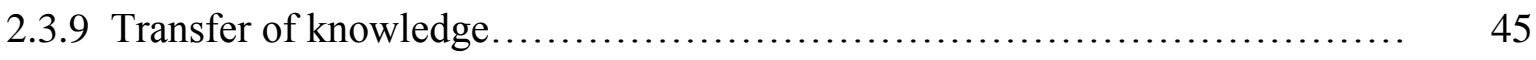

2.3.10 Implicit theory - behaviour......................................... 46

2.3.11 Personal knowledge in the workplace culture............................ 46

2.3.12 Influence of legal training firms........................................ 47

2.3.13 SRA work-based learning pilot...................................... 49

2.4 Approaches to instilling/teaching professionalism........................ 50

2.4.1 Approaches to learning............................................ 50

2.4.2 Teaching of Professionalism......................................... 51

2.4.3 Professionalism cannot be taught...................................... 51

2.4.4 The Traditional apprenticeship approach - Mentoring/Role models........... 52

2.4.5 Hidden curriculum................................................ 56

2.4.6 Small group learning/reflection....................................... 57

2.4.7 Experiential learning.............................................. 58

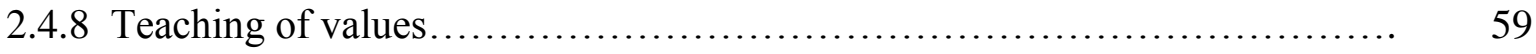

2.4.9 A pedagogical shift.................................................. $\quad 60$

2.4.10 Competence based approach - the commercialisation of Law Schools....... $\quad 60$

2.4.11 Explicit learning with cognitive base................................. 62

2.4.12 Assessment of professionalism...................................... 64

2.4.13 Implications for legal professional education........................... 65

2.5 Summary of Chapter............................................ 66

CHAPTER 3: RESEARCH DESIGN ................................... 67

3.1 Epistemological and theoretical perspectives.......................... 67

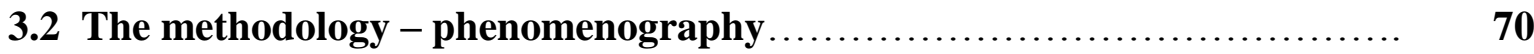

3.3 Data Collection/Participation selection .............................. 74 


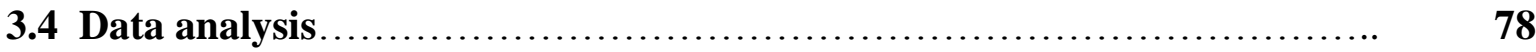

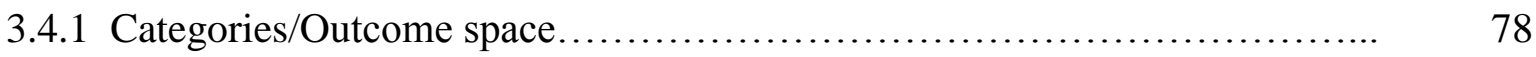

3.4.2 Analytical frameworks - Structural and referential aspects................... 82

3.5 Limitations/Validity/Reliability of methodology ........................... 83

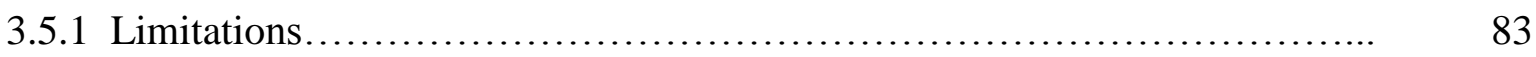

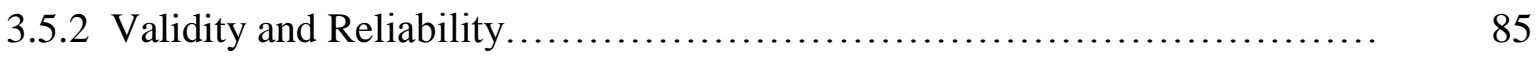

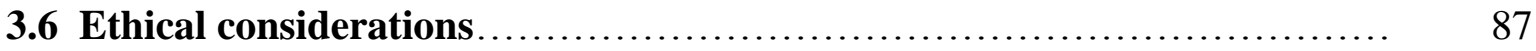

CHAPTER 4: PRESENTATION OF THE RESEARCH FINDINGS AND

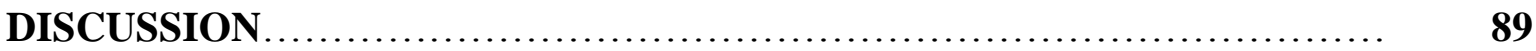

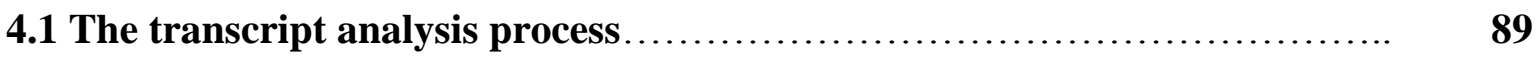

4.2 Section 1: Perception of the concept of professionalism...................... 93

4.2.1 Category A: Professionalism is based on ethics, values and autonomy........ 93

4.2.2 Category B: Professionalism is behaviour-based............................ 94

4.2.3 Category C: Professionalism is about managing clients....................... 95

4.2.4 Category D: Professionalism is based on competence and efficiency........... $\quad 96$

4.2.5 Structural relationship between the categories................................. 99

4.3 Section 2: Stakeholders' perception of how best to nurture professionalism. 102

4.3.1 Section 2.1: Can everyone pick up professionalism?.......................................... 102

4.3.1.1 Category A: No - not everyone can pick up professionalism.......... 103

4.3.1.2 Category B: Yes - everyone can pick up professionalism but only

if they actively choose to do so................................................ 104

4.3.1.3 Category C: Yes - everyone can pick up professionalism.............. 104

4.3.2 Section 2.2: Explicit teaching of professionalism - Is it possible?.................... 107

4.3.2.1 Category A: Professionalism can be taught explicitly................ 107

4.3.2.2 Category B: Explicit teaching of the basic principles of professionalism

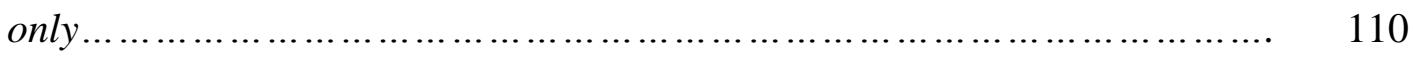

4.3.2.3 Category C: Implicit teaching only of professionalism............... 111

4.3.2.4 Category D: The instilling of professionalism requires a role modelling approach .................................................................. 113

4.3.3 Section 2. 3: Should standards of professionalism be assessed in order to instil it and by whom? 
4.3.3.2 Category B: Professionalism can be assessed but method of assessment is not clear....

4.3.3.3 Category C: Professionalism should be assessed.................... 121

4.3.4 Section 2. 4: Is it important to define professionalism in this context? ........ 124

4.3.4.1 Category A: Professionalism needs to be defined.................... 125

4.3.4.2 Category B: There is no need to define......................... 126

4.3.4.3 Category C: Professionalism is too difficult to define................ 127

4.3.5 Section 2.5: What influences the instilling of professionalism?..................... 129

4.3.5.1 Category A: The existence of barriers influences the learning

professionalism....................................................

4.3.5.2 Category B: Positive learning experience influences the instilling of professionalism.

4.3.5.3 Category C: The instilling of Professionalism is influenced by the culture of the firm....

4.3.5.4 Category D: Professionalism is influenced by an individual's background and /or personality....

4.4 Findings and discussion - summary of key points

4.4.1 What is professionalism: variance in perceptions'

4.4.2 Variance in perceptions in relation to one's ability to assimilate professionalism 135

4.4.3 Variance in perceptions in relation to the explicit and implicit teaching of professionalism.

4.4.4 Variance in views on the assessment of professionalism.

4.4.5 Influences on nurturing professionalism: variances in perceptions

4.4.6 Divergence between the data and the literature.

CHAPTER 5: CONCLUSION

5.2.1 How do the stakeholders perceive and understand professionalism as a concept 
and is there variance in their perceptions (Part 1)....

5.2.2 What are the qualitatively different ways in which the stakeholders vary in their understanding of how professionalism can be fostered (Part 2)....

5.3 General implications for professional legal education in Ireland and Workplace learning

5.4 Strengths, weaknesses and limitations.

5.5 Significance/Contribution to knowledge and practice

5.6 Concluding remarks.

5.7 Implications for future research and publication.

REFERENCES

APPENDICES

Appendix 1 -sample interview questions..................................... 162

Appendix 2 - BERA Ethical guidelines for Educational Research..................... 164

Appendix 3 - Information Sheet for Interviewees................................ 172

Appendix 4 - University of Sheffield Ethical Consent Form....................... 176 


\section{List of Tables}

\begin{tabular}{|l|l|l|}
\hline Table 1 & $\begin{array}{l}\text { Outcome space: Part 1 - } \\
\text { Perception of } \\
\text { Professionalism }\end{array}$ & p. 100 \\
\hline Table 2 & $\begin{array}{l}\text { Outcome space: Part 2.1 - } \\
\text { Can everyone pick up } \\
\text { professionalism }\end{array}$ & p. 106 \\
\hline Table 3 & $\begin{array}{l}\text { Outcome space: Part 2.2 - } \\
\text { Explicit teaching, is it } \\
\text { possible? }\end{array}$ & p. 118 \\
\hline Table 4 & $\begin{array}{l}\text { Outcome space: Part 2.3 - } \\
\text { Should professionalism be } \\
\text { assessed? }\end{array}$ & p. 123 \\
\hline Table 5 & $\begin{array}{l}\text { Outcome space: Part 2.4 - } \\
\text { Should professionalism be } \\
\text { defined? }\end{array}$ & $\begin{array}{l}\text { p. } 128 \\
\text { Influences on teaching } \\
\text { professionalism }\end{array}$ \\
\hline Table 6 & p. 134 \\
\hline
\end{tabular}




\section{List of Figures}

\begin{tabular}{|l|l|l|}
\hline Figure 1 & $\begin{array}{l}\text { The relational position of } \\
\text { Phenomenography }\end{array}$ & p. 73 \\
\hline Figure 2 & $\begin{array}{l}\text { An example concept map: } \\
\text { variance in Stakeholders } \\
\text { understanding of } \\
\text { professionalism }\end{array}$ & p. 91 \\
\hline
\end{tabular}




\section{Chapter 1}

\section{INTRODUCTION}

\subsection{Introduction}

As Erikson observed in the context of nurseries, signature pedagogies prefigure the cultures of professional work and provide the early socialization into the practices and values of a field. Whether in a lecture hall or a lab, in a design studio or a clinical setting, the way we teach will shape how professionals behave-and in a society so dependent on the quality of its professionals, that is no small matter. Shulman (2005, p.59)

Fostering and developing professionalism is of utmost importance for any profession. The Law Society of Ireland is currently the sole provider of legal professional training in the Republic of Ireland, resulting in qualification as a solicitor. Its educational policy provides that it must ensure students are prepared for professional practice and instil in them a lifelong commitment to high professional standards and behaviour. Its regulatory policy expects compliance with a professional code of conduct, ethics and professional behaviour. Concerns regarding the teaching of professionalism are nearly as old as the profession itself. In a preamble to the first statute regulating the solicitor's profession in Ireland, a 1773 Act, it was stated that the lack of a proper structure of education has resulted in solicitors "who are guilty of mean and improper practices to the dishonour of the profession" (Hogan, 1986, p.16).

Many in the legal profession see this profession as in crisis. There is concern within the profession; not only in Ireland but internationally, that professionalism has lost its meaning. Kronman (2000) talks about the pillars of the profession being under assault by the forces of commercialisation, privatisation and specialisation. He is concerned that if the current crisis of legal professionalism "is a consequence of the weakening of those elements that make the practice of law a profession, and if these very elements contribute in some demonstrable way to the good of society as whole, then society's welfare is implicated directly in the demise of legal professionalism" (Kronman, 1999, p.4) 
This study examines the teaching of professionalism from the perspectives of the key stakeholders in professional legal education in Ireland. These stakeholders are: the solicitors primarily employed in training firms i.e. solicitors' firms who contract to train student solicitors, Law Society tutors, the trainee solicitors (the students known as trainees or trainee solicitors) and the Law Society Course Executives (who are involved in the design and delivery of modules dealing with professionalism and responsible for the trainees in the Law Society). This group are referred to as the stakeholders throughout the study.

This chapter begins with the context in which the study is set. This is followed by the aim of the study and the research question. It then discusses the rationale for undertaking the study.

\subsection{Context}

\subsubsection{Professionalism in crisis}

Like all debates about the best approach to fostering professionalism, this study is set in and framed by a particular socio-political context. In the last few decades there has been widespread media reporting and discussion of a lack of professionalism in political, banking, legal and other spheres. There is concern that professionalism has lost its value; where the anxieties concerning professionalism that lawyers are experiencing are part of a wider crisis of professionalism. Kronman (2000) advises that any weakening of legal professional culture has wider social and cultural implications:

The legal profession is an integrative force in a world of disintegrating powers ... it is why everyone - and not just lawyers - should be concerned by a threat to the culture of legal professionalism. For the values that define this culture are the key to the work that lawyers do in bridging the division of our world, divisions whose disintegrative effects are at once the familiar and most dangerous features of modern life (p. 37).

Evans (2007 as cited in Bailey, 2011) maintains "that it is the substance of professionalism that is important today" (p.10). She draws attention to the view that the erosion of expert knowledge, one of the core components of professionalism, is having an effect on the security and power of the professional.

\subsubsection{Crisis of trust and the rise of rule-based professionalism}

A general crisis of trust that some commentators see as arising from an increase in bureaucracy, has implications for professionalism. For example, O’Neill (2002) asks if the culture of accountability and audit supports or undermines trust. She suggests that the 
accountability revolution is in fact obstructing the aims of professionalism. She maintains that a profession's aim cannot be reduced to a set of prescribed procedures to meet set targets. This over-emphasis on meeting targets and auditing effectively means less time for interaction with the clients or patients that professionals serve. Moreover, she questions if this worldwide "crisis of trust" is more a "culture of suspicion" (p.45): "Plants don't flourish when we pull them up too often to check how their roots are growing: political institutional and professional life too may not flourish if we constantly uproot it to demonstrate that everything is transparent and trustworthy" (p.19).

The tensions that arise between a more intrinsic approach to professionalism and overcompliance with externally imposed standards set by regulatory bodies are explored by a number of other commentators. Some argue that over-compliance or requirement for strict obedience erodes autonomy. For example, Braithwaite (1990) points out that historically, under the US Canons of Professional Ethics, 1908, professionalism meant 'honourable character' while now lawyers must comply with the American Bar Association's Model Rules of Professional Conduct, 1983 with the result that "law abidingness has supplanted the aspiration to moral excellence. Obedience, not honor, is now the lawyer's primary trait" (p.72). Here too, there is concern that professionalism and ethics have been reduced to a set of rules with greater emphasis on compliance with bar disciplinary codes thus leading to a failure to recognise that professionalism is an induction into a culture (Rhode, 1985; Kronman, 2000). Taylor (1997) points out that accountability structures are often led by managers who increasingly do not come from the professions they manage. This, according to Taylor, can result in difficult dilemmas, as manager, employers and professions do not always share the same values or priorities.

Commentators warn that the restrictive control of the professional's practice can result in professionals being backed into a corner. This leads to the professional taking defensive action which ultimately compromises the needs of the client (Eraut, 1994; Freidson, 2001 and Taylor, 1997). Evans (2008) and Bailey (2011) are also concerned with the consequences, for the client, of this climate of accountability. Bailey questions whether legislation which introduces restrictive control results in fairness and transparency for all, while Evans (2008) asks if accountability has eroded professional autonomy to the point where it has negative consequences for the client. 
These concerns are of particular relevance in an Irish context with the Irish Government intervention in the regulation of solicitors (see section 1.2.3) and the ensuing consequences for the autonomy of the solicitor. O'Neill (2002) warns of public accountability leading to the imposition of inconsistent central control by government regulators. She describes professionals as perhaps "responding to incentives to which they have been required to respond rather that pursuing the intrinsic requirements for being good (professionals)...the new culture of accountability provides incentives for arbitrary and unprofessional choices" (p.56).

\subsubsection{Irish context/the Legal Services Regulation Act 2015}

As a legal educator in the Law Society of Ireland, the ways in which these concerns and the questions relate to the Irish socio-economic context is of particular relevance to my decision to carry out this study. In the last decade, the legal profession in Ireland has been mired in controversy, with a number of notorious rogue solicitors emerging. For example, the high profile ex-solicitor, Michael Lynn, defrauded clients and banks in the amount of $€ 80$ million. The Law Society Compensation Fund paid clients' claims. Moreover, the profession's vulnerability to being de-valued in the current economic and social climate is also evident in the controversial provisions for extensive de-regulation provided for in the Legal Services Regulation Act 2015 Act (2015 Act), which stems from the European Union/International Monetary Fund (EU/IMF) Programme of Financial Support for Ireland. This Programme emanates from the 2006 Competition Authority Report on Professional Services: Solicitors \& Barristers, which, in turn, was based entirely on matters relating to market forces. The recently enacted 2015 Act was the subject of intense debate within the Irish legislative process due to its controversial nature. The overriding concern, both nationally and internationally, with the 2015 Bill (draft Act), was the impingement on the separation of powers which, in a democracy is based on a trinity of separated powers - the judiciary, the executive and the legislator. The 2015 Act provides for the transfer of the regulatory function of the Law Society to the Irish Government. The Executive (the Dáil or Government) now has authority, albeit somewhat limited after extensive lobbying from the legal profession both in Ireland and abroad, over the regulation of solicitors which can impinge on the judiciary function.

One of the recommendations of the EU/IMF Programme is that sole responsibility for regulating and providing professional legal education be removed from the Law Society. This 
recommendation is provided for in the 2015 Act through the commissioning of a report to be carried out within two years from the enactment of the legislation. The report's objective is to analyse the effectiveness of the current system of legal professional education in Ireland and to consider opening the professional education market to other providers. The introduction of competition is widely expected. There is concern that decisions about the provision of legal education will be taken solely on the grounds of market forces and that ultimately the quality of the teaching of professionalism will suffer because of the commercialisation and commodification of legal education.

\subsubsection{Social control and the control of knowledge}

There are also concerns amongst scholars regarding control exerted by professional institutions. For example, Boon, Flood and Webb (2005) maintain that the use of bureaucratic surveillance and training by professional associations is a means by which they can exert authority and legitimatise the association's existence. But as they poignantly ask, "if control over knowledge is lost, what happens to power?" (p.474). Martimianakis, Maniate and Hodges (2009) point out the importance of considering the political and economic goals of the professional institutions that specify the traits and behaviours expected of their professionals and the control that institutions exert in constructing professional identities. They also explore the view that the process of professionalization is a means of controlling the production of knowledge and ultimately, the end users of this knowledge. How professionalism is defined can be used as a form of control by persuading members to behave in a particular manner as determined by the organisation (Evetts, 2003). This analysis is of particular relevance in light of the proposal to open up the professional education function to competitors following the 2015 Act. The Law Society currently has a monopoly on the knowledge production.

Parker (2002) explores the traditional form of social control exerted by the legal profession whereby lawyers decide what is best for their clients, the public and the administration of justice, on the basis that non-lawyers do not have the intelligence or expertise. She warns that the traditional self-regulatory control of the profession over areas such as requirements for entry to the profession, discipline and liability "for breach of fiduciary duty, are not responsive to public concerns about justice and customer service" (p.676). She argues in favour of a move towards a moral activist approach whereby the client is an equal participant in the necessary decision making and shares the ethical responsibility. 


\subsubsection{Commercialisation of the profession}

A number of commentators view the commercialisation of the legal profession as being one of the greatest challenges facing the profession (Kelly, 1994; Rhode 1985; Kronman, 2000; Kullgren \& Lowenstein, 2003). It is suggested that the commercialisation of the law practice threatens the future of the profession and is in conflict with the notion of professionalism. Braithwaite (1990) laments the noble profession's move away from, its traditional role, towards the "model of commerce and partisan politics" (p.72): "todays commercialization model of law practice is not collegial in spirit. Nor is it even political, except in the narrow sense implying contentiousness of conflicting desires. It is corporate in form, competitive in character, and all too often avaricious in aims" (p.71).

Various commentators discuss the concerns arising from the international growth in large law firms and the view that this has led to a decline in this 'noble virtuous' profession to a business obsessed with the 'bottom line' (Phillips, 2004; Dolin, 2007). Kronman (2000) maintains that as lawyers become more specialised and more corporate, profitability takes precedence over collegiality and social responsibility. He points out that lawyers can no longer afford to comply with their professional responsibilities because of an increase in competition. Moreover, lawyers particularly in larger legal institutions, experience a sense of alienation and a sense of detachment from the profession. Kelly (1994) explains that contemporary practice organisations must compete aggressively in a difficult market where lawyers perceive themselves as employees and less as independent professionals. On the one hand, this adoption of a business management style is seen as a beneficial to the disorganised world of lawyers, while the other view is that of a decline in values and the law degenerating into a commodity. Bowie (1988 as cited in Philips, 2004) goes as far as saying that "most lawyers are using their specialized knowledge to enable the rich and powerful to exploit the poor and ignorant while enriching themselves in the process" (p.17).

Philips (2004) questions this concern with commercialisation. He points out that following business methods does not necessarily lead to a decline in professional standards. Boon et al. (2005) and Maute (2011, cited in Bartlett, Mortensen and Tranter, 2011) argue that commercialisation does not necessarily lead to a decline in professionalism but perhaps a modernisation in response to an increasingly competitive and global market. Notably, Pearse (1995) rejects professionalism in favour of a business paradigm for the legal firm, a move 
which is strongly criticised by Stempel (1999). Stempel rejects the premise upon which Pearse basis his argument in favour of the business model.

\subsubsection{Professional legal education in a new era}

\subsubsection{Professional Education}

In the light of these concerns and the academic and professional debates that address them, a brief overview of the literature on what professional education entails is important in the framing of the context for this study and is further developed in Chapter 2. Shulman (2005) explains that:

Professional education is not education for understanding alone; it is preparation for accomplished and responsible practice in the service of others. It is preparation for 'good work.' Professionals must learn abundant amounts of theory and vast bodies of knowledge. They must come to understand in order to act, and they must act in order to serve (p.53).

In similar fashion, Taylor (1997), points out that:

Professional education is distinctively different than higher education primarily because of its dynamic relationship with the professions, and more recently with employers and government...Furthermore, compared to many other students in higher education, students in professional education are distinguished by their motivations to study for a very specific purpose which will have a direct influence on the rest of their working lives (p.3/4).

Taylor argues that the growing array of stakeholders, and the powerful diverse influences on professional education, shapes the education structure and management. In an English context, she explains that there may be conflicting interests: the employers seeking suitably qualified individuals; the government as the policy maker, who often provide financial support (the Irish government does not currently provide this role), are perhaps more focused on operational technical knowledge and skills; and the professional and representative bodies who attach more importance to value-based reflective skills and knowledge. In this vein, Eraut (1994) explains that professional education implies not only propositional learning but also personal and process knowledge.

\subsubsection{Commodification of professional education}


There is concern that, generally, higher education is in crisis as its traditional role adapts to an employability agenda, thereby placing it in a service role (Brennan \& Little, 1996). While the Law Society's Professional Practice Course (PPC) is for the most part an applied knowledge professional course, the concerns that commentators have are also relevant in this context. With the emphasis on education, in general, as a marketable commodity, the trend towards standardization and a competency approach has a significant effect on professional legal education. A number of the leading education commentators are concerned that the teaching and standards of professionalism will suffer because of the commercialisation and commodification of legal education (Braithwaite 1990; Maharg, 2006). While Boon et al. (2005) recognise that commodification can encourage new approaches to learning in a flexible, capitalist economy, they do express concerns that the emerging process of commodification of legal education places an increasing emphasis on the student as the customer, standardising of learning outcomes, and occupational and skills-based vocational learning. Taylor (1997) draws attention to the requirement for efficient delivery of professional education as a commodity and to the compounded impact that reduced resources and economic cutbacks have when there is reliance on qualified professionals as a teaching resource. She also comments on the challenges arising from the "shifting boundaries of the professions (p. 13)" in the form of interprofessionalism or interdisciplinary courses developed in response to market needs. Taylor also refers to Jarvis' 1993 study of the shift from the conservative ideology of knowledge in the hands of the professional expert towards the ideological position of education as an empowerment of the individual.

\subsubsection{The Law Society Professional Practice Course}

Legal professional education or the solicitor training programme in Ireland comprises three stages: 1) a six-month Professional Practice Course I (PPC I), 2) twenty one months in-office training in a solicitor's firm under the supervision and guidance of a training solicitor, and 3) a three-month Professional Practice Course II (PPC II). Following Section 44 of the Solicitors (Amendment) Act, 1994, the training solicitor must be a practising solicitor with four years continuous practice unless consent is obtained from the Society. Training solicitors must be able to provide reasonable and appropriate instruction and experience in core areas of legal practice and practical legal skills including professional development (Law Society of Ireland, 1994). Larger firms have training executives who assist with the training obligations of the training solicitor. 
I am employed as a Course Manager with the Law Society's Education Department and I am part of the PPC lecturing and course design team. I have held this position for over ten years. It involves lecture and tutorial delivery, recruitment of course tutors to deliver certain lectures and tutorials, material and course design, authoring and editing of course manuals and student mentoring. PPC I and PPC II are practice and procedure based. The PPC I comprises five core modules: Applied Land Law, Probate and Tax, Business Law, Litigation and Skills. PPC II comprises of three compulsory subjects: Professional Practice Conduct and Management (PPCM), Employment and Family law together with a number of electives. Modules are assessed by way of open book exams with the exception of Ethics which forms part of the PPCM module. The majority of the students are in their twenties having passed the Law Society entrance exams (FE1's) within a few years of completing a third level law degree. Lectures and tutorials are delivered by course managers and members of the solicitors' profession (course tutors). Lectures are generally teacher-led followed by active problembased tutorials.

Professionalism is embedded in various aspects of the PPC course modules. Specifically, the PPC I Professional Development skills course objective is to provide an overview of the key professional competencies and behaviours of a good solicitor, including professional standards and ethics. The PPC II trainees complete the Professional Practice Conduct and Management (PPCM) course which contains a module on Professional Conduct with the aim of making trainees aware of the importance of professional behaviour and ethical conduct for solicitors. Professionalism in the PPCM is underpinned by the Law Society Guide to Professional Conduct of Solicitors in Ireland (2013) and the explicit definition of professionalism contained therein (see section 2.2.2).

It is against this contextual backdrop that this study takes place.

\subsection{Aim and research question}

Legal professional training plays an important role in fostering and protecting professionalism. This is of particular importance in the current socio-economic climate discussed above (see section 1.2). In an educational setting, including the one I work in, a number of initial questions and dilemmas come to mind relating to professionalism: What is professionalism? And fundamentally, can this notion be taught? What role do training solicitors and course executives have in fostering professionalism and, more specifically, how do they perceive this role? How do the students (trainee solicitors) understand 
professionalism, and how can professionalism be instilled? Is it necessary to evaluate and define it in order to embed the principles of professionalism? Do the perceptions of the various stakeholders differ and how might this variation impact on students' learning?

These questions reflect difficult tensions that arise from the particular socio-economic setting of this study and therefore form the basis of the rationale for this study and the research questions outlined below. Specifically, this study aims to identify and explore how and to what extent the stakeholders' perceptions vary in terms of how they understand professionalism and the ways in which the concept should be fostered. Moreover, it aims to critically explore any effect that such variance in perceptions might have on teaching and instilling professionalism in trainee solicitors and on the quality of teaching professionalism.

The core research question to be investigated is as follows: Is there variation in key stakeholders' perceptions on how best to instil or teach professionalism and what are the implications of any variance for professional legal education in Ireland?

The sub-questions raised in this thesis are three-fold:

1. How do the stakeholders understand professionalism as a concept and is there variation in their perceptions?

2. What are the qualitatively different ways in which the stakeholders vary in their understanding of how professionalism can be instilled:
a. Can everyone assimilate professionalism?
b. Is it possible and desirable to teach professionalism explicitly?
c. Should standards of professionalism be assessed in order to instil it and by whom?
d. Is it important to define professionalism in this context?
e. What influences the instilling of professionalism?

3. What are the implications of any variance for the stakeholders in professional legal education in Ireland?

The methodology adopted in this study is phenomenography (discussed in depth in Chapter 3). The sub-questions are structured in line with the aim of this approach: to investigate variation in the underlying ways that a phenomenon can be experienced (Marton \& Booth, 
1997; Akerlind, 2002). In this case, the phenomenon is the notion of professionalism and the teaching of the concept. Perceptions or ways of understanding the concept of professionalism and the understanding of how it is taught and fostered are analysed phenomenographically in this study.

\subsection{Rationale for Research/Claim to knowledge}

While variation in stakeholders' perceptions has been explored in other educational contexts, leading to insights into how the variance affects education (Prosser \& Trigwell, 1999; Shreeve, 2010; Martin, Trigwell, Prosser \& Ramsden, 2003; Akerlind, 2002; McKenzie, 2002), my review of the literature reveals that this exploration has not been carried out to any significant extent in a legal education setting. Similarly, the perceptions of those involved in the education of professionalism, both the concept and the teaching, in the medical field (particularly medical students) have been explored relatively extensively (Beckett \& Gough, 2004; Ratanawongsa, Bolen, Howell, Kern, Sisson and Larriviere, 2006; Park, Woodrow, Reznick, Beales and MacRae, 2010; Riley \& Kumar, 2012; Byszweksi, Hendleman, McGuinty \& Moineau, 2012; Cuesta-Briand, Auret, Johnson and Playford, 2014). While professional learning generally in the workplace is discussed by various commentators (Eraut, 1994; Boud, 2001; Evans \& Rainbird, 2002), commentary on workplace learning in a legal context is limited (Corbin, 2005; Mather, McEwen and Maiman, 2001). Notably, there appears to be no study or commentary exploring the teaching of legal (or medical) professionalism in a professional education setting in an Irish context.

In an era of a "crisis of trust" in professionalism (O'Neill, 2002) and vulnerability of the profession to a decline in value in the current socio-economic climate, ensuring that the best methods to teach or instil professionalism are adopted is crucial. It is therefore important to identify and examine any variation in perceptions of those involved in educating students in professionalism and the students themselves. There are two reasons for this: in order to critically discuss if the variation has a negative effect on the fostering of professionalism and if so, how to address the lack of a co-ordinated approach. Only then can we attempt to develop and safeguard the notion ensuring that newly qualified solicitors' reach and maintain high standards of professionalism.

\subsection{Structure of the study}

Chapter 1 introduced the study and outlines the context of the study describing the socioeconomic and learning environment. It then sets out the aims and research questions of the 
study. The study's rationale discussed the vulnerability of professionalism in the current climate and the need to understand the experiences of the educators. Chapter 2 critically explores the relevant literature. Chapter 3 outlines the research design, the ethical considerations and the methodology applied. Chapter 4 explains the approach to the data analysis. It also presents and discusses the findings in depth. Conclusions to the study, delimitations, recommendations and suggested further research are discussed in Chapter 5. 


\section{Chapter 2}

\section{LITERATURE REVIEW}

\subsection{Introduction}

In order to enrich the debate on professionalism and the perceptions of its educators and their students, I explore literature from both the legal and medical profession and the commentary on workplace learning in general. Both the legal and medical professions share similar unique characteristics of what a traditional profession entails such as self-regulation, autonomy and complex judgement. It is evident from the literature that the issues pertaining to the teaching of professionalism and a discussion of the notion are well researched in the medical field but are less prominent in the legal field. Nevertheless there is a body of legal commentary, particularly from the United States, which explores how the notion is defined and how best to instil professionalism and maintain standards of professionalism. The perceptions of those involved in medical or legal professional education internationally are not widely researched but there are a number of core international studies of interest and relevance to this study. There is a stark lack of commentary dealing with professional education, both legal and medical, in Ireland. There is extensive and rich literature dealing with learning in the workplace which is of particularly relevance to the professional education of solicitors in preparation for practice.

I will explore the commentary pertaining to how professionalism is defined by regulatory, representative, professional bodies and both legal and medical academics. The core components which underpin the concept will then be discussed, followed by an extensive analysis of workplace learning in the context of legal professional education. Finally, the varied literature on approaches to instilling and teaching professionalism will be explored. This analysis will illuminate this study's research question as to whether a variation in perception exists on how best to teach professionalism among the key stakeholders in legal professional education in Ireland and what the implications are of any variation.

\subsection{What is professionalism?}

In a study exploring the perceptions of those involved in the teaching of professionalism, it is important to explore how professionalism is defined, who defines it or if it needs to be defined more clearly.

\subsubsection{A Profession}


The term profession is rooted in the Latin profession, or declaration, meaning to make an avowal or a declaration of belief (Coquillette, 1994). Oxforddictionaries.com (2014) "defines profession as a paid occupation, especially one that involves prolonged training and a formal qualification”. Over a century ago, Flexner (as cited in Phillips, 2004) described a profession as having the following characteristics: if an occupation has a degree of complexity above the norm; has a theoretical grasp of the phenomenon with which the occupation deals; is able to apply this theory to the circumstances; continue[s] to increase its knowledge in particular fields; strives to increase this knowledge; makes a deliberate effort to instil its values in succeeding members of the occupation; strives to set and maintain standards through established admission and disciplinary procedures; and encourages altruism among its members; then the occupation is a profession (Hession, 2012). Eraut (1994), in rather simpler terms, maintains that it is the specialised knowledge that distinguishes a profession apart from other occupations.

How professionalism is defined varies widely among professions, professional bodies and academics.

\subsubsection{Regulatory, representative and professional bodies}

A review of the codes of the regulatory and representative bodies of lawyers and the learning outcomes of the legal professional training centres is an appropriate starting point for exploring the concept of professionalism.

Professional representative and regulatory bodies which govern lawyers in Ireland, the UK and the US vary in how they define or to what extent they define professionalism. Both the American Bar Association's Model Rules of Professional Conduct (1983) and the New York State Bar Association's (2013) describe at length what is required of a professional. The latter's Rules of Professional Conduct are contained in over seventy four pages. While, the Law Society Guide to Professional Conduct of Solicitors in Ireland (2013) (the Guide) succinctly states that the core values of professionalism are integrity, honesty, competence and independence.

Although the Solicitors' Regulation Authority of England and Wales (SRA) does not explicitly define professionalism, the Training Regulations (2014 Regulations) list ten 
mandatory principles which they describe as all-pervasive and state that they apply to all those whom they regulate. The principles are:

uphold the rule of law and the proper administration of justice; act with integrity; not allow your independence to be compromised; act in the best interests of each client; provide a proper standard of service to your clients; behave in a way that maintains the trust the public places in you and in the provision of legal services; comply with your legal and regulatory obligations and deal with your regulators and ombudsmen in an open, timely and co-operative manner; run your business or carry out your role in the business effectively and in accordance with proper governance and sound financial risk management principles; run your business or carry out your role in the business in a way that encourages equality of opportunity and respect for diversity; and protect client money and assets (p.2).

The trainee solicitor's learning outcomes, also contained in the 2014 Regulations, are directly related to these ten principles. In response to the recommendation of the recent Legal Education and Training Review that the SRA should use competence standards as a key tool for the education and training of solicitors, the proposed competence standard for ethics, professionalism and judgement in the commissioned report requires compliance with SRA codes of conduct, which would include the principles above. Notably, the competence standard is broader than the principles themselves in terms of their directness in requiring solicitors to draw on their knowledge but to work within their limits and apply critical thinking and analysis. The Law Society of Scotland's (2014) learning outcomes for the professionalism module on their PEAT 2 training programme are broadly similar to the SRA's Training Regulation 2014.

The Council of the Bars and Law Societies of the European Union (CCBE) Code of Conduct for Lawyers in the European Union (2013) set out a number of the general principles of the profession. They include "independence, trust and personal integrity, confidentiality, respect for the rules of other bars and law societies" (Law Society, 2013, p.95/96) protection of clients' interest, avoidance of incompatible occupations and personal publicity and selfregulation as the general principles of the profession. The CCBE Code is incorporated in the Law Society Guide. The Guide forms the core course material to the Law Society Professional Practice Course Professional Development Skills Module. The compulsory course syllabus states that the solicitor's profession is founded on the core professional values 
as set out in the Guide. It describes the benefit of adhering to these values: "A solicitor should at all times observe and promote these core values of the profession... When the solicitor observes the highest professional standards, this is to the ultimate benefit of the client whether an individual or an organisation” (Law Society of Ireland, 2014, p.1).

While these bodies agree on the core components of professionalism, what is striking is the variance in the extent to which they define the concept.

\subsubsection{Legal Academics}

There is large body of mainly American academic legal and medical literature which explores the concept of professionalism (Braithwaite, 1990; Coquillette, 1994; Shestack, 1998; Kronman, 2000; Silver, 2005; Hamilton, 2008, Montgomery, 2008; McCallum, 2014). While a definition of professionalism varies widely among academics, most agree on the basic core components that it entails: professional knowledge, integrity, honesty and independence. Braithwaite (1990) describes professionalism succinctly as "upright character, proper work habits and genuine good manners" (p.70). This list of core professional values and components has been extended by a number of commentators to includes rules compliance, emotional competence, empathy and compassion to clients, colleagues, adversaries and to oneself, ethics, competence, independence, meaningful continuing education, fundamental civility, pro bono service and civil trusteeship and public altruism to the rule of law and justice system. (Shestack, 1998; Silver, 2005; Montgomery, 2008). Martiminakis et al. (2009) broaden the characteristics of professionalism even further. They refer to an 1890 description of a professional as having a duty "to display no political or religious emblems, portraits, etc. about your office" (p.830). While recognising objectivity and neutrality as central to the American legal system, Wilkins (1999) questions this traditional, what he refers to as, 'bleached out professionalism' ideal whereby a professional's actions are not affected by identity-specific stereotypes. He sees this ideal as being out of touch with increased heterogeneity of the profession. He argues that a lawyer's identity persists and has value in his or her role as a professional. What the professional must ultimately ensure, he advises, is that the use of identity is fundamentally fair, is morally justified and professionally acceptable.

It is noteworthy that many commentators stress the importance of improving the legal system as a core principle of professionalism (Shestack, 1998; Wilkins, 1999; Kronman, 2000; 
Parker, 2002; Montgomery, 2008; Hamilton, 2008; SRA, 2014, Law Society of Scotland, 2014; McCallum, 2014). Maharg (2012) strongly advocates the promotion of what he terms democratic professionalism. In discussing the evaluation of students' standard of professionalism he maintains that students should demonstrate an "awareness of his or her responsibility to improve the capacity of legal institutions and process" (p. 23). Moreover, students should display an interest in how the justice system works and develop a "sense of the regulatory framework of professional ethics" (p. 23).

Professionalism according to Kronman (2000) has four dimensions to it: Firstly, a public dimension in that even while pursuing a livelihood, a lawyer must also to some extent be aware of the public good. Shestack (1998), Freidson (2001), Pearce (2002), Hamilton (2008) and McCallum (2014) also advocate serving the public good. Hamilton expands on this characteristic and describes it as having a fiduciary duty whereby the interests of the client's and the public good take precedent over the lawyers' self-interest. Lawyers, pursuant to this duty would not only carry out pro bono work but would continually reflect on "the relative importance of income and wealth in light of the other principles of professionalism" (p.115). Stempel (1999) points out that under the professional paradigm lawyers' duties override their ability to maximise profits at the expense of their clients. This is an essential component of the lawyer's identity and not simply altruism, according to Stempel, without which law cannot be practiced; secondly, a generalist training: the aim of legal education should be to acquire and to continue to acquire transferable skills applicable to a broad range of practice areas and not to produce specialists. Kelly (1994), a number of decades ago, recognised that increased specialisation in the law was leading to a rapid transformation of our understanding of professionalism. Boon (2005) also recognises this shift towards specialization in the UK legal practice; Thirdly, good judgement: lawyers taking a holistic view of competing interests rather than a narrow sectoral approach based on generalist training; Fourthly, a consideration of the location of law: lawyers have an ability to place their practice in an historical context and that through a constant reference to and reliance on precedents, a lawyer is well placed to contextualise proposed courses of actions with reference to past events.

Although Kronman (2000) adopts a somewhat limited description, he expands on this by contrasting these four characteristics of professionalism against forces of societal disintegration identified by sociologists, namely privatisation, whereby the individual is solely concerned with private wealth; specialisation, relating to an increased tendency to 
separate different lines of work; alienation, a sense of detachment from others and ones' livelihood; and forgetfulness, where individuals exist solely in the 'here and now' without reference to the past or the future. He believes that each disintegrative force can be counterbalanced by each of these four characteristics of professionalism described above, thereby benefiting society. In a somewhat similar vein, Kreiger (2005) discusses Maslow's contention that professionalism character traits such as self-governance, holistic thinking, service orientation, superior awareness of truth and a highly democratic personality, demonstrate a person who has experienced growth fulfilment and psychological maturity and lead to a satisfying life experience. He points out that extrinsic values and motivations, such as choices directed at external awards (money, grades), avoidance of guilt or fear and the need to impress others, lead to loss of lawyer professionalism: those "values and motivations that promote or attend professionalism have been empirically shown to correlate with wellbeing and life satisfaction, while those that undermine or discourage professionalism empirically correlate with distress and dissatisfaction" (Kreiger, 2005, p.427).

Core values underpinning professionalism are discussed by a number of commentators. Hamilton (2008) based his elements of professionalism on common themes found in American Bar Association (ABA) reports, the Preamble to the Model Rules of Professional Conduct and from judicial statements on professionalism in the National Action Plan made at the Chief Justices conferences: a professional lawyer complies with the minimum professional skills and ethics standards as set out in the Model Rules (ethics of duty), strives to achieve the highest of these standards and realise the core values and ideals of the profession. The core values include: "competent representation, including reasonable diligence and reasonable communication with the client; loyalty to the client; confidentiality of client information; zealous advocacy on behalf of the client, constrained by the officer of the legal system role; independent professional judgement; public service to improve the quality of justice....and respect for the legal profession and all persons involved in the legal system" (p. 490). The ideals of the profession include "the commitment to seek and realize excellence at both skills of the profession and the other core values and ideals of the profession, integrity, honesty and fairness" (p. 491) (ethics of aspiration); agreement to ensure colleagues meet the minimum standard, helping them realise the highest standards and holding them accountable if this standard are not met (peer review); agreement to act as a fiduciary; and continual growth in personal conscience. A number of commentators explore this latter concept. It is developed further below. 


\subsubsection{Personal conscience}

Hamilton (2008) explains that personal conscience involves an awareness that there is a moral issue and "a reasoning to determine the moral goodness or blameworthiness of one's intentions and conduct together with a sense of obligation to do what is morally good (p.485)" It requires self-reflection and an openness to feedback from others. He looks to the Four Component Model found in moral psychological literature to explain what is required for moral behaviour to take place in the context of the legal profession. The four components are: moral sensitivity (being aware of how one's actions affect others); moral reasoning and judgement (deliberating and taking an action that is the most morally justifiable - judgements will vary depending on the individuals internalised beliefs); "moral identity and motivation" (p.118) (giving more importance to moral values over and above other competing values); and moral implementation (having strength of character and courage including the ability to manage conflict and communicate effectively). He maintains that students should be engaged in developing each of the components of the Model in a professional context and encouraged to foster growth in personal conscience.

In her President of Ireland Ethics Initiative speech to the Law Society, Brownlee (2014), spoke of conscience being genuine moral responsiveness which includes responsiveness to the complexity of our moral lives. She also referred to the notion of moral identity and motivation where our conscience guides us to privilege certain values over others and "settle the contest between competing moral demands". While she maintains that lawyers' professionalism can be concerned with how lawyers wish to be seen and echo "Mencken's facetious notion of conscience as the inner voice that warns us others might be looking", she maintains that conscience is something we can cultivate. Similarly, Kelly (1994) explores this notion of a lawyers firm's attempts to portray a particular image of professionalism and professional practice without considering what this entails. Brownlee (2014) also referred to the self-reflective approach required to gain inner knowledge of our own hearts and mind in order to cultivate practical wisdom, virtue and integrity.

\subsubsection{Medical Profession's understanding of professionalism}

There are extensive contributions from the medical field to the debate on what professionalism entails (Swick, Szenas, Danoff and Whitcomb, 1999; Kullgren, 2003; Stern, 2005; Steinert, Cruess, Cruess and Snell, 2005). Cuesta-Briand et al. (2014) refer to the 
identification of ninety different components of professionalism in the literature. Nagler, Andolsek, Rudd, Sloane and Musick and Basnight (2014) point out that there are over 200 resources on the topic of defining professionalism on the Association of American Medical Colleges database resulting in a "diverse pool of definitions and standards" (p.2) which vary according to demographics, generation and individuals' perceptions. They suggest that the definitions emphasise three components: integrity; conducting proper doctor-patient relationship; and obligations to address larger social issues which their role has an impact on. Stern (2005), one of the leading commentators in this regard, describes a professional medic as one who exhibits "excellence, humanism, accountability and altruism” (p.ix).

From a regulatory perspective the American Board of Internal Medicine (2002) "defines professionalism as those attitudes and behaviors that serve to maintain patient interest above physician self-interest... and ....aspire to altruism, accountability, excellence, duty, service, honor, integrity, and respect for" (p.129) others. Based on the Accreditation Council for Graduate Medical Education Outcome Project, Ratanawongsa et al. (2006) add sensitivity, "confidentiality, communication and shared decision making, compassion and empathy, competence, managing conflicts of interest, self-awareness, and ongoing professional development" (p. 759) to the attributes of a medical professional.

\subsubsection{Cultural influence on understanding of professionalism}

A number of commentators recommend self-reflection. In this regard, Epstein (1999) suggests including the practice of continual critical self-reflection, which he describes as mindfulness, to ensure medics "listen attentively to patients' distress, recognize their own errors, refine their technical skills, make evidence-based decisions, and clarify their values so they can act with compassion, technical competence, presence and insight” (p. 833). While Ginsburg and Stern (2004) maintain that it is difficult, in a medical context, to use forms of unprofessional behaviour (such as communicative violations, role resistance and accountability to colleagues or patients) in order to define professional behaviour. In their study of the perceptions of medical students on professionalism and the "good doctor", Cuesta-Briand et al., (2014) maintain that often those involved in educating medics resort to assessment of professionalism based on identifying unprofessional behaviour. From a legal perspective, Maharg (2012) does not hesitate to list plagiarism, arrogance, intemperance and abusive behaviour as negative indicators of professionalism. 
Notably, other commentators advise against the idea of composing a list of appropriate traits or behaviours to describe professionalism (Parker, 2002; Martimianakis et al. 2009). Adopting a different approach, Eraut (1994) maintains that lists of professional traits do not solve the problem of defining professionalism as they are based on the author's personal and possibly unjustified view of what certain characteristics professionals have or should have. Moreover, a number of these traits, he explains, are culturally specific. In a similar vein, Martimianakis et al. (2009) argue that professionalism is a lot more than a list of behaviours it "is an extremely value-laden term with societal, institutional, historical and contextual expectations built into it" (p.830). They recognise that, while the checklist approach has been widened to include a societal role, this approach has endured in professional organisations despite its shortcomings. They have concerns with the lack of consideration given to how professional behaviour arises other than a tendency to see it as an innate quality that can be nurtured. They explore the development of the study of professionalism and describe how, in the 1950 s, attention was drawn to how professional identity was associated with power and legitimacy and is socially constructed. They maintain that it is just as important to consider the professional organisations economic and political goals as it is to consider the specific behaviour and traits of the professional: "we can think about professionalism, not in terms of a stable construct that can be isolated, taught and assessed, but as something that is socially constructed in interaction (p.835)".

Hazard and Dondi (2004) also draw attention to the distinct cultural character of each jurisdiction or region's legal system which, in turn, affects the lawyer's role and his or her understanding of professionalism and legal ethics. They maintain, that beyond the shared norms, each individual has a personal set of values and levels of moral sensitivity. Mather et al. (2001) agree that variance in understandings of professionalism is shaped by the organisations themselves, the type of legal practice and individuals' characters, values, gender and experience. They refer to individual lawyer's professional decisions and judgement being shaped by the informal community of practice that lawyers create.

\subsubsection{Social Contract}

Many key authors emphasise the peer review social contract that exists between professionals and the public (Freidson, 2001; Parker, 2002; Beauchamp, 2004; Montgomery, 2008; Hamilton, 2008; McCallum, 2014). Traditional professional controls involve self-regulation: which Parker (2002) claims is supposedly on the basis that only lawyers are knowledgeable 
enough about the law to set its own standards and also to allow the profession to remain independent from the Government to enable the legal profession defend individuals against the state on an unbiased basis. She explains that regulation of entry to the profession, discipline imposed by the professional organisations for" breach of fiduciary duties and other ethical obligations are the traditional regulatory controls on the ethics of the legal practice" (p. 680). Freidson (2001) recognises that this peer review social contract is based on a reciprocal promise that professionals are responsible for balancing self-interest and serving the public good. In a medical context, Beauchamp (2004) maintains that professional autonomy and liberty to make decisions in a fiduciary role are important privileges granted to medics under this social and moral contract.

This ideology of professionalism is in contrast with the dominant market-competition ideology organisation of work where each business is managed to meet the preferred services of the consumers at the lowest price. Hamilton (2008) maintains that this autonomy exercised by professionals must be justified for the public good. Moreover, if there is a failure in professionalism which undermines the public's trust in this social contract, the public will attempt to renegotiate toward the standard market competition model. This can, according to Martimianakis et al. (2009), result in revoking or limiting by government of the profession's self-regulation. This observation is of particular relevance in the Irish context as the Legal Services Regulation Act 2015 proposes to transfer regulation of the profession from the Law Society to the Irish Government (see section 1.2.3). As Hamilton points out, this social contract is always subject to renegotiation. He emphasises the importance of informing the public of this contracts benefits and duties. McCallum (2014) agrees: "The essential attributes of the profession of law frame an important set of obligations that are correlative of the privileges and status we enjoy as lawyers. If we fail in these obligations we lose, our clients lose and society loses (p.1)". Montgomery (2008) maintains that the legal profession is protected to a certain extent from market forces due to two crucial elements of professionalism: self- regulation and the exercise of complex judgement. He concurs with the views expressed above, that the profession assumes, in being granted the privilege of selfregulation, the obligation to serve the public good and improve the justice system to ensure fair and equal treatment. 


\subsubsection{Shift from the traditional}

A number of commentators (Kelly,1994; Pearse, 1995; Kronman, 2000; Boon et al., 2005; Corbin, 2005) recognise the shift from the traditional professionalism paradigm based on the premise that lawyers will, using their specialised knowledge, advance the good of their client over their own self-interests to a more commercialised model of professionalism. Rhode (1985) claims that, "as the profession's competitive ethos and partisan loyalties grow more pronounced, the pretence that the Bar remains above trade becomes more difficult to accept" (p. 589). Philips (2004) also claims that "profitability and competition is taking precedence over collegiality and public spiritness" (p.110) with professionalism and commercialisation working hand in hand. Corbin (2005) explains that increased competition has resulted in a gap between what is expected from professionals and what occurs in reality in practice. She suggests that the traditional ideals are underpinned by the structural functionalist theory, that is, society need professionals' expertise whereas the commercialised professionalism is a reality underpinned by social conflict theory, that is, where lawyers ensure "ongoing reliance of the community on their services for their own self-preservation (p.267)". Kelly (1994) claims that our current understanding of professionalism is not adequate to deal with the transformation of the notion and the reality of professional life today. He maintains that "we can no longer define professional values independently of specific organizations and cultures as variegated, as elements of a common professional culture fragment into thousands of professional cultures" (p.17). Evans (2007) argues that it is the "substance of professionalism that is important today" (p. 851) with the erosion of one of the core components of professionalism - expert knowledge.

From a medical perspective, Beauchamp (2004) recognises that confusion exists about the meaning of professionalism. He proposes a re-examination and re-interpretation of the concept in light of social and economic changes to ensure compatibility with the new millennium. He maintains that traditional professionalism has been modified by the need for the medical profession to participate in the public healthcare system, accountability and social responsibility. Moreover, the notion has evolved to include a balance between responsibility and lifestyle in response to post-modernity individualism (where the interests of the individual take precedence over interest of society or the group). Furthermore, professionalism must be interpreted in light of developments in technology in this era of hyper-modernism (a form of resistance to modernism). Kelly (1994) also explores the transformation of the concept with the importation of business management styles and 
technologies resulting in a contemporary new form of professionalism. He discusses the more critical view of this development and talks about the decline in values as the "profession degenerates into a mere business (p.3)"

Pearce (1995) uses the core components of traditional professionalism (namely esoteric or complex knowledge beyond the capacity of the layperson, self-regulation and autonomy), in order to reject this ideology in favour of a business paradigm. In an interesting critical analysis of this proposition, Stempel (1999) maintains that Pearce's definition is too narrow. Stempel argues that complex knowledge and autonomy does not distinguish the professional from the non-professional. He refers to a need to appreciate the broader skills and judgement of lawyers in defining professionalism: "it is the "judgement" required by the complexity that sets law apart from most other occupations (p.45)". He also points out that the vulnerability of the client is unique to legal services and it is this that distinguishes it from other business and which creates the need for a professional paradigm as a framework for regulating lawyers' activity and behaviour.

\subsubsection{Rule-based professionalism}

Lawyers confuse professionalism with mere compliance with particular codes of professional conduct, according to Kronman (2000). He argues that protecting legal professionalism is good for society generally because the core characteristics that define law as a profession have a wider use and effect on society. Similarly, Coquillette (1994) maintains that when professionals view compliance with a code of conduct as a standard of professionalism, they fail to engage in a 'deep theory' of professionalism, that is, there is no consideration of the ultimate motivation for obeying the rules. He suggests that there are three common categories or theories of professionalism: a goal-based theory whereby individuals obey the rules as a means of achieving personal objectives; a rights based theory that underpins the defence of a client in democratic institutions but which Coquillette argues is not an adequate grounding philosophy for professionalism as it does not provide practical guidance on what actions to take when there are competing rights; and a duty based deep theory underpinned with notions of justice and humanism. Coquillette believes that the latter is best placed to provide a robust basis for professionalism with its central concept being that all good deeds are not necessarily rewarded with monetary gain or power with lawyers linking their professional identity with the system of justice. He argues that the crisis in legal professionalism, as discussed at earlier 
in section 1.2 , can be linked to the move from this theory to a more goal-based theory where there is no objective standard as to the means of achieving the goal.

\subsubsection{Defining professionalism and social control}

As discussed above, the notion of a profession is underpinned by autonomy. Parker (2002) describes this in terms of social control whereby the profession, based on the perception that non-lawyers do not have the intelligence or expertise, decide what is best for their clients, the public and the administration of justice. Martimianakis et al. (2009) refer to Larson's 1977 sociological analysis of professionalisation in which Larson argues that it is a means of controlling knowledge production. Martimianakis et al. (2009) draw attention to the profession's control over the definition of professionalism. Sociologists in this field, they point out, are not concerned with what professionalism entails but who decides what it entails and why. They link the governance of the individuals in the profession to the way professionalism is defined as a narrow, rigid list of "appropriate" behaviours. In their study, Martimianakis et al. (2009) draw attention to the view of Williams that "conceptions of professionalism are shaped by accounting logic or the drive to enumerate, quantify and report on every activity within the academy" (p. 834).

The influence of the 'hidden curriculum', the control over the teaching of professionalism and the influence of the organisation are discussed in further detail below, in the context of work place learning. Professionalism as a means of control is also discussed in section 1.2.4.

In conclusion, it is clear that professionalism is extremely contested and difficult to define and no commonly accepted definition exists. Kelly (1994) states that "the meaning of professional values is now so malleable that the terms professional and professionalism are now well-nigh useless" (p.13)

\subsection{Workplace learning}

Before analysing the commentary regarding the teaching of professionalism below, I will explore the core literature on learning in the workplace. Trainee solicitors spend approximately eighteen months in a solicitor's practice (the trainee's workplace) as part of their traineeship programme. This study explores the perceptions of the training firms about their role in instilling professionalism and so, an analysis of the key arguments and commentary regarding how learning occurs in the workplace is crucial. 
There are a number of key researchers who strongly advocate learning in the workplace and organisational learning (Marsick \& Watkins, 1990; Eraut, 1994 to 2012; Evans, 2002; Boreham, 2004; Evans, Guile \& Harris, 2011). Yet, while there is growing recognition that the workplace is a place for learning, there are relatively few researchers who explore the specific processes involved in this form of learning. Boud, Solomon \& Symes (2001) describe workplace learning in narrow terms as a university programme that creates new learning opportunities by way of collaboration between the university and work organisations. Others explore the concept in wider terms. For example, Brennan and Little (1996) describe it as "experience-led learning in the workplace i.e. the skills and knowledge which people acquire while doing their jobs" but add that this learning "is susceptible to assessment in academic terms" (p.90). 'Workplace' learning and 'Work-based' learning are used interchangeably in this discussion.

\subsubsection{Learning process}

The basic assumption with workplace learning is that knowledge is created through work. Evans et. al (2011) discuss the importance of "understanding how different forms of knowledge are 're-contextualised' as people move between sites of learning and practice in work, education and community settings" which "provides new ways into longstanding and seemingly intractable problems of bringing together 'theory' and 'practice' in and through work-based learning." (p. 149). Boud (2001) points out that "not only do new forms of learning and work require us to focus on what constitutes knowledge, they also require a new look at the notion of learning. When students are engaged in work-based learning what are they actually learning? (p.38)". Boud recognises that while work and learning occur at the same time they are directed towards different end goals, that is, work is directed towards producing something whereas learning is directed towards the acquisition of knowledge which may or may not be related to what the work organisation produces. However, he also argues that generally work related learning does involve the development of knowledge of use of workplace processes and practice and use of knowledge may lead to organisational change. He uses the Gibbons, Limoges and Nowotny Mode 1/Mode 2 dichotomy in an attempt to contrast the kinds of knowledge created in an academic setting with that in workplace settings:

In Mode 1 problems are set and solved in a context governed by the, largely academic, interests of a specific community. By contrast, Mode 2 knowledge is carried out in a context of application. Mode 1 is disciplinary while Mode 2 is 
transdisciplinary...Mode 2 is more socially accountable and reflexive. It includes a wider, more temporary and heterogeneous set of practitioners, collaborating on a problem defined in a specific and localized context (p.3)

Notably, Boud (2001) limits the use of this dichotomy to identifying the way academic and workplace knowledge may need to be treated differently - he perceives Mode 2 as only applying to research related activities. He again stresses the need for "more sophisticated conceptualizations" of work based learning.

Marsick and Watkins (1990) contribute to the discussion about informal learning in the workplace, describing it as "experience-based, non-routine and often tacit" (p.29). They discuss various factors that encourage or dis-encourage informal learning (which includes self-directed learning, mentoring, trial-and-error) and the related by-product: incidental learning (unintentional; implicit learning, for example, learning from mistakes; assumptions; hidden curriculum). They suggest that this form of learning is supported by creativity, proactivity and critical reflectivity and limited by capacity (in the sense of ability to project learning over time and different learning outcomes), by framing i.e. how one selects a problem and applies it to a context and various interpretations. Marsick and Watkins term these factors delimiters and enhancers.

In his extensive research, Eraut (1994) explores the informal learning process in the professional workplace. His study of the learning process by professionals in the workplace is important in understanding the process through which the notion of professionalism might be acquired in the workplace. He explores informal learning along an intentional-incidental continuum which he develops into three types of learning on a scale from the most intentional to the least: deliberative, reactive (explicit learning which takes place "almost spontaneously" (p.9) and implicit (where there is no awareness of learning). Moreover, Eraut (1994) distinguishes between propositional knowledge which underpins professional action i.e. the discipline based theories and concepts together with general and specific practical principles regarding cases and actions and process knowledge being the 'knowing how' in professional practice. This includes the 'knowing how' to apply the propositional knowledge. He explains that process knowledge comprises five types, namely: "acquiring information, skilled behaviour, deliberative processes (e.g. planning and decision-making), giving information and the meta-processes for directing and controlling one's behaviour" (p.107). The trainee learning model is based on this coming together of theory and practice (Evans et al., 2011) 
and the application of the propositional knowledge as process knowledge in professional practice. Eraut $(2000,2004)$ makes a further distinction - cultural knowledge and personal knowledge both of which can be codified (cultural knowledge that is codified is considered discipline-based propositional knowledge while codified personal knowledge is associated with an individual's authorship) or uncodified.

\subsubsection{Personal knowledge}

Eraut (2007) explains that as individuals have experienced a different range of situations, uncodified and, to some extent, codified knowledge is personalised. Personal knowledge, according to Eraut (2004) is a holistic view of knowledge with an emphasis on the use value of knowledge. It focuses on "what the individual persons bring to situations that enables them to think, interact and perform." (p.55). It includes public and private knowledge (which includes the form in which the individual uses codified knowledge i.e. academic and organisational textual material), implicit and tacit knowledge, practices, skills know-how, everyday knowledge of "people and situations...memories of episodes and events, selfknowledge, attitudes, values and emotions" (p.55). Taylor (1997) suggests that the learner's experience is the primary component of personal knowledge and that process knowledge enables one to use this experience constructively. She explains that this process involves critical analysis and control of the learner's values and assumptions. This, she points out is essential for professional practice. Eraut (1994) also advises that learners should ensure that experience is consciously processed and be in the learner's critical control. In his discussion of signature pedagogies (the particular processes of teaching and learning for preparing students for professional life) Shulman (2005) describes three dimensions to this particular form of pedagogy - surface structure or learning (concrete operational acts), a deep structure (a "set of assumptions about how best to impart the knowledge and know-how" (p.55) and an implicit or tacit structure which is the moral dimension comprising a set of professional attitudes, values and beliefs.

\subsubsection{Tacit knowledge}

The pervasive presence of tacit knowledge is of particular relevance in exploring how one can instil professionalism. Evans and Rainbird (2002) describe tacit knowledge as "the implicit or hidden dimensions of knowledge or skill ...which experienced workers draw upon in everyday activities and continuously expand in tackling new or unexpected situations" (p.21). From a medical perspective, Beauchamp (2004) recognises the challenge that teaching 
professionalism entails due to extensive tacit knowledge involved and the difficulty with finding a balance between values and making judgement. Eraut (2000) maintains this is an unconscious type of knowledge as it is acquired or embedded unconsciously by socialisation or that it becomes implicit by being known so well on an explicit level making it difficult to understand. He questions whether this knowledge cannot be communicated or is not communicated. Evans and Rainbird (2002) question whether the codification of tacit knowledge is necessary or makes pedagogical sense. In the interesting debate on whether it is possible to codify tacit knowledge, Evans' (2002) view is that the recognition and understanding of tacit forms of knowledge is important in "creating new possibilities for interdisciplinary endeavour with learning professionals and educational/social researchers in trying to understand better what it is that actually constitutes the 'knowledge base' of the economy and the place of non-formal learning in this scenario" (p.80). While she is aware that this type of knowledge is subjective and difficult to convey there is an increasing interest in its codification which recognises its importance in organisation and the individual's performance. The Solicitors Regulation Authority's report on Workforce Education and Training Arrangements in Regulated Entities (2014) recognised the effectiveness of on-thejob/internal learning such as work shadowing and mentoring which are underpinned by tacit knowledge and concluded that this educational approach should be documented. Boud (2001) points out that as tacit knowledge is difficult to categorise and understand (and decipher from personal knowledge) it is a factor in the difficulties seen with learning in the workplace.

In their practical working guide, Eraut \& Hirsh (2007) discuss learning occurring as a consequence of work processes. They stress the importance of working alongside others (which involves observation and discussion) for learning intuitive decisions that are difficult to explain, and tacit knowledge as "multi-sensory engagement over some time enables the gradual development of tacit as well as explicit situational understanding." (p.26).

\subsubsection{Cultural knowledge}

Evans, Kersch and Sakamoto (2004) analyse various forms of knowledge such as knowledge or "competence related to attitudes and values, learning competence, social cooperative competence (patience, caring and adaptability) methodological and strategic competence" (p.19). They point out that the terms 'acculturation' or 'socialisation' are used to describe these culturally embedded knowledge and point out that tacit learning or understanding contributes not only to understanding in the organisation but to relationships and to important transactions with those that the organisation liaise with externally, for example, clients and 
stakeholders. Eraut (2004) maintains that uncodified cultural knowledge "is so taken for granted that people are unaware of its influence on their behaviour" (p.2). He questions the extent to which this knowledge can be made explicit and points out that it is much wider in scope than implicit learning which is normally associated with knowledge generated by socialisation. Not only does this type of knowledge relate to cultural practices and dialogue relating to particular professions and occupations but also, he maintains, includes the influence of colleagues and clients' cultural knowledge. Evans and Rainbird (2002) advise that learning in this context requires engagement with learning situated practically, in the culture of the profession or in the learner's social world. Their model aims to, in summary, "provide an authentic context which reflects the way knowledge will be used in real life (p.19)", promote mentoring, reflection, transfer of knowledge to new situations, the linking of concepts and practices, collaboration of knowledge and encourages the articulation of tacit knowledge. Brownlee (2014) draws attention to how the legal practice is, in turn, influenced by certain features of the legal system in which it practices but also by the traditions, expectations and reputational pressures that lawyers place on each other.

\subsubsection{Organisational learning}

Brennan, Little, de Weert, Delve, Harris, Josselyn, Ratcliffe, Scesa (2006) point out that workplace learning literature focuses on learning by participation (this paradigm is underpinned by social constructionism) over learning by acquisition (this paradigm assumes an individual focused process to learning separate from the social world). This focus on learning by participation or collectively is evident in Boreham and Morgan's (2004) model of organisational learning. They also recognise the cultural knowledge generated in the workplace and emphasise the collective nature of the knowledge created in an organisational setting. They describe it as a "collective resource, the dynamic product of interactions between people, artefacts and information" (p.309). Boreham and Morgan describe three particular practices which underpin organisational learning: "opening space for the creation of shared meaning, the reconstitution of power relationships and providing cultural tools to mediate learning" (p.315). Their model of organisational learning identifies dialogue (structured verbal and unverbal exchange of messages) as fundamental to learning in the workplace. Dialogue, in their view, is "a set of cultural practices which constitute a common world by creating shared meanings" (p.315). They maintain that the adoption of a social structure based on particular relational practices is required to sustain this learning process and promote collaboration. They point out that "the use of the term 'learning' in the 
organisational sense has been contested" (p. 315) and emphasise the relational self in organisational learning to reconcile the concept of the autonomous individual learner with learning collectively. In this regard they rely on Vygotsky's view that higher psychological function is only developed through relationships and therefore autonomous learning depends on relationships. In their study they concluded that the effectiveness of the dialogue through which learning takes place in the workplace is dependent on a shared and accepted way of behaving in the organisation (which may involve a cultural change) based on the adoption of certain practices. This approach is worthy of consideration in the context of instilling professionalism in the workplace.

Fuller and Unwin (2002) refer to Lave and Wenger's (1991) concept of communities of practice which arises out of a social theory of learning. This theory maintains that learning is both collective and individual. But Rainbird, Fuller and Munro (2004) argue that Lave and Wenger's concept of learning overlooks an analysis of the power relations and structure/agency in the workplace that can impede this type of learning. Ellstrom (2011) also points out that learning at work stems from an interaction between individual factors (such as motivation, individual characteristics, self-efficacy and skills and knowledge previously acquired) and the workplace characteristics and environment. Fuller and Unwin (2011) question Boreham and Morgan's (2004) implication that learning in an organisation cannot occur without the "harmonious cultural and organizational conditions and reinforcing social practices their research highlights" (Fuller and Unwin, 2011, p.55).

\subsubsection{Situated learning}

Situated learning is also relevant in this study's context. Developed by Renkl, Gruber and Mandl, Evans and Rainbird (2002) describe it as "a specific approach to learning, viewing learning as a social process of interaction situated in a community of social practice; a set of methods situating learning in authentic contexts; a process aiming for full participation (p.17)" Eraut (2007) supports the general theories underpinning situated learning that the social interaction, together with codified knowledge and other features of the situation strongly determine what is learned in a particular situation. He explains:

the personal meaning of a concept, principle or value is significantly influenced by the situations in which it was encountered and the situations in which it was used (p.6)"....Learning is always situated in a particular context which comprises not only a location and a set of activities in which knowledge either contributes or is embedded, but also a set of social relations which give rise to those activities. (p.26). 
However, Eraut (2007) does point out that support for learning transfer is required for those transferring from one situation to another e.g. the newly qualified professional moving from the setting of the specialist education institution to the new workplace setting.

Engestrom (2004) adopts a socio-cultural theory of workplace learning. This cultural historical activity theory expands on the situated learning theory. It encompasses the idea of organizational learning and organisational knowledge formation to "expand the unit of analysis of learning beyond the skin of the individual to examine collectives and organizations as learner" (Engestrom and Karosuo 2007, p.337). This theory embraces the notion of expansive learning. He has developed an expansive learning cycle to deal with new situations which appear to have no existing resolutions. This cycle moves from the abstract to the concrete through conditioning, acquisitioning, questioning, reconstruction and consideration of the 'hidden curriculum'. Hager (2011) explains that learning occurs within such activity systems because they raise contradictions and tensions that need resolving. Engestrom (2004) also draws attention to the alternatives to the conventional knowledge hierarchy whereby learning takes place horizontally or sideways through peers either within the particular organisation or outside. As Boud and Middleton (2003) found in their study, while a crucial role is played by the hierarchical nature of the organisation in the scope of learning that occurs, learners may not follow the structure in place for knowledge acquisition. Frequently, informal networks or peers play more significant roles than expected by management. This is particularly evident, according to Boud and Middleton (2003), when dealing with what they term delicate or atypical situations where there is no documentary source of knowledge. They argue that this has an impact on the scope of informal learning.

Notably, Illeris (2003) does not accept the situated learning and communities of practice trends as genuine learning concepts on the basis of their failure to understand the individual human psychological processes involved and the assumptions these notions make in this regard. He suggests that learning comprises what he terms cognitive (including knowledge, skills and meaning), emotional (includes motivation, attitude and mental balance) and socialsocietal dimensions (includes empathy, communication) and claims that situated learning does not consider all three.

\subsubsection{Different but legitimate knowledge}

Eraut, Alderston, Cole and Senker (2000) discuss the different type of learning required for practice: 
We have shown that learning in the workplace is very different in kind from learning in school or college [...] The attributes and dispositions required for lifelong learning in the workplace cannot be acquired outside the workplace; and a significant amount of preparation for work can only be undertaken in employment. To pretend otherwise would be to deceive the public and limit the quality of the outcomes of both general and vocational education. (Eraut et al., 2000 quoted in Brennan et al., 2006, p.259)

While most commentators recognise that work-based knowledge is different from academic knowledge, Brennan et al. (2006) point out that there are approaches that stem from adult and experiential learning theory that do not distinguish workplace learning from academic learning. Generally though, commentators acknowledge it as 'legitimate' knowledge with the same value as conventional knowledge. Boud and Solomon (2001) claim that it is "profoundly misleading to regard work-based learning as a pragmatic and operational endeavour. It is as potentially theoretically complex and intellectually demanding as any form of education" (p.56). They point out that the workplace, the learner and the teaching institution need to join forces to validate this knowledge. Rainbird et al. (2004) maintain that there is a place for formal learning, institutions and qualifications in workplace learning.

Interestingly though, Brennan et al. (2006) claim that Boud and Solomon (2001) and other workplace learning commentators often adopt an anti-academic stance describing the formal learning model as hierarchical and authoritarian and that this uncritically supports the employability agenda of higher education. Boud (2001) suggests that developing an awareness of the learning process involved in workplace learning will help address the criticism that such learning lacks a " 'critical distance' in the development of professionals, that is, that it does not enable learners" (p.42) to separate the immediate context from the perception of what they are learning.

\subsubsection{Workplace knowledge needs support}

Eraut (2004) also makes the point that where knowledge appears to be irrelevant in the workplace, it may be a case that the individual does not yet know how to use it in a new context. This process is not automatic and such learning requires time and resources. He suggests an integrated programme to link theory and practice - concepts which have been separated by time, space and culture. While stressing the importance of the authenticity of professional practice programmes it is recognised that learning to practice does not occur without the support needed for this type of learning: "Learning to practice and learning to use 
knowledge in education settings do not happen automatically...it is not a natural consequence of learning knowledge on its own and practice independently of any critical questioning of its appropriateness and effectiveness" (Eruat \& Hirsh, 2007 p.35). Eraut (2004) recommends commitment of resources to programmes which link theory and practice to support the critical knowledge transfer process. Eraut \& Hirsh (2007) advise that the effectiveness of this type of learning is affected by appropriate levels of support, confidence and commitment, and personal agency.

\subsubsection{Transfer of knowledge}

The question here is how can students learn to ensure that they apply their learning in situations other than those in which they were originally developed. In the context of trainees, the ability to transfer their professional skills beyond the Law Society and the training firm is imperative. Bowden and Marton (1998) suggest moving away from the notion of transferring the knowledge and focusing on understanding the different sorts of variations and how they relate to each other and drawing upon this in new settings. Boud (2001) stresses the importance of engaging in deep learning and developing an awareness of learning in improving the ability to use knowledge gained in a new situation. He discusses the contribution of the key phenomenographic researchers, Marton and Booth (1997) and Bowden and Marton (1998) to the question of how we learn to deal with unknown situations. This is of particular relevance in workplace settings. Bowden and Marton, (1998) suggest firstly, understanding what the problem really is, which involves focusing on the varying aspects of each situation whereby students come to focus on salient points by reflectively comparing and contrasting the differences. This enables them to deal with the new situation. Secondly, they recommend "the integration of disciplinary and professional frameworks of knowledge" (Boud, 2001, p. 40) in dealing with the unknown situation. Boud (2001) point out the difficulties in applying these existing Mode 1 and Mode 2 forms of knowledge to the work-based learning framework. He maintains that development of an integrated disciplinary and work-related knowledge framework is a pre-requisite to applying Bowden and Marton's second recommendation. Boud does point out that the development of professional knowledge in the traditional disciplines such as law and medicine has been the subject of research for many years. 


\subsubsection{Implicit theory - behaviour}

Eraut (2004) discusses the status of personal theories as knowledge and explores implicit theories "developed by the unconscious aggregation of experiences of similar situations or by participation in a community of practice for whom certain implicit theories form part of their taken-for-granted world" (p.57). He stresses the importance of the individual recognising these actions based on personal theory to ensure they accept responsibility for the effects of those actions. This is important to consider in terms of professionals taking responsibility for unprofessional behaviour. Argyris and Schon (1974) attempt to reconcile what they term espoused theories, namely theories attained or assimilated during professional education, and 'theories-in-use' which determine what individual's actually do. Eraut (2004) suggest that the mismatch between the two theories is due to the dualistic approach to professional education. Espoused theories provide a 'professional conscience' which represents the image the professional potrays to the public whereas the theories in use are developed separately to deal with the practicalities of practice which may devalue the profession. Argyris and Schon (1974) argue that professionals "are committed to espoused theories which describe the world as they would like it to be, but which do not accurately describe their actions" (p.20). They explain this in terms of single-loop and double-loop learning concepts. For example, when ineffective routines or restricted feedback due to power differential lead to single-loop learning, double-loop learning is required to escape from this. They suggest that this can be solved by genuine feedback on the consequences of their actions, discussion, critical reflection and stepping back from the espoused theories. This mismatch might be considered by training solicitors in attempting to instil professionalism in their trainees.

\subsubsection{Personal knowledge in the workplace culture}

Eraut (2004) maintains that the individual brings personal knowledge to the workplace. This transfer of personal knowledge is relevant in the analysis of the extent to which professional values can be instilled in the training office or the extent to which they can be taught. Eraut and Hirsch (2007) maintain that while the individual acquires workplace cultural knowledge as part of a group, the individual's personal knowledge shapes the interpretation of that cultural knowledge because of that individual unique set of circumstances and experiences in other groups. Eraut (2004) points out that:

members of a group acquire only part of the knowledge present in that group, and interpret it within a personal context and history that has been shaped by their experiences in other groups, both prior and contemporary. There will also be aspects 
of a person's knowledge that have been constructed through lifelong learning and become unique to them i.e. outside the circle of shared cultural knowledge, because of the unique set of situations in which they have participated (p. 56).

In contrast, Lave and Wenger (1991), whom Eraut (2004) strongly disagrees with, focuses on common features of people's knowledge and ring-fence knowledge in the group situation.

\subsubsection{Influence of legal training firms}

The discussion so far raises questions about the extent that the trainee solicitors working environment (i.e. the training firm) mould their sense of professionalism. Is this to the extent that professionalism can only be instilled in training firms and explicit teaching is ineffective? Do training firms play a role in teaching professionalism to the employees? While the learning process in the legal workplace itself is not explored to any great extent there are a number of legal educational researchers who emphasise the influence of the legal training firm in the embedding of or teaching of professionalism (Corbin, 2005 and Mather et al., 2001).

Notably, Corbin (2005) is one of the few studies that analysis the perceptions of lawyers (graduates and experienced practitioners) in this context. Corbin (2005), in a study on lawyers' perceptions of professionalism, refers to a number of legal commentators who recognise the influence that the work organisation has on a lawyers' way of thinking and conducting themselves (Wolfgast, 1992; Kelly, 1994). Corbin, in her study, found that experienced practitioners generally comply with the workplace understanding of professionalism. According to the graduates (those who had recently qualified and joined the firm) it is this group of experienced practitioners' whose personalities were reflected in the values, culture and working environment of the firm. These practitioners also set the firms policies and procedures. Graduates believed they were under pressure to "fit in" and conform to the values norms and policies of the workplace. She found that the graduates had a traditional view of professionalism in the sense that lawyers had a role in serving the community and were surprised by the emphasis on budgetary targets. Interestingly, she expressed the view that while the experienced practitioners believed they had created a positive professional culture some of the firms required a programme to boast morale.

In her data analysis, Corbin (2005) states that "the legal practitioners made many references to their role of educating the graduates concerning these unwritten standards, which one 
practitioner suggested are part, of the definition of professionalism" (p.279). The general consensus among the experienced practitioners was that the younger solicitors needed to be educated about "professional courtesies" (unwritten rules) otherwise the reputation of the firm could be destroyed. Corbin's view was that reputation was indicative of one's level of professionalism. Although the graduates did refer to the valuable practice of mentoring in the data: "Most young lawyers have a mentor and that shapes who they become and the practitioners that they are in 5, 10, 15 years" (p.281). How the experienced professionals intended to educate the younger lawyers was not discussed in any detail in the study. Evett's (2003) analyses found that the notion of professionalism can be used or defined by an organisation to act as a motivator for occupational change by persuading or perhaps cajoling employees to behave in a particular manner determined by the organisation.

Mather et al., (2001) in their publication on divorce lawyers believe that individuals in an organisation share norms and values and formalise sanctions for non-conformity. Riley and Kumar (2012) share the view that reliance on learning professionalism from positive role models presumes the "presence of a homogenous society sharing values" (p.9). Stempel (1999) explains that "lawyers are social beings...who behave largely in accordance with group norms...in accordance with their social or peer incentive structures". In his analysis of various studies in this regard he suggests that individual conduct and behaviour can improve with consciousness-raising efforts at organisational level. He maintains that the structure and norms, both formal and informal, that society, the work organisations and regulatory system choose will have a powerful effect on the way lawyers behave. In support of the professionalism paradigm as opposed to the business paradigm he maintains that if a lawyer's environment "rewards ethical behaviour and punishes breaches of professional responsibility, most lawyers will conform their conduct to the set, scrutinised and enforced professional standards" (p.68). An empirical study by Nelson and Trubeck (1992) supports this contention. It found that the values and culture of the work organisations had a strong influence on the professional conduct of the organisations lawyers.

Rhode (1994) recognises that while lawyers are influenced by the firm's perception of professionalism certain individuals will not conform when the values of the work organisation differ from their own. The data from the graduates in Corbin's (2005) study appears to support this view. Many of them asserted that, despite the pressure to conform to the firm's ideals, they would make every effort to maintain their individual understanding of 
professionalism: “...guidance from the people that have been there longer and have more experience but by the same token that ethical guidance isn't necessarily right and so you are left back with the situation of, well ok I'll take that on board but what do I do about it" (Corbin, p.283). Corbin does point out that these comments were made in private. This is consistent with Eraut's (2004) claim that individuals bring their personal knowledge to the workplace. Wilkins (1999) strongly advocates making law students how one's organisation's structures and norms influences and shapes one's career and personal life and the practical interpretation of legal rules.

Of interest in the context of a trainee's (formerly referred to as an apprentice) workplace learning is Fuller and Unwin's (2002) assertion that an expansive or restricted learning environment for modern apprenticeships is a major factor affecting learning at work. They describe an expansive learning environment as one which includes "opportunities for 'onand-off-the-job' learning, knowledge and skills development through participation in communities of practice, access to knowledge-based qualifications and a structure for progression" (Brennan et al., 2006, p.95). They see expansive environments as a symbiotic relationship between personal and organisational goals (2011). In contrast, a restrictive working environment does not allow these opportunities or development. Interestingly, other literature points to the limits of an expansive learning environment that is subject to unequal power relations within not only the workplace but also the wider society (Brennan et al., 2006).

\subsubsection{Solicitors Regulation Authority (SRA) work-based learning pilot}

In 2005 the Law Society of England and Wales Training Framework (TFR) proposed a dramatic pedagogical shift in legal education with a move towards an audited form of workplace learning. It envisages an outcome-based model and removes any requirement for any higher education qualification or formal legal training. In response to this proposal and a need to widen access and reduce barriers and explore a new or alternative option to qualification, the SRA in 2014 introduced a work-based learning pilot, to provide an alternative to the training contract stage of training solicitors. Candidates were assessed either by their employers or independently against work based learning outcomes devised for the pilot or by one of the University legal practice providers supported by learning logs or portfolios. The report on the effectiveness of the pilot found it contributed to a lowering of barriers to access the legal profession and produced candidates who were adequately skilled to enter the legal profession. In response to the TFR, Boon et al. (2005), recognise the attempt 
to introduce flexibility to legal education and encourage access and diversity in education and knowledge by adopting a democratization approach but they warn of the "possible contamination of undergraduate stage by vocationalism," (p.479) leading to deprofessionalization. They maintain that this workplace learning approach requires a complex audit regime to assess a students' learning outcome supported by a rigorous supervision process based on completing learning portfolios. Furthermore, they raise concerns about whether there may be a diminishing of understanding of the underlying concepts with a reliance on experiential and performative knowledge.

\subsection{Approaches to instilling/teaching professionalism}

\subsubsection{Approaches to learning}

While learning in the workplace is discussed extensively above, the commentary about the approaches to learning is relevant in a professional education institution context. Boud (1998) maintains that if students are given the opportunity to learn to be independent learners they will apply this in practice. He identifies taking responsibility for learning, such as determining their own learning needs and outcomes and reflection, as the main characteristic of this type of learning. Taylor (1997) maintains that Boud's assertion that self-directed or independent learning involves a linear continuum from independence, dependence and interdependence, does not apply to the professional learner. She argues that the professional learner needs to learn to operate from all three positions as required and to recognise which position is appropriate at any given time. However, she recognises that in order to work independently and collaboratively the learner must learn to work independently in the first instance. Of interest is her discussion of Perry's (1970) stages of readiness for self-directed learning whereby the student develops from listening to the lecturer and waiting for their answer to considering different theories and an awareness that an answer is dependent on the particular frame of reference or context. Taylor (1997) emphasises that the ability to use initiative together with skills of critical reflection and self - evaluation are essential aspects of the self-directed learner and professional practice.

Of particular relevance to this study are Prosser and Trigwell's (1999) exploration, based on phenomenographic studies, of the relationship between the variation in individuals' acts of learning, the students' perceived learning situations and their prior experience, and the effect this relationship has on students' learning outcomes. They found that students' prior experience of learning and teaching and their prior understanding of key concepts have a 
strong influence on how they approach their studies in a particular learning situation and ultimately on whether they achieve their learning outcomes. Notably, Prosser and Trigwell maintain that student's approaches to learning are not static: educators can change students' perceptions of the learning situation to encourage a deep learning approach i.e. learning to understand as opposed to learning to remember (surface learning). They also found that educators evoke certain aspects of their prior experiences of teaching and learning in current teaching situations and that teachers and students' approach to a learning situation are closely related. Shulman (2005) refers to faculty members, in the context of what he terms signature pedagogies (the characteristic forms of teaching and learning for professional preparation), modelling their own teaching on what they themselves received which he describes as the "very architecture of teaching encourages pedagogical inertia" (p.57).

\subsubsection{Teaching of Professionalism}

The issue of teaching professionalism is profession-wide and the importance of adopting the correct approach is crucial:

The brightest teacher can teach a course using the best pedagogical skill, and students can still fail to learn, we don't think too much about this in the world of teaching [medical] knowledge and skills, but when teaching professionalism, it becomes critical (Stern, 2003, p.1))

While the education commentators' views and studies regarding how best to embed professionalism vary considerably, they fall into a number of broad categories albeit with an element of overlapping. There are those studies or views that believe that professionalism cannot be taught; those who recognise mentors and role models in the education setting or workplace as critical in instilling professionalism; and those that advocate explicit teaching and assessment to instil professionalism.

\subsubsection{Professionalism cannot be taught}

A number of both medical and legal education studies found that practitioners believed that professionalism is intuitive and that by the time students commence professional education it is too late to have an effect on their values or instil a sense of professional responsibility (Braithwaite, 1990; Steinert, Cruess, Cruess and Snell, 2005; Hamilton, 2008). According to Pearce (2002) there are three schools of thought which resist the teaching of professionalism: firstly, many legal commentators believe that legal professionalism need not be taught because the professionalism system itself controls its members i.e. an unprofessional solicitor's reputation will affect his business and subject him to disciplinary committees. A 
second group of academics argue that the concept cannot be taught as "values are fully formed before entering law school and are not easily or likely to change through education" (p. 161). Thirdly, others believe that the values of professionalism should not be taught. This, Pearce states, is based on the scientific paradigm in higher education that distinguishes between facts that can be taught and values that cannot. This then dictates a pedagogical approach of separating the core law from professionalism and ethics. Riley and Kumar (2012) recognise that there is support for the view that the individual must possess certain inherent qualities before professionalism can be nurtured in them. Stern (2003), coming from a different perspective, makes the point that human nature is evolutionary hard-wired to selfprotect and survive which is the antitheses to professionalism (Hession, 2014).

\subsubsection{The Traditional apprenticeship approach - Mentoring/Role models}

A number of commentators emphasise the importance of role modelling and mentoring in the process of learning both in the workplace and in teaching institutions. The influence of training firms in the embedding of professionalism is dealt with in more detail in section 2.3.12. There are a number of empirical studies in the medical field that found that positive role modelling was the most effective means of fostering professionalism (Schon, 1987; Roberts, Green Hammond, Geppert and Warner, 2004; Riley and Kumar, 2012; Cuesta Braind et al, 2014). The results of a study on residents' perceptions of professionalism in training and practice at the University of Virginia School of Medicine reported that professionalism was learnt mainly by observing positive role models and interacting with patients (Ratanawongsa et al. 2006) and in a similar study of medical students' perceptions of professionalism, Byszewski et al. (2012), found that role modelling was, in the context of professionalism, "the single most important component of the medical school experience" (p.5). Interestingly, Cruess and Cruess (2006) discuss role modelling as means of encouraging compliance with agreed standards of professionalism and a more altruistic community based approach.

In a legal context, Whitcomb (2005) discusses the Carnegie Foundation for the Advancement of Teaching's project entitled Preparation of the Professions Program in his paper. Sullivan, a co-director of the Program, argues that the current pedagogies used to support the understanding of professionals are not producing true professionals with civic responsibility. He believes that the analytic approach to teaching professionalism as opposed to a practical narrative approach is a cause for concern. He advises that students must carry out an 
apprenticeship in a law firm which allows them acquire an understanding of what it means to be a true professional and "grasp the meaning of the profession's fundamental purposes" (p.882). This, he explains, involves allowing the student to become familiar with the professional and ethical standards required, understand their role and their responsibility to society. Coulehan (2005), in recognising the professional role modelling as vital in instilling professionalism in student doctors, also favours a narrative approach.

Hamilton and Brabbit (2007) define a mentor in the legal profession as one who assists a lawyer or trainee lawyer to instil the principles of professionalism and achieve their personal professional goals. They adopt a broad view of mentoring. The functions of a mentor, they explain, includes aiding the student lawyer's career advancement, building their selfconfidence and self-worth, acting as a role model to develop the student's professional knowledge and skills and ensure they meet or exceed professional standards and aid the student in instilling the principles of professionalism. They maintain, that while many occupations will have mentors as role models, this last function is unique to the traditional professions which rely on society granting them self-autonomy on the basis of the professions agreement to abide by the principles of professionalism.

Positive role models are not confined to the lawyer's workplace. Maharg (2012) and Braithwaite (1990) are one of the few legal commentators who explore role modelling in the legal educational faculty. Maharg (2012) claims that student tutors can act as positive role models. Braithwaite (1990) goes as far as saying that "the way teachers conduct themselves in the classroom is likely to have more impact on the way students come to believe a lawyer should behave than any of the other things that usually go on in law schools" (p.72).

There are caveats to consider with this form of learning. Evans and Rainbird (2002) point out that general workplace research is challenging this traditional apprenticeship or rolemodelling model whereby the older master teaches the younger trainee: they maintain that younger workers are bringing skills and other knowledge to the workplace and imparting these to the more experienced in the workplace. They emphasise the pedagogical implications this has for workplace learning.

Eraut and Hirsch (2007) warn against mentoring in an organisation without careful 'matching' of both mentors and mentees and recommends establishing clear guidelines on 
how to manage the mentoring relationship. They stress that feedback is vital for learning in the workplace and recommend obtaining feedback from both mentor and mentee not only after a specific task or on a short term basis but also on a more long-term strategic basis. Eraut (2012) points out that this form of learning is strongly influenced by the mentor or manager's interpretations of work practices. From a legal perspective, Branch (2010) and the New York State Bar Association (2011) also advise against sporadic unstructured rolemodelling. Branch suggests the adoption of active role modelling whereby the practitioner recognises a learning opportunity and carries out a series of learning steps. Similarly, the NY State Bar Association strongly recommends that the legal firm use a structured mentoring programme in the first year of practice. It finds this the most effective approach to further developing a well-grounded sense of professionalism. Hamilton and Brabbit (2007) also advocate a well-designed formal mentoring programme to foster the principles of professionalism, the four components of moral action based on the work of moral psychologist Lawrence Kohlberg (this is discussed in more detail in section 2.2) and important interpersonal skills.

Boud and Middleton (2003) explore the impact a rigid role modelling structure has on the scope of informal learning. Interestingly, they found in their study that often the 'official' role model in a structured process or a supervisor is not the first source of learning: "there is a diverse range of people that we learn from at work, very few of whom are recognised by the employing organisation as people with a role in promoting learning - that is people designated as supervisors or trainers" (p.201). This loss of control as to who is developing the trainee's knowledge of professionalism and the standard of professionalism being instilled in this informal manner is an issue to be considered by those involved in the education of trainees.

The Law Society recently piloted what was called a Supervision Programme for Trainees (2015). A small number of trainees attended a series of supervision sessions facilitated by an experienced solicitor and a qualified supervisor. The programme involved trainee solicitors bringing professional issues, and/or difficulties they had encountered in professional practice to the group for discussion. The facilitator presented them with a range of legal professional and ethical scenarios to discuss and work through as a group. The facilitator provided his own take on the scenario and also provided training in stress management skills. This is a form of structured mentoring and could be adapted to evaluate professionalism. The pilot 
programme was evaluated. In the draft report it was found that "participants felt that supervision provided an open, confidential, safe space in which they could discuss professional issues and ethical grey areas. Additionally, they noted that supervision enabled them to consider past events experienced in practice in new ways, and enabled them to draw on different perspectives from the group to help scaffold and augment their ethical reasoning abilities." (Dowling, 2015). An extended pilot is being considered at the time of writing before considering implementing the programme.

In exploring the informal learning process, Fuller and Unwin (2002) maintain that, while the coaching and instructing or acting as a role model to the more inexperienced members of the workplace occurs informally in an unplanned way, the act involves using various explicit pedagogical skills: it:

involves a conscious and explicit process in which skills and knowledge are passed from one person to another or others using a range of pedagogical skills, which may or may not reflect knowledge of experiential or didactic approaches to teaching and learning...the act is usually instinctively collaborative as the parties recognise that each has something to bring to the occasion (p.96).

In their practical working guide, Eraut \& Hirsch (2007) discuss work processes with learning as a by-product. They stress the importance that working alongside others (which involves observation and discussion) for learning difficult-to-explain intuitive decisions and tacit knowledge. This is because "multi-sensory engagement over some time enables the gradual development of tacit as well as explicit situational understanding.” (p.26). However, they maintain that coaching and mentoring and shadowing are mainly for inducting newcomers. They point out that coaching is often limited by coaches being too busy at work and a lack of opportunity for mentors to build up an appropriate relationship. They also point out that the “deceptively simple phrase 'manager as coach' does not really unpack either the complexity or the scale of learning which is often needed" (p.35).

Historically, the assimilation of professionalism relied solely on implicit learning from role models. While Stern (2003) points out that role modelling alone is not sufficient as there is no guarantee that students are actively learning, he does not explore the learning process involved. Steinert, Cruess, Cruess and Snell (2005) also found that role modelling was no longer adequate to instil professionalism in students and that faculty members in their study 
did not possess the required knowledge and skills to teach professionalism. Steinert et al. (2005), Cruess and Cruess (2006) and Branch (2010) are also cognisant of the requirement for systematic faculty development to ensure the role models are effective and that there is consensus among role models as to the definition of professionalism and the behaviours expected of a professional in a medical faculty. Notably, Wilkins (1999) recognises that newly qualified solicitors can no longer rely on what he refers to as the traditional forms of socialisation to learn to think like a lawyer as they are entering practice in an array of professional and nonprofessional entities including in-house counsel, global law firms and multi-disciplinary firms.

\subsubsection{Hidden curriculum}

Stern (2003), Cruess and Cruess (2006), Ratanawongsa et al. (2006), Park et al. (2010) and Nagler et al. (2014) are among those who recognise educational role models and the hidden curriculum as powerful tools in transmitting professionalism. Both Stern (2003) and Cruess and Cruess (2006) recognise the challenge for students to distinguish between negative and positive role models and to attempt to emulate positive role models and foster their positive qualities. They refer to this challenge in the context of the:

extremely powerful 'informal curriculum' consisting of unscripted, unplanned and highly interpersonal forms of teaching and learning that take place among and between faculty and students. Role models at several levels, from peers to senior physicians, particularly at this level can have a profound effect for good or ill on the attitudes of students (p.207).

Notably, Park et al.'s (2010) study carried out in the medical field is one of the few that attempt to understand the learning process involved in the instilling of professionalism. It explores how medical faculty members as role models influence the professional attitudes, values and behaviours of trainees and describes the "sources and processes perceived to be involved in learning professionalism" (Park et al., 2010, p.137) i.e. how students respond to role models, their perceptions of what aspects of the role-modelling they find important and how they differentiate between those who are a good or bad role model. The findings of the study indicate, in concurring with other studies, that trainees assimilated professionalism mainly from positive role models and it also refutes the idea that professionalism is easy to recognise. Park et al. (2010) refer to Hafferty's definition of the hidden curriculum: "the unintentional or even unrecognised transmission of implicit social and cultural rules" (Hafferty, 1998 in Park et al. 2010, p.138) and advice against reliance on this curriculum for 
transmitting professionalism. They suggest, based on their findings, a more active and structured form of role modelling: one which is guided by "the processes identified by the participants in our study - specifically, observation, reflection, and reinforcement" (p.138). This model would include, for example, more explicit explanation and demonstration of professional, structured student reflectiveness to review their reasoning process and formative feedback.

Suchman, Williamson, Lizelman, Frankel, Mossbarger and Inui (2004) state that the hidden or informal curriculum of the medical school has the greatest influence on a student's behaviour and ultimately his or her standards of professionalism. In their study, they harness this influence and use the informal social environment and organisational structure to reinforce the values of the formal curriculum. They adopt the "nonlinear perspective of "making ripples in a pond" envisioning our work as introducing constructive disturbances in existing patterns of interaction that other people might then adopt, modify and propagate (p.501)". Byszweksi et al. (2012) also refer to Hafferty's studies on the effect of the hidden curriculum and emphasise the importance of ensuring the learning environment (the medical schools) reflect the professionalism curriculum to ensure consistency and clear expectations for the students who so often have to deal with a conflict in this regard. This issue is also discussed by Coulehan (2005) in section 2.4.11 below.

Of relevance in an Irish context, albeit not in a legal or medical context, Molloy (2014) recommends, in a report on corruption within the Garda Síochana (the Irish Police force), an explicit programme of cultural change in dysfunctional institutions. He stresses the requirement for it to be explicit, in order to ensure negative values are not imbibed through the existing hidden curriculum. He suggests codifying a set of values with time set aside to reflect on whether these espoused values are being followed: "Frontline staff are not stupid. They will only believe the rhetoric about value and culture if they see them consistently lived out in the policies and behaviour of senior people" (p.21).

\subsubsection{Small group learning/reflection:}

Other approaches to instilling professionalism include group learning. This approach is generally well recognised as having a critical role in fostering collective knowledge in the workplace (Eraut and Hirsch, 2007). In both the legal and medical field, commentators recognise the importance of group interaction and reflection in assisting students to 
understand what the notion of professionalism entails and impart professional traits (Suchman et al. 2004; Kullgren \& Lowenstein 2004; Steinert et al. 2005). Branch (2010) advocates small-group learning methods to impart professionalism and advises against not relying on sporadic unstructured role modelling. He maintains that small groups encourage reflective and active experiential learning.

Taylor (1997) recognises the importance the role of the facilitator has in this group type of learning. She advises that facilitators need to be very clear about their role and its implications for independent and interdependent learning. Kahn (2013) carried out a study to consider the impact the informal curriculum in the form of small group teaching has on the promotion of professionalism. His findings show that interaction in this form had an important effect on student learning in terms of professionalism: it helped students appreciate the diversity in the understanding of what the notion entails and steers the students away from the checklist and normative definitions approach. He stresses the importance of considering the interactions and experience of all parties (students and tutors) involved in "shaping informal curricula that serve education in the professions" (p.640). Shulman, L. (2005) recognises that signature pedagogies are ones of uncertainty and that learning to deal with the unpredictable setting of an informal small class group models the ability to make judgement in an uncertain situation which is a crucial professional trait. Interestingly, despite the recognition of the importance of reflectiveness, the English and Welsh Solicitors Regulation Authority's report on Workforce Education and Training Arrangements in Regulated Entities (2014) found that reflective learning and work shadowing were less prevalent than standard formal training in solicitors' firms.

\subsubsection{Experiential learning}

Experiential learning or learning by experience is, in a sense a move from the laissez faire approach to assimilating professionalism to a more applied form of learning. This model involves acquiring knowledge in authentic settings which transform the abstract to the applied. Many commentators consider it the most effective model of instilling professionalism in students (Maharg, 2006, 2007; Alexander, 2011; Riley and Kumar, 2012). Cruess \& Cruess (2006) discuss the views of various commentators which suggest a structured approach to allowing students to learn, particularly the tacit knowledge required to embed professionalism, in an authentic but safe setting. Maharg $(2006,2007)$ has designed a comprehensive transactional learning programme involving active learning in authentic 
transactions which he maintains leads to deep collaborative process learning and embedding of professionalism in students. Professional issues are dealt with by way of highly experiential methods of teaching simulations where models of behaviour and issues arising are discussed. Notably, Boon et al. (2005) question the experiential model in the context of the pedagogical shift of legal education in post-modernity. They recognise the tension between formal knowledge and applied knowledge: "the technician is attempting to tame the intellectual" (p.488) and ask if reliance on experiential and performative knowledge leads to a lack of understanding of the underlying concepts.

Brennan et al. (2006) suggest that workbased learning can be understood as a form of experiential learning with education starting in the experienced world. Taylor (1997) discusses Boud's propositions regarding learning from experience in the workplace. She explains that every experience is a potential stimulus for learning which is only processed when reflected upon; learners construct and deconstruct their experiences which in turn are influenced by social and cultural construction of learning and the socio-emotional context in which the learning occurs; and this learning is holistic in nature involving thinking, feeling and doing. This is similar to Kolb's (1984) 'experiential learning cycle' where a concrete experience is followed by observation and reflection to give the experience meaning. Generalisation and conceptualisation of the meaning then leads to propositional knowledge.

\subsubsection{Teaching of values}

The literature discusses various approached to teaching values. Maharg (2012) stresses the importance of teaching legal knowledge and practice skills in the context of the value system that underpins the professionalism. He distinguishes between democratic professionalism which encourages moral and democratic values in practice and technocratic professionalism which is motivated by self-interest and profit. He advocates a programme of teaching where there is a constant balance between high level values, the theory or professional education and the applications, procedures and processes used in professional education. Kreiger (2005) maintains that it is important to draw students' attention to the proven link between keeping professional values and life satisfaction. He uses an interesting teaching tool to identify students' values whereby students write their own eulogies which generally identify intrinsic traditional human values and virtues. The students are encouraged to reflect upon these throughout their careers. The Law Society's professional course Interpersonal ImpACT programme (2014) applies this model by encouraging trainees to identify their work and 
interpersonal values and to reflect on how on they are moving towards those values throughout their time in practice. Nichols (2005) maintains that while cognitive learning (knowledge, understanding, issue-spotting, and problem solving) is required for acquiring professional knowledge, affective learning is required to develop the fundamental values of the profession. This form of learning calls for an altering of the individual's attitude and an internalisation of the necessary attitudes and values. Interestingly, it is argued by some, to make professionalism meaningful for students, that it needs to be described in terms of actual behaviour and not described in abstract terms such as values (Wear \& Kuczewsji, 2004). Ginsberg, Regehr, Hatala, McNaughton, Frohna, Lingard \& Stern (2000) argue that assessment of professionalism behaviour as opposed to abstract values is more satisfactory. In clear contrast to what Maharg (2012) maintains, Pearse (2002) discusses the view that values cannot be taught.

\subsubsection{A pedagogical shift}

The literature recognises a pedagogical move from the traditional view. Cruess and Cruess (2006) explain that professionalism was "traditionally transmitted by role models in the profession" (p. 205). They recognise a shift towards a more directive form of teaching professionalism:

this method [role modelling] depended for its success on the presence of shared values in a relatively homogenous medical profession serving a similarly homogenous society, a situation that no longer exists in our wonderfully diverse world. Thus role modelling, which remains an immensely powerful tool is no longer sufficient. It is now felt that professionalism must also be taught explicitly (p.205).

Byszewski et al. (2012) maintain that, in the medical field, role modelling is no longer adequate as the traditional apprenticeship model has been replaced by a competency-based model. The Solicitors Regulation Authority of England and Wales are currently proposing such a model.

\subsubsection{Competence based approach - the commercialisation of Law Schools}

A number of commentators recognise the implications for professional education of the increased pressure on education generally as a marketable commodity and the trend towards standardisation (Taylor, 1997; Boon, 2005). One of the most significant implications is the move towards a competence approach with standardised learning outcomes and more of an emphasis on the occupational or technological competences of the 'customer'. The challenge 
for professional education, according to Taylor (1997) is to ensure that process knowledge is protected while ensuring trainees have achieved the technical skills required. Boon (2005) argues that this shift "goes beyond simply treating knowledge itself as a product in the marketplace; it implies strong epistemological ties between new approaches to learning and the new, flexible, capitalist economy" (p.481).

In England and Wales, the Solicitors Regulation Authority (SRA) is currently accepting submissions from stakeholders regarding the proposed use of competence standards for ethics, professionalism and judgement based on the SRA codes of conduct principals. This is in response to the Law Society of England and Wales Training Framework Review (TFR) and more recent legal education and training review reports. Furthermore, the reports recommend a route to qualification as a solicitor which does not require formal legal training or qualification. The SRA recently introduced a work-based learning pilot with rigorous assessment to ensure compliance with the standard learning outcomes. The aim of the pilot was to provide an alternative to the training contract stage of training solicitors (see Section 2.3.13).

The SRA Training (Qualification and Provider) Regulations 2014 which govern legal professional education in England and Wales demonstrate a pedagogical shift to an outcomebased model "providing positive outcomes which when achieved, will benefit and protect clients and the public" (p.1) and removes any obligatory formal legal training. While Boon et al. (2005), in their article discussing this model at its proposal stage, recognise that this democratised approach will introduce flexibility to legal education and encourage access and diversity in education and knowledge they warn of de-professionalization. They poignantly ask whether "the emphasis on educational outcomes pander to the performative tendencies of a training culture rather than enabling students to engage in a deep learning process" (p.484) leading to a marginalisation of certain types of knowledge for which there is currently limited market need for. Interestingly, they maintain that attempts to blur this distinction between formal and technical knowledge is how control can be exerted by the professional representative or regulatory bodies by inferring knowledge from the skilled activity or elevating the performance of a skilled activity. Moreover, by restructuring legal education to a more flexible model subtle regulation and control is exercised by the professional body through rigorous compliance with outcomes set by it and auditing by it of vocational stages of training. 


\subsubsection{Explicit learning with cognitive base}

Brainard and Brislen's (2007) commentary is one of the few written by medical students. They strongly advocate engagement in an explicit objective professionalism curriculum with a clear and cogent definition of professionalism. They maintain that medical educators only support an explicit curriculum on a theoretical basis as established hierarchies and the hidden curriculum prevent proactive engagement. They are not alone in this view. Cruess and Cruess (1997) also strongly believe that professionalism needs to be taught not only explicitly but with a clear definition of what professionalism entails (a cognitive base) to ensure professionals hold up their side of the social contract agreement: "a variety of educational techniques can be used, but professionalism must be taught explicitly, and the point made that professional status is a privilege granted by society that can be changed if society wishes" ( $p$ 206). Whitcomb (2002), Steinhart et al. (2005) and Hamilton (2008) all advocate a clear understanding of the components of the notion and the behaviours and actions expected to enable the teaching and evaluation of professionalism. Hamilton maintains that "confusion about the meaning of professionalism greatly reduces the possibility that the concept will actually influence the conduct of students in professional school...students will give more attention and energy to expectations that are clearly stated and rigorously evaluated" (p.477). Steinert et al. (2005) point out that the definition must be very clear, capable of being taught and evaluated: "We cannot tell students simply to be like us" (p. 129). Moreover, they advise, that the cognitive base should not only include a definition of the concept but also its obligations arising from the social contract with the public and its historical roots.

While Coulehan (2005) also maintains that doctors cannot expect professionalism to occur by osmosis by simply 'walking the walk' and 'talking the talk' he is critical of this explicit directive approach and warns against it: in an attempt to quantify professionalism, "skills and practices become surrogates for virtue" (p. 893). As discussed, he suggests a somewhat novel approach to learning professionalism based on a narrative tradition to bridge the gap between the formal curriculum (explicit teaching of professional values) and the tacit, informal or hidden curriculum (which he maintains are "objectivity, detachment, self-interest and distrust - of emotions, patients, insurance companies, administrators, and the state" (p.894)). He explains that trainee doctors experience internal conflict as they attempt to reconcile both curriculums. He agrees with Thomas Inui's 2003 report that this conflict exists due to a nonreflective approach to professionalism and advises that the narrative based professionalism 
will require a change not only in the behaviour of the trainees but also the medical institutions. He explains that this approach to professionalism involves four requirements which reinforce each other: professional able role-models; a safe environment for selfreflection; "development of narrative competence understood as the ability to acknowledge, absorb, interpret, and act on the stories and plights of others" (p.896); and participation in community services. Dolin (2007), coming from a different angle, expresses concern with the lack of relevance of the explicit socratic law school pedagogy in the US to the legal services provided in this consumer oriented world.

While Cruess and Cruess (2006) are strongly in favour of an explicit approach to teaching professionalism, it is interesting to note that in more recent studies they recognise that "a balance must be struck between teaching the cognitive base explicitly and providing opportunities where learning can occur in an authentic context” (p. 206). They are one of the few professional education commentators of the 'explicit teaching of professionalism genre' who recognise the importance of not only coming to a clear explicit consensus of what professionalism entails with the teaching faculty but also ensuring that the faculty have the skills and knowledge to teach the concept.

A number of commentators suggest a pervasive approach to the teaching of professionalism by integrating the notion throughout the curriculum i.e. professionalism forming part of all substantive areas of law or medicine to ensure knowledge of professionalism develops with growth of knowledge in other areas of knowledge (Braithwaite, 1990; Rhode, 1994; Shestack, 1996; Pearce, 2002; Cruess \& Cruess, 2006). Rhode (1994), a past president of the Association of American Law Schools, describes professionalism as a "central constituent of all legal practice and needs to occupy an equally central place in law school curriculum". Maharg (2012) advises that professional values such as integrity, service and duty, wisdom, compassion, accountability and responsibility are skills that can be embedded in an experiential curriculum leading to the development of professionalism in students. However, Pearce (2002) does explore the view that values cannot be taught and therefore the core law that cannot be taught must be separated from professionalism. 


\subsubsection{Assessment of professionalism}

Taylor (1997) discusses assessment of professional education in the context of the educational institutions. The basic principles that underpin the assessment of professional education, according to Taylor, are that it should reflect assessment of workplace professional practice and meet the standard of knowledge required to include propositional, personal and process knowledge. Concurring with Boud, and to encourage independent and interdependent learning, evaluation should be staff, self and peer evaluation; and, both formative and summative feedback are required. Poikela (2004) argues in favour of context-based assessment in the context of evaluating in the workplace which requires the consideration of situational and contextual factors. She points out that "repeating a certain skill or retrieving a propositional piece of knowledge based on memory is not a valid proof of knowing. It is at least as important to assess the skills and know-how in a changing, problem situation" (p.268). In her study she found that traditional means of assessing were not adequate as regards tacit and potential knowledge. Ginsberg et al. (2000) recommend a longitudinal assessment approach where students are assessed in a variety of forms over the entire programme by different assessors. The Law Society of Scotland's Diploma in Legal Training adopts this approach.

A number of commentators, particularly in the medical field are very strong advocates of formative evaluation to ensure students are meeting the professional standards expected of them. Cruess and Cruess (2006) draw attention to the fundamental social contract that underpins the traditional professions. They point out that medicine is given the privilege of being self-regulated and therefore the public need to be assured that there is rigorous assessment of explicit norms of professional behaviour and standards. This is what provides evidence of accountability and compliance with this contract. The effect the proposed move towards independent or government regulation in Ireland as discussed above (see section 1.2.3) will have on the approach to evaluation will be of interest to stakeholders. Byszewski et al. (2012) believe that it is crucial to 'teach' and evaluate professionalism in light of Papadakis' study which found a link between disciplinary actions of practising medics by medical boards with unprofessional behaviour in medical school. Stern (2005) believes that evaluation drives learning. Moreover, resources, outstanding teachers and curriculum do not ensure that students have learnt. While he recognises that it is difficult to measure professionalism as there are limited opportunities to observe students in realistic settings, he maintains that students who are not graded on professional behaviour are under the 
impression that it is not important. Ginsberg, Regehr and Lingard (2002) explore how behaviour is contextual. They found that it was difficult for evaluators to be objective in the sense that their perception on what was professional differed. Beauchamp (2004) argues that even were these difficulties arise it is important to evaluate what he calls the 'soft aspect' of medical practice as there is no way to gauge progress or development if there is no assessment of performance in terms of professional behaviour. From a legal perspective, Hamilton (2008), Maharg (2006, 2007), Steinert et al. (2005) are also strongly in favour of the assessment of professional standards. Medical students, Brainard and Brislen (2007) advise against subjective or narrative forms of student evaluations and favour trained evaluators. Byszweski et al. (2012) and Cruess and Cruess (2006) also draw attention to the importance of faculty development in the context of explicit teaching and assessment.

\subsubsection{Implications for legal professional education}

The literature review suggests the following key areas as being significant for further exploration in my study: any variation in the stakeholders understanding of professionalism; how to define professionalism; how trainees learning occurs in the workplace i.e. their training firm; consideration of delimiters and enhancers to workplace learning by training firms; the stakeholders' perception of tacit knowledge in the context of role-modelling in the workplace; consideration of structured role-modelling or a learning model, for example, Evans and Rainbird's (2002) model (section 2.3.4) to foster learning and create knowledge in the workplace; the implicit and explicit approaches adopted in the workplace and a consideration of the existence of any dialogue (Borehan and Morgan, 2004, See section 2.3.5) and workplace cultural influence; limitation of the influence of the workplace culture and hidden curriculum by personal knowledge; whether learning takes place horizontally among trainees and use by trainees of full community of learning and limiting this use for fear by retribution from individuals in the organisations hierarchy; the coming together of theory and practice and the trainees ability to transfer knowledge beyond the training firm and the professional training course (PPC); concern with the diminishing understanding of the core components of professionalism with a reliance on performative knowledge; any influence of learner's experience on both trainees and the educators; the influence of the informal curriculum; perceptions on how best to embed professionalism and whether to assess this embedding. 
A number of these areas emerged in the study's data and are explored further in the Findings Chapter (Chapter 4): the extensive variation in the stakeholders' perceptions of professionalism; the emphasis on a technical non ethical value-based understanding of professionalism; differing views on defining professionalism; the explicit and implicit approaches to embedding professionalism; the importance of role modelling and tacit learning; the influence of the culture of the firm and personal knowledge on the understanding and teaching of professionalism; positive and negative influences (delimiters and enhancers) on learning professionalism in the workplace and on the professional practice course; horizontal learning from peers in the workplace and on the professional practice course; dialogue within the workplace; and, views on assessment of professionalism

\subsection{Summary of Chapter}

While regulatory or representative bodies and academics have different views on how wide or narrow the notion of professionalism is, generally, commentators agree on the basic core values which underpin professionalism. Views vary widely as regards the teaching and assessment of professionalism. Many advocate the transactional learning approach supported by an all-encompassing definition of professionalism to aid in assessment. While others indicate that professionalism is neither something that can be taught or assessed but is instilled intuitively. The rich and varied workplace learning debates and commentary are of particular importance in the context of the trainee's period in the training firms. 


\section{Chapter 3}

\section{RESEARCH DESIGN}

This chapter begins with the epistemological and theoretical perspectives of this study and its methodological approach. This is followed by an in-depth discussion of phenomenography, the methodology adopted in this study, its limitations and its approaches to reliability and validity. The form of data collection and analysis is then discussed. The chapter concludes with the ethical considerations of this study.

\subsection{Epistemological and theoretical perspectives}

I consider interpretivism to be the epistemological position most suited to this study. While positivism as a theoretical perspective involves taking a value-free, detached approach, interpretivism is "predicated upon the view that a strategy is required that respects the differences between people and the objects of the natural sciences and therefore requires the social scientist to grasp the subjective meaning in social action" (Bryman, 2008, p.16). The interpretivist approach "looks for culturally derived and historically situated interpretations of the social life-world" (Crotty, 1998, p.67). It assumes that "knowledge is a question of meaning in a social and cultural context" (Svennson, 1997, p. 12). This is relevant to the contextual setting of this study and how the socio-economic context affects the perceptions of the group of stakeholders involved in the teaching and learning of legal professionalism in Ireland. Interpretivism assumes that social reality is constructed through humans' perceptions and how they process their experiences. It raises the question whether the contention that professionalism is in crisis in an Irish context, as discussed in section 1.2, is reflected in the perceptions of the group of stakeholders in this study. The British Educational Research Association (2014) explain that interpretivists argue that one must understand how a person interprets the world (their perceptions, attitudes and beliefs) before one can understand why a person does what they do or why a particular institution operates in a certain way. This characteristic of interpretivism is of particular relevance to my choice of methodology. Furthermore, the question arises of whether the literature discussed in the context of this study reflects how this particular group of stakeholders interpret professionalism and the fostering of the notion.

While phenomenographic researchers generally agree that the interpretative social research paradigm guides the phenomenographic study, there is debate about the underlying 
epistemological assumptions. For example, Ireland, Tambyah, Neofa and Harding (2008) identify the constructivist-interpretive approach as appropriate to a phenomenographical study as the focus is on the "collective meaning or conceptions of knowledge generated by identifying a wide range of individual experiences" (p.6). Crotty (1998) explains that we do not create meaning, we construct it - "all knowledge, and therefore all meaningful reality as such, is contingent upon human practices, being constructed in and out of interaction between human beings and the world, and developed and transmitted within an essentially social context" (p. 42). Constructivism is concerned with how the individual makes meaning as they engage with the world they are interpreting. It also assumes that people will construct knowledge in different ways.

In contrast, Prosser \& Trigwell (1999) and Svensson (1997) hold a different view to Ireland et al. (2008). They reject constructivism as a suitable epistemological position for this methodology by asserting that the phenomenographic approach holds a non-dualistic view of the world. Limberg (2014) describes this non-dualistic view as the assumption that an individual's understanding of a phenomenon and the way they act in relation to that phenomenon or situation is intertwined. According to Ireland et al. (2008), there is not an objective and subjective reality: "individuals and the world are internally related through the individual's awareness of the world. The world is an experienced world" (Proswell \& Trigwell, 1999, p.12). The seminal phenomenographic commentators, Marton \& Booth (1997) and Bowden (2005) also emphasise that this research approach is non-dualistic in that "there is an internal relation between the inner and outer world" (Ireland et al., 2008. p.6).

Constructivism is considered dualistic: "the inner world and outer world are divided with one explaining the other" (Ireland et al., 2008, p.6) i.e. "there are two elements: the student and the world" (Prosser and Trigwell, 1999, p.34). Prosser and Trigwell (1999) explain that phenomenography is a form of constitutionalism which in essence is the belief "that meaning is constituted through an internal relationship between the individual and the world" (p.13). This approach is, they maintain, distinctively different from other learning perspectives such as constructivism (or constructionism, which is often confused with constructivism, which involves the collective generation of meaning). For other perspectives "there is a separation between the individual and the world. Knowledge is brought in from the outside or constructed on the inside (Prosser \& Trigwell, 1999, p. 13)". Notably, Ireland et al. (2008) argue that phenomenography shares a number of key characteristics with constructivism 
because it aims to understand how the individuals interviewed experience a phenomenon and how they construct meaning from the experience. Ireland et al. rely on Crotty's (1988) description of constructivism, specifically his comparison of constructivism and constructionism, to support their argument:

It would appear useful then, to reserve the term constructivism for epistemological considerations focusing exclusively on the 'the meaning-making activity of the individual mind' and to use constructionism where the focus includes 'the collective generation [and transmission] of meaning. (p.58)

While it would appear that the constructivist approach could be adopted in this study, as it is concerned with understanding how this group of individuals (the stakeholders) construct meaning from their role in teaching and learning professionalism to develop professionalism in a particular socio-cultural context, I agree with the view that phenomenography is a nondualist approach and therefore at odds with constructivism. It is non-dualistic in the sense that each stakeholder's understanding of professionalism, together with their experience or understanding of the teaching, learning and fostering professionalism and the way they act in relation to teaching and learning professionalism, is intertwined. It is not simply one explaining the other as objective and subjective worlds.

Svensson (1997) describes a number of epistemological assumptions pertaining to phenomenography. He argues that there is a fundamental assumption that knowledge is relational and holistic in nature. This approach, he explains, involves a description of an experience and therefore the assumption is that descriptions are important. The importance of the descriptions becomes very clear in the findings of this study. This is related to an understanding of knowledge as similarities and variances in meaning. Furthermore, as phenomenography uses categories of description (see section 3.4.1) analysis as a form of abstraction, reduction and condensing of data is required. This form of analysis, he explains, assumes that "conceptions may be described in terms of their reduced content, where the reduction which is also an abstraction, is a reduction of the meaning of the main parts of the phenomenon conceptualised, with preserving of the main content of the parts as parts of an organised whole" (p.168). Marton and Booth (1997) and Limberg (2014) maintain that the structural relationship between different ways of experiencing a phenomenon i.e. the relationship between the research unit (ways of experiencing a phenomenon derived from the 
individuals) and the outcome of the research (the categories of description which describe the collective experiences) is a distinct theoretical feature of this methodological approach

\subsection{The methodology - phenomenography}

I adopted a phenomenographic approach in conducting this study. Phenomenography is a relatively novel approach to research which is aimed at the way something is experienced and with the human experience as its research object. I do provide an in-depth and at technical description of this methodology which I believe is important given the somewhat unusual nature of the approach.

In a higher education context phenomenography emerged as a methodology in the 1970's to investigate surface and deep learning approaches among students. It developed into two strands. On the one hand, it encompasses an empirical research approach in education and on the other, it developed as a variation theory from a theoretical point of view. Phenomenography represented a move from an objectivistic view of knowledge to a more subjective and relative view (Limberg, 2014; Svensson, 1997). It provides a particular lens through which to view certain research questions. For example, in education phenomenographic research, Prosser and Trigwell (1999) maintain that educators' approaches to teaching are not stable but relational as educators' perceptions of their situation changes. This methodology is particular suited to exploring the research questions raised in this study (see section 1.4 above).

Marton (1986) led the group of researchers who developed this approach, in a higher education context. He describes it as a research method "in which people experience, conceptualise, perceive and understand various aspects of and phenomena in, the world around them" (p.31). Notably, a decade later Marton and Booth (1997) maintain that phenomenography is a research specialisation and not a research method. In a similar vein, Marton and Booth (1997) explain that "at the root of phenomenography lies an interest in describing the phenomena in the world as others see them, and in revealing and describing the variations therein especially in an educational context...this implies an interest in the variations and changes in capabilities for experiencing the world in certain ways (p.111)". Phenomenography takes the position that ways of experiencing a phenomenon are relational whereby a relationship exists between the individual and the phenomenon. Moreover, the different ways of experiencing the phenomenon (described in the Categories of Description) 
are related to one another in a logical structured set (the Outcome Space. See section 3.4.1) (Marton \& Booth, 1997; Akerlind, 2005).

Other commonly adopted qualitative methodologies were considered for this study and could have been adapted to explore the teaching of professionalism. For example, action research (reviewing current teaching methods, experimenting with different strategies, collecting data from relevant sources on the effectiveness of the new strategy, evaluating such data, reflecting and gaining insight); case study (the detailed analysis of a single case or one or more cases within a particular setting) and Phenomenology (concerned with finding common experiences of a phenomenon) were considered. The latter merits more discussion because this and the methodology I have adopted are often confused. While phenomenography is a distinct methodological approach it derives certain lessons from the phenomenological philosophy. Phenomenology involves a detailed investigation of how people see or experience themselves and the world. This is a similar to phenomenography but with an important difference, namely that phenomenography is interested in the variations in and perceptions of experiences. On a general level, Crotty (1998) describes phenomenologists talking about 'immediate, original data of our consciousness' referring to "what we directly experience; that is, the objects of our experience before we start thinking about them, interpreting them or attributing any meaning to them" (p.79) leading to the "possibilities for new meaning" (p. 78, Crotty, 1996a). This direction to make sense of a phenomenon directly and immediately, with a view to making new meaning, is not evident in the methodology I have adopted. While, the phenomenographic approach does suggest that the interviewer "bracket" their perceptions (see below for in-depth description) in collecting data, phenomenology directs those being interviewed to set aside their prevailing understandings and "revisit our immediate experience of" (p. 78, Crotty, 1996a) the phenomena. Moreover, phenomenology does not require the distinct form of data analysis that my methodology suggests i.e. Categories of Description placed in a hierarchical fashion and structurally compared in an Outcome Space (see section 3.4.1).

Phenomenography is especially suited to analysing the variation in perceptions which underpins the research questions raised in this study. The critical variance provides useful educational insights. I adopted this methodology in a small scale MA study (referred to as MA study) that I carried out a number of years ago. It involved the study of the perceptions of legal professional educators, from two ends of the spectrum, of their role as educators of 
professionalism: four training solicitors from large Dublin based commercial law firms and four Law Society tutors, for an MA in Legal Education and Skills. The MA study found a stark variance in perceptions between the two groups. In undertaking this doctoral level study, I had a keen interest in engaging with this approach again and improving my phenomenographic analysis. In the earlier study the level of variance was very limited: I understood the analysis to require the extremes of potential variations in those being researched. I had concerns that my findings and the level of variance in perceptions were skewed and not representative of all those involved in the instilling of professionalism. This was particularly influential in my choosing this methodology for this study. I also wished to add the voice of the trainee solicitor to the pot!

Phenomenographic researchers suggest that this relatively complex approach should be applied to a test study before embarking on the core study. I consider the early MA study my test study. It provided me with an opportunity to understand the concepts involved, become familiar with the process of analysis and explore its limitations and benefits for educational research. Furthermore, it gave me the opportunity to consider its effectiveness in dealing with the research questions raised with regard to the teaching of professionalism.

The chart below, adopted from Bowden (2005), represents the relational position of phenomenography whereby knowledge is created from the relations between individuals and the world (in the form of the phenomenon). The object of the study is the relationship between the study's group of individuals (the stakeholders) and the phenomenon (Stamouli \& Huggard, 2007). 


\section{Researcher}
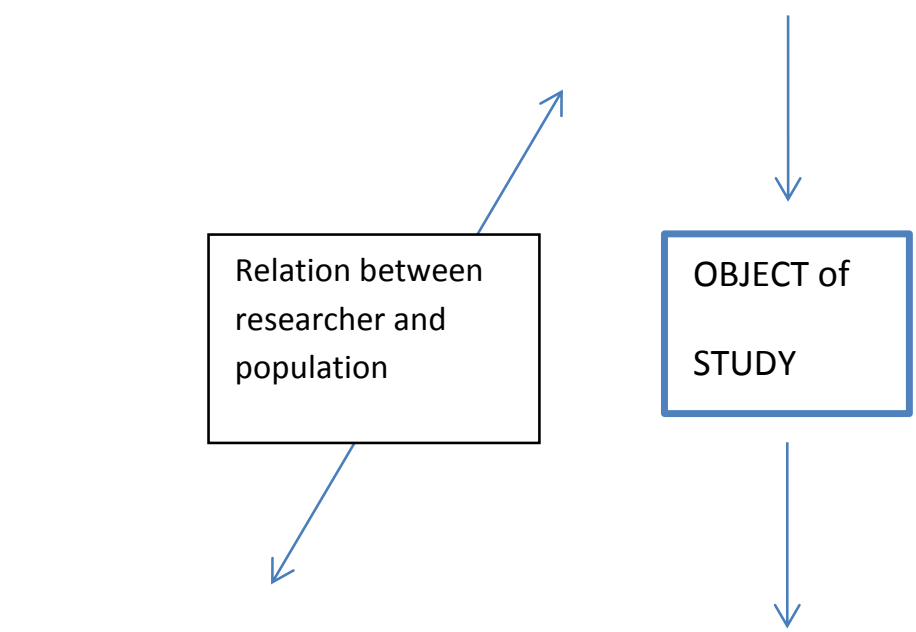

\section{Population of the study}

Relationship between the population of the study and phenomenon

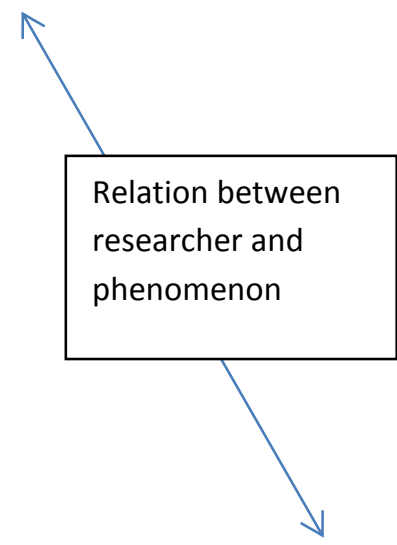

\section{Figure 1 - the relational position of Phenomenography}

Phenomenography seeks to examine and understand the qualitative variation in ways of experiencing a particular phenomenon which, in this study, is the instilling of professionalism as understood or experienced by a group of stakeholders involved in professional legal education. This group comprises a varied group of training solicitors/firms, Course Managers/Training executives (employees of the Law Society), tutors; and trainee solicitors. As the aim of the research is to explore the variance in perceptions of a varied group of individuals, this methodological approach and form of data analysis is particularly appropriate to the research questions raised in this study.

While phenomenology also has human experience as its main focus, its principal aim is to capture the essence of a phenomenon while phenomenography is concerned with mapping the variation in experiences of a phenomenon (Limberg, 2014). Moreover, this methodology is used where the phenomenon can be experienced in varying ways and, for the most part, where the variance is educationally critical and will assist in future educational development. 
I interpret variance to be educationally critical where there is a critical level of variation in the perceptions of the group which is having an effect on education. This, in my opinion, is a variance that needs to be addressed because it generally has an adverse effect on education and requires a more coordinated approach among educators. If, for example, there was very little variance among the perceptions of the group of stakeholders in this study's findings there is no educational criticality and one might question the appropriateness of this methodology to the study.

It is the perceptions and experiences of a group of individuals and not those of the researcher or the individuals themselves that are of interest when this methodology is adopted. This is referred to as the second-order perspective by phenomenographic researchers. Limberg (2014) points out "that it is not the world as such that is being explored but the world as experienced by .... group of people" (p.2).

\subsection{Data Collection/Participation selection}

Data for this study were collected by means of face-to-face, dialogical and semi-structured interviews. This method of collecting data is the predominant method adopted in phenomenographic studies designed to provide data on interviewees' perceptions and experiences in an educational field (Marton, 1986). Kvale (1996) describes the structure of the qualitative research interview as a professional conversation which has a specific approach and technique of asking questions. Its purpose is to 'understand themes of the lived daily world from the subject's own perspectives' (p.27). The semi-structured nature of the interview ensures that, while there are suggested questions or partially prepared questions, there is an openness to the form and the sequence of the questions (Hession, 2012). This form of data collection is not as personal or emotional as a therapeutic interview or as neutral or anonymous as a questionnaire (Kvale, 1996). Data collection did not involve the use of surveys or unstructured interviews. Unstructured interviews do not allow as much comparability as semi-structured interviews while structured interviews can fail to reveal the interviewees' true perceptions (May, 2001).

Ireland et al. (2008) point out that the aim of the phenomenographical interview is to understand the interviewee's perception of the phenomenon. It is not to understand the phenomenon itself or to compare the interviewee's perceptions with the researcher's. However, Ashworth and Lucas (2000), Marton (1986) and Limberg (2014) argue in favour of 
a mutual understanding of the phenomenon. Limberg (2014) suggests that the "researcher should thoroughly delineate and penetrate the phenomenon under study in order to discern its outer and inner structure, the various possible meanings of the phenomenon, and various characteristics that may be linked to the phenomenon..." (p.2). He recommends analysing existing phenomenon within different research traditions. The purpose of this understanding is not to pre-impose certain assumptions but to enable the researcher to be as open as possible to the perceptions of those interviewed. Marton (1986) maintains that the interview is carried out in the form of a dialogue whereby the experiences are jointly constituted by the researcher and the participants. Akerlind (2005) stresses the importance of encouraging interviewees to reflect on their experiences with follow-up questions to elaborate on experiences and understanding of the phenomenon. She advises that "follow-up questions are extracted from what the interviewee has said in the interview and not formed through predetermined views" (p. 330) of the interviewer. In this study I engaged in semi-structured interviews using open-ended descriptive questions as prompts for the professional conversation regarding the interviewee's perception of professionalism (to ensure there was a common understanding) and regarding their perception and experiences in teaching and learning professionalism in this particular context.

The literature argues that the interviewer should bracket their assumptions about the phenomenon, their personal knowledge and beliefs to ensure there is no influence over the interviewee's views and perceptions (Ashworth and Lucas, 2000; Bowden, 2005). Ashworth and Lucas (2000) emphasise the importance of being empathetic to the interviewee's experiences of the concept being considered while bracketing assumptions regarding earlier research findings, particular theories or interpretations, personal knowledge or beliefs. 'Bracketing' practices range from not referring to other participants to "not laughing at jokes for fear of implying approval of a statement" (Ireland et al. 2008, p.207) or making judgemental remarks (Bowden, 2005). In my interviewing style, I adopted a balanced approach between personal expression and bracketing my assumptions in order to encourage a natural flow to the conversation, to demonstrate interest in the interviewees' perceptions and to avoid a defensive attitude in discussing a somewhat sensitive topic. Ireland et al. (2008) describe this approach as 'gentle enthusiasm'. Furthermore, I made my positionality as a researcher, in terms of my role with the Law Society, explicit to the interviewees before the interview commenced. I hoped here to attempt to avoid any perceptions of imbalance of power between the interviewer as an employee of the Law Society and the training firms and 
trainee solicitors. Bracketing of my assumptions regarding research findings that I carried out previously for the MA study (see section 3.2) was important because of the potential influence the findings from the small scale study might have. Also, of importance was to avoid preconceptions based on my position as a Course Manager in the Education Department of the Law Society.

Pilot interviews with those in the target group are recommended to test whether the interview questions illuminate the research questions and to test the interviewing skills of the researcher (Bowden 2005). Bowden (2005) also recommends not including the data collected from these pilots as they may contain errors and invalidate the results. I carried out two pilot interviews with one solicitor and one trainee solicitor. I found the pilot participants reluctant to expand on their views and questions were answered very succinctly. This is an interesting observation: perhaps it is a facet of a solicitor's professional identity as part of their nature or as a result of their training and experience that they take a 'to the point' approach to questioning or tasks. Solicitors, in my experience from practice and in my dealings with solicitors as associate faculty, are efficient and hesitant to divulge outside the given parameters. There is a fear of being held responsible for statements made. Moreover, they provide and are expected to provide legal advice to clients in a succinct manner. As a result, for the study itself, I adopted a more conversational approach with follow-up questions to encourage discussion and openness.

Generally, the number of participants in phenomenographic studies ranges from fifteen to thirty participants. (Ashwin, 2006, Akerlind, 2005). I interviewed sixteen stakeholders in total: six solicitors/training solicitors (two of whom were also Law Society tutors), six trainee solicitors, three Law Society Education Department staff members and one non practising Law Society tutor. As advocated by other phenomenographic studies (Prosser \& Trigwell, 1999; Shreeve, 2010; Ashwin, 2006; Akerlind, 2005), I attempted to engage a group of solicitors/training solicitors from various size firms (ranging from sole practitioners to very large firms employing more than 200 solicitors), location (Dublin based, regional city based or rural), types of practice (ranging from general to commercial), gender and age. I also interviewed six trainee solicitors at various stages of the traineeship. Again, I attempted to select a diverse group of trainee solicitors to interview in terms of gender, age, background, location, size of firm and so on. This enables some exploration of how their backgrounds may 
influence trainee solicitors' perceptions, notwithstanding that this particular group of students come from a relatively narrow cultural range in terms of background.

I interviewed two pre-PPCI trainees, one trainee while attending the Professional Practice Course Part I (which is generally before they begin any training in the training office) and three while attending the Professional Practice Course Part II and near the end of the traineeship period. This gave the opportunity to compare their perceptions before and after completing twelve to eighteen months in their solicitor's firm. Due to the restricted time period of the EdD it was not possible to interview the same trainees throughout their traineeship period (2.5 years approx.). Three tutors with our teaching team in the Law Society were also interviewed. While the tutors had varying degrees of tutoring experience all had been tutoring for the Law School for a minimum of five years (it is a requirement that tutors are qualified lawyers and have at least 3 years PQE) and were all qualified solicitors (two of these tutors are comprised in the solicitor group above). Again, as is highly recommended by leading phenomenologists (Prosser \& Trigwell, 1999; Akerlind, 2005), participants were selected on the basis of how they varied from other stakeholders in terms of gender, age, type of firm, whether they practiced in firms with no trainees or with trainees. One tutor was no longer in practice while one other tutor had recently retired from full time employment and was a solicitor's firm legal consultant. I also interviewed those in the Education Department of the Law Society, namely two Course Managers, who are responsible for the design and the delivery of the Professional Conduct module (one of the Course Manager is also the trainee counsellor). Finally, I interviewed the Law Society Traineeship executive who is responsible for trainees while in their training offices. There was no opportunity to introduce variance to this particular sub group. It was important to introduce as much variance as possible among the participants; there was limited variance in the group I interviewed in the MA study and this, I would suggest, skewed the findings somewhat.

Interview questions were carefully considered and derived systematically from the research questions. Moreover, they were influenced by the methodology adopted and the literature reviewed. Examples of the questions asked, which acted as prompts during the interview discussion, are as follows: "Professionalism" - What does it mean to you? What you think is the best approach to ensure trainee solicitors assimilate professionalism? (and can apply it), 
What influences the learning of professionalism? What do you think are the barriers to/promoters of learning professionalism? Should it be assessed and if so, how? (see Appendix 1 for further examples.)

While the above questions may appear relatively closed, they were used as prompts only. It some cases, the prompts were not required where the interview naturally followed a certain course. Follow-up questions were required in some interviews to ensure interviewees were given an opportunity to discuss their perceptions in further detail or to illicit further meaning. I ensured that the interviewee was given the opportunity to think about and reflect on their experiences. To avoid any perceived imbalance of power or the influence of hierarchical structures which may restrict interviewees' views, I held interviews outside the Law Society where possible or gave the interviewees the option of holding interviews at their place of work, at the Law Society or an alternative venue. Interviews were audio-recorded and transcribed verbatim.

\subsection{Data analysis}

\subsubsection{Categories/Outcome space}

With phenomenography, preliminary analysis is carried out during the interviewing process and during the transcription of the data. The researcher identifies particular themes as they familiarise themselves with the data collected. Limberg (2014) explains that the process "moves between empirical data and theoretical concepts to let one illuminate and contribute to the other" (p.2). In phenomenographical data analysis, categories are used to pinpoint various aspects of a phenomenon as it appears to a group of people (Limberg, 2014). Bowden \& Walsh (2000) explain that categories are developed from the individual 'conception' - an individual's way of experiencing a particular aspect of reality. Limberg (2014) points out that the concept of an approach to experiencing has replaced earlier terms such as conception and way of understanding but that in many studies the terms are used interchangeably. The researcher identifies, formulates and describes the critical features of the various ways of experiencing the phenomenon.

In practical terms, the analysis process starts by familiarisation with the data whereby the researcher fully immerses themselves in the audio recording, the transcripts and personal reflection, at all times attempting to bracket assumptions. This involves reading and rereading the transcripts, which are the only source of data. As the unit of analysis is the 
sentence or paragraph reflecting the full expression of the perception this process leads to an emergence of utterances, which illuminate the research questions raised. The process continues with continuous sorting, adjusting, grouping and re-grouping and re-sorting resulting 'in a stable set of categories and relationships' (Martin et al., 2003 p.250). I used mind maps (see example at section 4.1, Figure 2, p.91) at this stage of the process - this does not appear to be alluded to as a recognised technique in the literature exploring this methodology but I found it served a purpose in the initial sorting of themes. Phenomenography involves an inductive approach or bottom up approach initially to work meaning from the data but, as Niikko (2003) points out, as the analysis progresses the data is read deductively.

There are variations in the methods used in phenomenographic data analysis. It is therefore important to clearly set out the procedures adopted at each stage (Bowden and Walsh, 2000). In determining the categories of descriptions, Bowden (2005) recommends focusing on the entire interview transcript to give a holistic view of the experience. With this approach, transcripts with similar meanings are grouped, with similarities and differences noted to ascertain preliminary categories. Each of these categories are developed further when a transcript is identified that does not appear to fit into any category or reveals a particular nuance that needs to be considered. Other researchers take a decontextualising approach whereby extracts from transcripts are combined for analysis thus ensuring focus on the collective view (Akerlind, 2005). In this study, the focus was on transcript extracts to establish the categories of description as it was easier to manage the data and determine the collective view and variance of the group of interviewees. Furthermore, this approach ensured that interview data could contain more than one of the categories of description formed as the objective is to determine the variation across all of the transcripts, rather than each interviewee fitting in to a particular category (Ashwin, 2006). Marton and Booth (1997) describe this decontextualised approach well and remind the researcher that the pools of meaning that emerge from the process should remain faithful to the full interview approach:

All of the material that has been collected forms a pool of meaning. It contains all that the researcher can hope to find, and the researcher's task is simply to find it. This is achieved by applying the principle of focusing on one aspect of the object and seeking its dimensions of variation while holding other aspects frozen. The pool contains two sorts of material: that pertaining to individuals and that pertaining to the 
collective...one particular aspect of the phenomenon can be selected and inspected across all of the subjects, and then another aspect, that to be followed, maybe, by the study of whole interviews to see where these two aspects lie in the pool relative to the other aspects and the background... This process repeated will lead to vaguely spied structure through and across the data that our researcher/learner can develop, sharpen, and return to again and again from first one perspective and the another until there is clarity (p.133)

These categories of description are not lengthy or rich descriptions of the interviewees' experiences. They describe the key features of the variances and do not deal with aspects of the experiences for which there is little or no variation. Mann (2009) points out that the categories and how they are described are clarified by the transcripts as a whole. The researcher only relies on what is included in the transcripts in writing the descriptions of the categories. The meaning of the categories in this study were delimited fully with sufficient extracts from interview transcripts supporting the distinguishing features as advised by Entwistle (1997).

The qualitatively different ways of perceiving a phenomenon or more precisely, the variations in the common phenomenon experiences of the group are presented in logically related categories of description which can be hierarchically ordered based on an increasing complexity of ways of experiencing the phenomenon. This presentation is fundamental to this methodology and involves a thorough logical analysis of the difference in meaning. The categories are an attempt to ascertain the differences in perception of a group "who are all confident that their interpretation is the most reasonable" (Akerlind, 2005, as cited in Mann, 2009 , p. 1). The aim is to describe the phenomenon in terms of its essential meaning (Svensson, 1997). Limberg (2014) describes the relationship between the ways the phenomenon is experienced (the research unit) and the outcome of the phenomenographic process i.e. the categories created to describe the experiences, as a distinct theoretical feature of this process. The "hierarchical relationships between the categories are not value judgments from 'better' to 'worse' "(Akerlind, 2005 p.303). Marton and Booth (1997) point out that these variations or differences are educationally critical differences. They describe three criteria for judging the quality of the categories of description: Firstly, each category describes something distinct about the way the phenomenon is experienced; secondly, the categories are related logically and generally, in a hierarchical fashion; and; thirdly, as few as 
possible categories are created to reflect the critical variation in how the phenomenon is experienced.

The categories and their relationship to each other represent a structured set known as an 'outcome space' (Marton and Booth, 1997; Martin et al., 2003; Akerlind, 2003, 2004, 2005, Limberg, 2014). The set forms a hierarchy which aims to "capture the essence of the whole experience and reveal the essential variational structure of that experience" (Booth \& Ingerman as cited in Tutty, Sheard and Avram, 2008 p.174). It is an inclusive hierarchy in the sense that categories higher up the hierarchy are more complex in that while they maintain the essential element of the category lower down the hierarchy they also incorporate a new qualitative element (Martin et al, 2003). Akerlind (2004) explains that this structure is based on the relationships between the critical aspects of the variances i.e. the different ways of understanding a phenomenon and suggests that it provides useful educational insights. Some commentators favour the constitution of structure later on in the process for fear of losing meaning in the data (Ashworth \& Lucas, 2000) while others maintain that meaning and variance should be co-constituted (Akerlind, in Bowden and Green, 2005). The former approach was adopted in this study. Both Bowden (1996) and Ashworth \& Lucas (2000) discuss the concern that some commentators have with the requirement by the researcher to form or establish this outcome space and the potential of this requirement being imposed on the data rather than emerging from the data.

The structure of the outcome space can vary and as Akerlind (2005) points out it may not always take the form of a linear hierarchy. Some studies focus on the weighting of perceptions (Taylor, 1997) while others establish very comprehensive and descriptive category based outcome spaces (Tutty, Sheard \& Avrim, 2008). This study adopted a more pared back approach to the structure of the outcome space, similar to Shreeve (2010), Akerlind (2010), Martin et al. (2003) and Ashwin (2006), to capture the essential variants between the categories. This approach and the choice of methodology were perhaps influenced by my position as a researcher in the sense that I favour a logical structured approach to work in general. As a practising solicitor, I practiced in conveyancing, which involves a series of systematic steps to complete the sale or purchase of property. This is reflective of the phenomenographic process. 
Akerlind (2005) points out that ideally, "the full range of possible ways of experiencing the phenomenon" (p.323), for the representative group at that point in time, should be represented in the outcome space. Furthermore, Akerlind stresses that the focus is on the collective, in that; the individual's experience is interpreted within the context of the group of experiences in terms of similarities and meanings. She points out that "no one interview transcript...can be understood in isolation" (p. 323) as it is interpreted within the group of meanings as a whole. The categories of variation are identified from the data collected as a whole and not on variation in any individual's experience: they are not descriptive of the individual's experience or of the dimensions for which there is little variance (Martin et al. 2003). Marton and Booth (1997) stress that "individual voices are not heard. Moreover, it is a stripped description in which the structure and essential meaning of the ...[categories] are retained while the specific flavors, the scents, and the colors of the worlds of the individuals have been abandoned" (p.114). Quotations from the interviews are used extensively to illustrate the key themes/features of the categories and the variation between the categories of description. This serves to provide a proper sense of the nature of the category rather than an abstract description (Akerlind, 2010). The quotations emphasise the variation in the categories. Generally they do not describe the common features except where the category is higher in the hierarchy and there is therefore more inclusiveness. It is important to note that using single quotations from the transcripts to describe the phenomenographic categories of description represents only a fragment of the particular category (Martin et al., 2003). As the methodology involves investigating a search for meaning across the interview data it is difficult for a single excerpt to describe the category as a whole (Hession, 2012).

\subsubsection{Analytical frameworks - Structural and referential aspects}

In phenomenography the structural and referential aspects of an individual's experience can assist in analysing the variance in experiencing a phenomenon and creating an outcome space. The referential or meaning dimension of an experience is the overall meaning that has been assigned to the phenomenon by the individual experiencing it, while the structural dimension analyses how the parts are related i.e. how the phenomenon can be distinguished from its context and how the individual parts of the phenomenon relate to each other and the overall phenomenon (Gardener and Edwards as cited in Harris, 2011).

Other analytical frameworks include distinguishing the 'how' and 'what' aspects of an experience. Generally, this how/what framework is used in the analysis of the experience of 
learning - the 'what' aspect relating to the content that is learned while the 'how' aspect refers to the learners approach to the task of learning (Harris, 2011). This framework can also be applied to the phenomenon of the teaching experience - the 'what' aspects of teaching is what is taught or what the teachers perceive as teaching, the 'how' aspects of teaching are the acts that the educator uses in teaching and the indirect outcomes that the educator aims to achieve as a result of teaching (McKenzie, 2002). In his evaluation of these frameworks and their utility, Harris (2011) refers to the weakness of the link between these frameworks and theory but also maintains that they serve a purpose in data analysis process as they "provide researchers with a way to 'think apart' intertwined understandings, processes, parts, motives, and contexts" (p.117). Moreover, while Harris (2011) disagrees with Cope's (2002a) argument that frameworks may improve the validity and reliability of the study, he does recognise that they contribute to the knowledge about the phenomena.

These analytical frameworks can be applied to this study and assisted in the data analysis process and ultimately the understanding and knowledge about the phenomenon. The referential aspect in this study is the meaning attributed to the teaching of professionalism and the notion of professionalism itself by individual interviewees. This is linked to the 'what' aspect: what the stakeholders perceive as the teaching of professionalism. The 'how' aspect is how the individuals perceive the teaching of professionalism comes about. Again this is related to the structural aspect in this study: how the individuals explain their experiences. There are two components to the structural aspect: Firstly, how the individuals contextualise these perceptions i.e. how the teaching of professionalism is perceived and how it is distinguished from its context and secondly, an examination of the individual parts of the phenomenon (the teaching of professionalism) and how they relate to each other. An example of how a stakeholder's perception may be contextualised or distinguished from the context is how their perceptions may be affected by teaching in a particular context i.e. in the Law Society or in a training firm. The second component examines the parts of how the individuals understand the teaching of professionalism and how they relate to each other. For example, what the individuals' perceptions were as regards the notion of professionalism, the various approaches to teaching, the influences to teaching and workplace learning. This analysis is taken a step further whereby the relationship of the parts of the phenomenon are considered. It complements the development of the phenomenographic outcome space.

\subsection{Limitations/Validity/Reliability of methodology}




\subsubsection{Limitations}

Although the sample selected in this study was sufficient to maximise the potential variation in the stakeholders' experience of their role in learning and teaching professionalism/perception of professionalism, it was not selected in a way that makes the results generalisable. The notion of generality to the general population is not applicable to this methodology, according to Akerlind (2002), as it explores the variations of experience for a specific group of diverse individuals. Marton and Booth (1997) expect that the range of variation in a particular study reflects the range in general. The results could be generalisable to a similar group with similar experiences and therefore, as Cope (2002) advises, detailed characteristics of the interviewees should be outlined to enable readers determine the generality of the findings to the reader's group.

Critics of this methodology argue that ways of experiencing a phenomenon are separated from the individuals in this form of data analysis (Limberg, 2014). Phenomenographers speak of abandoning the world of the individual where the experience of the group is important (Marton \& Booth, 1997; Marton et al, 2003; Akerlind, 2005). It is the variances in the groups' perceptions that form the categories of description. While the categories established in this study were based on the groups meaning and understanding, I do refer to individual transcripts to illustrate the distinguishing features of the category (this is in line with the phenomenographic approach, Entwistle, 1997) and, on occasions, discuss an individual's perception, where it adds depth and richness to the discussion.

Moreover, critics point out that there is a risk that the researcher and interviewee may not have the same understanding of the phenomenon when the concept is separated from the context in interviews (Limberg, 2014). A mutual understanding of the phenomenon in a particular context between the interviewer and interviewee is considered in this study. I interpret this to mean that I clearly understand the interviewee's view of what professionalism is and the teaching of the concept during the interviews. While a joint understanding between the stakeholders interviewed and this researcher of what professionalism entails and how it is understood to be instilled in the context of the Irish professional legal education is carefully considered, it is not necessary for the interviewee and I to explicitly or jointly construct or compromise our views of the phenomenon. 
The limitations of various stages and tools of analysis used in the application of the phenomenographic methodology are also discussed below.

\subsubsection{Validity and Reliability}

Validity is widely regarded as the extent to which the study's findings reflect the phenomenon being studied. Validity checks in phenomenography, Akerlind (2005) points out, ask how well the findings correspond to the experiences or perceptions of the phenomenon and not how the phenomenon exists in reality. The focus of the robustness of the research is on ensuring that the research methods appropriately reflect the research aims (Ashworth \& Lucas, 2000). Kvale (1996) discusses two types of validity checks as appropriate to phenomenographic research: communicative and pragmatic. The former includes the communication within the interview whereby participants are informed of the researcher's interest in the participant's experiences or perceptions of the phenomenon. A dialogue between the researcher and interviewer is established with qualification of statements encouraged to stimulate discussion in order to develop a joint understanding of the phenomenon as discussed above (Sandberg, 1994). In this study, participants are clearly informed of the aim of the study as part of the consent process. Moreover, interviews are conversational, based on open-ended questions with follow up questions to encourage discussion and for clarification purposes. As advised by Entwistle (1997) "questions are posed in a way which allows the [students] to account for their actions within their own frame of reference, rather than on that imposed by the researcher" (p.132).

While communicative validity checks include feedback from the research community (I interpret this to mean feedback of the findings and conclusions of the study and not the data analysis process), the intended audience of the research and feedback from the interviewees, Akerlind (2005) points out that phenomenographic research is seldom validated by the interviewees as the researcher's interpretations are not based on an individual interview but rather aim to capture the range of perceptions within the group of interviews. Moreover, she explains, interviewees may have a different perspectives of the phenomenon at the time of feedback as the underlying ontological assumptions of this methodology assume that an individual's understanding and experience is time and context sensitive. Therefore, there is no value in obtaining interviewees feedback at a later stage. Pragmatic validity checks 
involve demonstrating the extent to which the outcomes of the research study have value and provide useful knowledge, defined as the ability to perform effective actions (Sandberg, 1994; Kvale, 1996): "For researchers in higher education, however, the test is generally not its [phenomenography's] theoretical purity, but its value in producing useful insight into teaching and learning" (Entwistle, 1997, p.129) One of the aims of this research study is, ultimately, to provide useful educational insights into the teaching and development of professionalism based on the critical variance in perceptions of a group stakeholders in legal professional education. The concept of critical variance is discussed at section 3.4.1 above.

Moreover, because it is necessary for the researcher to have a mutual understanding of the phenomenon, a relationship exists between the researcher and the participant. The researcher needs to ensure not to impose their own interpretations of the concept on the interviewee. According to Stamouli and Huggard (2007), this can be overcome by the use of robust methodological guidelines which form part of the phenomenographic process. I would suggest that the reliability of this methodology, as with other qualitative approaches, is dependent upon careful formulation of the research questions, the standard of the researcher's interpretive awareness, interview skills and checking and reporting of interpretations. The MA study, as outlined at section 3.2, gave me the opportunity to develop and enhance the aforementioned skills before imparting on this larger scale study.

To ensure reliability in phenomenographic research, Mann (2009) suggests, firstly, formulating research questions that elicit variation in experiences and secondly, ensuring a diversity of carefully selected interviewees. He also suggests controlling interpretations by using pilot interviews to develop a consistent interview technique; using open ended questions with a focus on exploring variation in experiences rather than testing a preconceived theory; strict adherence to the interview scripts including reading excerpts in context; admitting to inconsistencies and using them as prompts to consider other categories/themes; and; systematic analysis of data to form a set of Categories of Description and the hierarchical Outcome Space (see section 3.4.1 above). I adopted these recommendations in this study's data collection and data analysis phases: pilot interviews informed the development of a consistent approach and a tweaking of the open-ended prompt questions to encourage openness; categories emerged from the limits of the interview scripts with any inconsistencies leading to further categories leading to the formation of the Categories of Description and Outcome Space as required by this particular methodology. 
Kvale (1996) recommends coder and dialogic as forms of reliability checks for ensuring quality and consistency in data analysis. Both rely on input from a number of researchers. The former requires two researchers to independently code all or a sample of the transcripts and compare the outcomes while the latter involves researchers coming to an agreement after critiquing the data and each other's interpretation. While Bowden (1996), Marton (1986), Ashwin, (2006) and Martin et al. (2003) recommend that the categories that emerge in phenomenographic data analysis be verified by another researcher, Akerlind (2005) draws our attention to the view that this is not necessary or appropriate for this methodology for the same reasons that interviewees are not asked to verify the findings, that is, the set of group transcripts are analysed to form the basis of the categories of description (not individual interviews) and are contextual sensitive. Sandberg (1994), Kvale (1996) and Akerlind (2005) maintain that clear presentation of the steps taken to interpret the data, with examples presented, is a valid alternative to particular reliability tests that involve verification by other researchers. This study adopted this approach in that the data analysis/determination of categories of description were not independently analysed or determined. Moreover, Sandberg (1994) argues that what is important is setting out how the researcher ensured their personal experiences and perspectives did not impinge on the findings to demonstrate reliability. The tension that exists between this somewhat positivist approach and this methodology's interpretive underpinning must be acknowledged and is also discussed in the context of bracketing at section 3.3.

\subsection{Ethical considerations}

The collection of qualitative data inevitably intrudes into people's lives and will often involve raising sensitive private matters with interviewees. Accordingly, consideration of ethical issues is important in an educational and social science study. This study involves in-depth interviews with trainee solicitors (students), training solicitors in solicitors firms, tutors in the Law Society and Course Managers (employees of the Law Society). The students are all over 18 years old. While there was no requirement to obtain consent to interviews from parents/guardians, the study did involve delving into the social and professional lives of the interviewees. Informed consent to interview/data collection was required from all those interviewed. I adopted the BERA code of ethical guidelines for educational research (2011) and was guided by the University of Sheffield's Research Ethics General Principles and 
Statements. Furthermore I obtained ethical clearance in accordance with University of Sheffield requirements.

The key principle underlying the University of Sheffield Ethics Review Procedure "is that researchers should reflect on the ethical issues that are raised by their research and be able to justify, in ethical terms, the practices and procedures that they intend to adopt during their research (p.4)". The BERA guidelines (see Appendix 2) advise researchers to ensure to obtain voluntary informed consent whereby participants understand and agree to participate without duress prior to the study being carried out. Furthermore, it advises that it must be made clear to participants that they have a right to withdraw and be accorded the right to confidentiality and anonymity. Data Protection requirements must also be complied with.

The interviews in this study involved in-depth discussions regarding perceptions of what the professionalism concept entails and how to instil the concept. The particular ethical considerations in this situation were firstly, the sensitivity of the topic and secondly as an employee of the Law Society, currently the regulatory body of the solicitors' profession, there may be a perceived imbalance in social power between the researcher and the researched. The researched might have felt that I was, in some way, testing their standards of professionalism on behalf of the Law Society. To address this I made my position as a researcher explicit in this regard and ensured that my research aims were made clear to interviewees. To alleviate their concerns, I ensured that participants understood that my role in the Law Society as an employee was separate to my role as an educational researcher. I also interviewed trainee solicitors at various stages of the traineeship. Again, to address any perception of imbalance of power on the basis that the Education Department of the Law Society are responsible for the examination and assessment of trainee solicitors I made my position as a researcher and my research aims clear.

For this study the participants Request for Consent (Appendix 3) was accompanied by an Information Sheet (Appendix 4) which outlined the extent of the anonymity and confidentiality, the voluntary nature of the participation, the right to withdraw, a right of complaint and the mode of recording. Notably, the clear aims of the study were identified and my role as a researcher and not an employee of the Law Society were outlined.

The education institution I am employed with (Law Society of Ireland) has no formal ethical/consent requirements for collecting data. Nevertheless, I did obtain verbal consent of the Director of the Education of the Law Society to collect data from students and employees 
in this regard. Moreover, solicitors are governed by the Guide to Professional Conduct of Solicitors in Ireland and various other Solicitors Regulations. Neither the Guide nor the Regulations require approval to carry out research where a study involves members of the legal profession. 


\section{Chapter 4}

\section{PRESENTATION OF THE RESEARCH FINDINGS AND DISCUSSION}

In this chapter I outline the phenomenographic analysis of the data collected in this study. The findings from this process are presented and supported by example figures, tables and relevant interview excerpts. The findings are then critically discussed in the context of the research questions, the literature reviewed and the earlier MA study I carried out.

\subsection{The transcript analysis process}

I transcribed the individual interview recordings, thereby ensuring that I was very familiar with the data before the phenomenographic analysis commenced. Notes and observations were made while transcribing which led to a preliminary analysis of data. While the transcripts were anonymised, the type of stakeholder (student, tutor, course manager, solicitor), size and location of firm (Dublin or regional) was noted, where relevant, to enhance and add richness to the data analysis, in the sense that it allowed for a more in-depth discussion of the variance in perception within each category and overall.

The data analysis was informed by this study's research questions. To reiterate, the core question is:

Is there variance in key stakeholders' perceptions on how best to instil or teach professionalism and what are the implications for professional legal education in Ireland?

Stakeholders' are defined as solicitors (including training solicitors), trainee solicitors and Law Society Course Managers, executives and tutors.

The sub-questions raised in this thesis, to reiterate, are three-fold:

1. How do the stakeholders understand professionalism as a concept and is there variation in their perceptions?

2. What are the qualitatively different ways in which the stakeholders vary in their understanding of how professionalism can be instilled:

a. Can everyone assimilate professionalism?

b. Is it possible and desirable to teach professionalism explicitly?

c. Should standards of professionalism be assessed in order to instil it and by whom?

d. Is it important to define professionalism in this context? 
e. What influences the instilling of professionalism?

3. What are the implications of any variance for the stakeholders in professional legal education in Ireland?

The sub-questions guided the grouping of the data into two broad categories: how professionalism is understood (Part 1) and whether it can be taught (Part 2). Phenomenographic analysis was carried out on each category to determine the variance in perceptions of that particular category of data.

As discussed in section 3.4, the phenomenographic process of analysis began with a prolonged exposure to and immersion in the transcripts. Initially, this involved reading and re-reading all the transcripts as a full set of data, listening to the audio recordings of the interviews and personal reflection. I compared narratives to identify similarities and differences in perceptions within the data. The analysis was informed by the research questions. I grouped narratives together according to common characteristics or common variances with qualitatively distinct categories, or 'pools of meaning', emerging based on variations in the stakeholders' perceptions. Structural and referential aspects of the experience were considered in analysing the data. I analysed extracts from all transcripts that related to a particular aspect of the experience of the interviewee. For example, variations in the ways the stakeholders understand professionalism should be assessed. Throughout the process I sought to 'bracket' personal opinions and experiences while immersing myself in the data.

I adopted concept/mind maps to assist in the analysis of the data by illustrating the variations and similarities in the stakeholders' understandings and by assisting in creating pools of meaning. In the example of a concept map below (Figure 2) the concept is the stakeholders' understanding of professionalism. Each mind 'bubble' represents an aspect of the perception of the concept of professionalism which is distinct from the other aspects represented in the other 'bubbles'. This particular map represents the second stage of analysis of this particular question in that the initial set of understandings extracted from the data have been grouped. While not alluded to in the literature on this methodology, this tool was very beneficial in determining the core variances in perceptions as required by this methodology. 


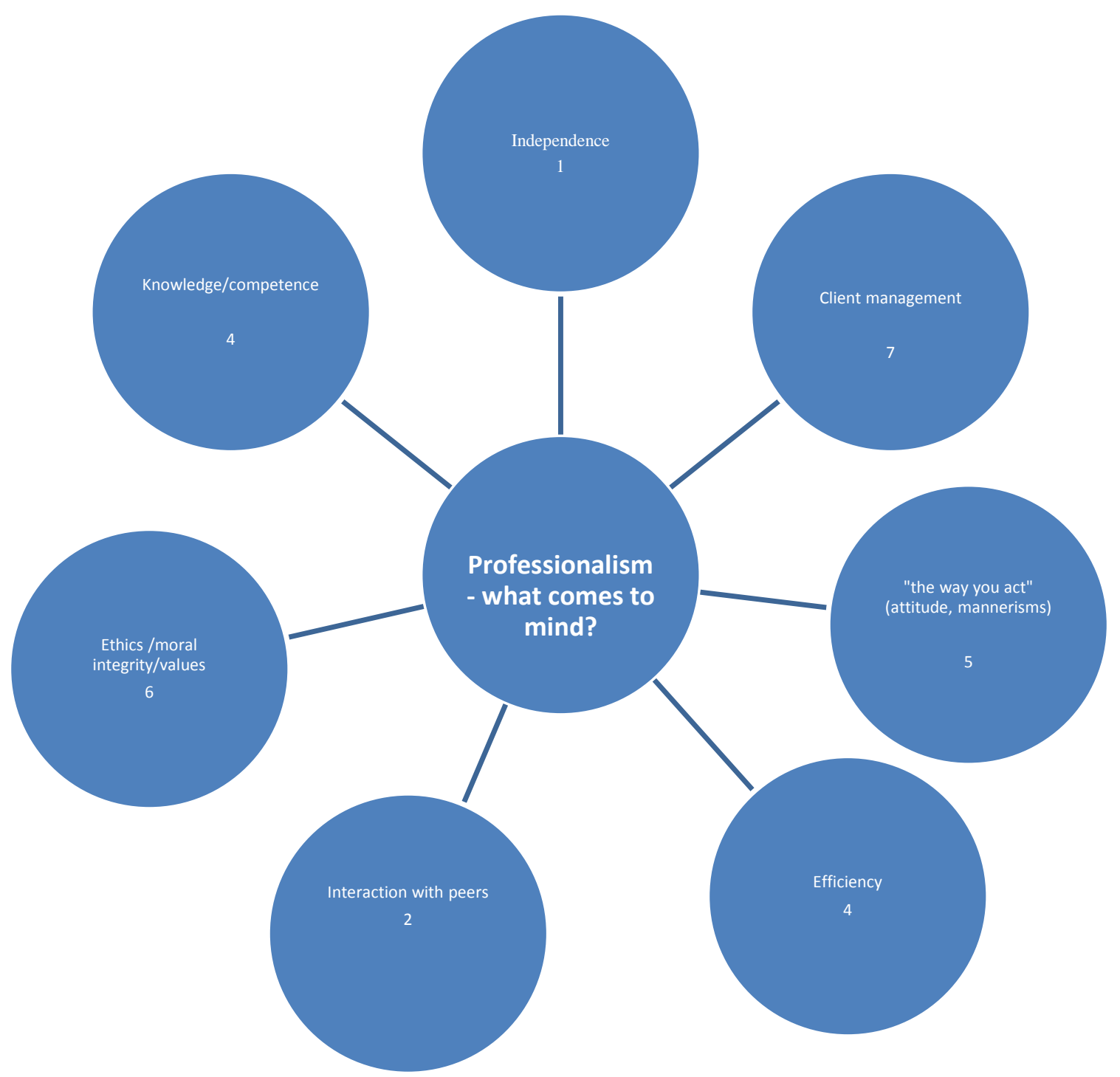

Numerics denote weighting e.g. four stakeholders understood professionalism to include efficiency

Figure 2: An example concept map: variance in stakeholders' understanding of professionalism

From this process, a number of tentative categories of description emerged based on common themes of variance in the meaning expressed by the interviewees. Categories were combined and worked on in an attempt to eliminate any overlap between categories. Categories continued to be reviewed until no further adjustments were necessary. These categories of 
description were labelled and represented the interviewees' distinctive conceptions of both the concept of professionalism and the approach to instilling professionalism. How these categories or themes compare to the literature reviewed is discussed in the analysis below.

Phenomenographic analysis, to reiterate, involves ordering the categories in a hierarchical fashion based on increasing comprehensiveness i.e. the higher a category is placed in the hierarchy (on an ascending scale from Category A to D, for example), the more inclusive the description of the experience or perception of the phenomenon it represented. This ordering is somewhat evident in the analysis of the data on how the professionalism concept is understood. Some references to aspects present in categories lower in the hierarchy were evident in the categories higher in the hierarchy but not vice versa. This generally results in more complexity (in terms of experiencing or understanding the phenomenon) the higher the category is in the hierarchy. This is because the higher category will have some of the essential elements of the previous category supplemented by a qualitative variance in perception. This is termed a nested hierarchy (Martin et al., 2003). Again, although there is evidence of this nested hierarchy in this analysis, the perceptions are relatively distinct and therefore ordering is not as obvious. This is in comparison to my earlier MA study where the hierarchical ordering was quite distinct. This may be as a result of the limited diversity in the group interviewees (large firm solicitors and tutors based in Dublin only). Empirical evidence obtained from this study's data confirms this inclusiveness in the hierarchy. This form of analysis is recommended by phenomenographic analysts (Akerlind, 2010).

In this study, basic empirical evidence was recorded: a record was kept of instances where certain aspects of a perception appeared throughout the categories. For example, instilling professionalism by good role modelling was evident in the more comprehensive categories and is a key perception in the lower categories.

The categories of description are presented in two parts to address two limbs of the research question as outlined above at sub-question 1 and 2. Part 2 involved more extensive data analysis. The structural relationship of each set of categories forms or establishes an outcome space.

The implications of the findings of Part 1 (section 4.2 below - perception of the concept of professionalism) and Part 2 (section 4.3 below - perception of how best to nurture professionalism) are also discussed in this chapter. The aim of this discussion is to attempt to 
answer the third limb of this study's research question: What are the implications of any variance in the stakeholders' perceptions for professional legal Education in Ireland?

\subsection{Part 1: Perception of the concept of professionalism}

The unit of analysis in this part of the analysis of the interview transcripts is the stakeholders' understanding or perception of the concept of professionalism. Four qualitatively distinct Categories of Description of different perceptions or ways of experiencing professionalism were constituted as follows:

- Professionalism is based on ethics, values and autonomy (Category A)

- Professionalism is behaviour based (Category B)

- Professionalism is about managing clients and managing interaction with peers (Category C)

- Professionalism is based on competence and efficiency (Category D)

Each category is described in more detail in the following sub-sections. The categories are illustrated with relevant quotations taken verbatim from the interview transcripts (see section 3.4.1 for further discussion about the use of quotations in phenomenographic studies).

\subsubsection{Category A: Professionalism is based on ethics, values and autonomy.}

This category sees professionalism in the broader sense of an ethical/value-based concept. As outlined in the mind map above, this was a perception held by about a third of the stakeholders; mainly among the Law Society stakeholders. Acting ethically, morally, honestly and with integrity were considered the core values of professionalism. Autonomy was also referred to. The following extracts help describe this category:

\section{Law Society Executive:}

"I think it means acting true to the values of your profession with integrity. Acting in a way that's with integrity and ethics".

\section{Law Society Course Manager:}

"Ethics, inside- out, moral compass, consciousness, conscience, awareness" 
Tutor:

"You have this body of knowledge but you also have autonomy and you can act in the best interest of your client. You can also act in compliance with the standards, the ethical standards of your profession."

This understanding of professionalism features widely in the literature particularly in professional representative bodies' definition of professionalism (Hamilton, 2008; Law Society Guide, 2013; CCBE Code of Conduct, 2013; Brownlee, 2014). While the social contract that exists between the professional and the public was not specifically alluded to, this category stressed the importance of a professional having autonomy. Freidson (2001), Parker (2002), Beauchamp (2004), Montgomery (2008), Hamilton (2008) and McCallum (2014) discuss this aspect of professionalism at length.

Notably, in my earlier MA study which, as discussed, involved two ends of the spectrum as regards interviewees (Law Society tutors and solicitors from large Dublin based firms), ethics featured more pervasively across all categories. In the MA study there was a lot more emphasis on this perception of professionalism by Law Society executives and tutors.

\subsubsection{Category B: Professionalism is behaviour-based.}

This category perceives professionalism as a way of behaving and presenting oneself with clients and colleagues as illustrated in these extracts. It is a relatively prevalent perception among the stakeholders:

Trainee - large Dublin firm:

"I would think of ethics and mannerism. Carrying yourself in a professional way "

Pre PPC trainee - large Dublin firm:

"When we start as trainees there is about a week and a half of training where we undergo training and guidance on what [X] firm expect of us as a firm, from the way you are dressed to your hygiene. So when we are trusted to meet clients on a daily basis they see us and we are representing the firm and it's important to come across in a professional manner."

PPC II trainee - large regional firm:

"There is the obvious dress code, how you talk to clients, appropriate behaviour in the office" 


\section{Solicitor, small firm regional:}

"By example, my mother told me about a doctor who didn't treat them very professionally. That he used to cycle into work in his lycras and straight away it gave them the impressionand our impression of a doctor is someone dressed a certain way and acting in a certain manner and that person was not acting in a certain manner. If I was a patient and was treated by a doctor dressed in lycras I would feel, even though he might be an excellent doctor, that the approach was wrong. [RH: It's all part of being professional - dressing appropriately?] Yea. Yes.

This category did not perceive professional behaviour as adherence to a code of conduct or fulfilling one's legal or regulatory obligations. Indeed, this adherence was alluded to by very few stakeholders. This is an interesting observation in that in an era of audit and crisis of trust (O'Neill, 2002), these obligations were not to the forefront of the stakeholders' perceptions. Moreover, compliance with a set of rules features strongly in the regulatory and representative bodies' definition of professionalism (ABA's Model Rules of Professional Conduct, 1983; SRA's Training Regulations, 2014). Rather, my data indicate that this category experienced professionalism more as behaviour in the sense of acting appropriately, mannerisms, appearance and presenting oneself in a professional manner. Braithwaite's (1990) somewhat traditional definition comes to mind: "upright character, proper work habits and genuine good manners" (p.70). This category also echoes Corbin's (2005) consensus that students solicitors need to learn, what he refers to as, professional courtesies. Also, Boreham \& Morgan's (2004) dialogue (structured verbal and unverbal exchange of messages. See section 2.3.5) is also relevant. They maintain that effective workplace learning is dependent on a shared and accepted way of behaving in an organisation. There was one outlier who perceived professionalism as "doing everything above board". Those from the larger firms, both Dublin based and regional, placed more emphasis on mannerisms, dress and presentation.

\subsubsection{Category C: Professionalism is about managing clients.}

The emphasis in this category is on the professional's relationship with clients and doing the best job possible for them. This was a deeply held view held by a large proportion of those interviewed. A tension exists between being available for the client at all times and managing clients' expectations as evident in the two transcripts extracts below: 
Solicitor - small Dublin firm:

"Dealing with your client in the most professional manner possible things like always being there for your client, dealing with all their calls... standing by them - being there until the finality of their case."

\section{Solicitor-large Dublin firm:}

"At the same time, one of the things I am concerned with working in a large corporate law firm is that it's at risk at going too much in the other direction. I think of it a pyschophantasism as regards the client. I think it comes under the guise of professionalism but I think it's not professionalism but is born out of a subservience to the client in what it is an extremely competitive legal market in that kind of competitive environment. Law firms, tend to mid-size and large firms tend to look at the institutional client who is at the cutting edge of corporate business and in a sense try to follow that, mirror that and reflect that back to the client. I think a large part of professionalism is trying to retain that ability to tell it as it is and achieving that balance between being dedicated to the client and supporting the client and being there for the client and being a real legal resources to the client and balancing that with not being overly subservient to the client and being a yes man or lawyer"

Those more qualified tended to emphasis the requirement to manage client's expectations whereas trainee solicitors' perceptions of the concept were more inclined towards an "always available" for the client approach. This was the case with one exception: a pre-PPC I trainee (large firm) stated: "I think its managing clients expectations. This is what I will take most from my time here so far. It's that, that I believe is professionalism. If you give your client unrealistic expectations it's not beneficial to them or you and just giving the client what you think they want to hear is often not what the client wants to hear."

While empathy, compassion (Silver, 2005), loyalty and "zealous advocacy on behalf of the client (p.490)" (Hamilton, 2008) is discussed, the perception that professionalism involves managing the client or being at their "beck and call" is not reflected in the literature and did not feature in my findings in the earlier MA study.

\subsubsection{Category D: Professionalism is based on competence and efficiency.}

The emphasis in this category is on the perception of professionalism as having competence in one's duties and in interacting with clients and peers. File management and professional 
knowledge was also alluded to. Emphasis was placed on being organised and efficient with attention to detail.

Pre PPC trainee - large firm:

"You are paid to provide a service of a particular standard. Drafting of documents attention to detail. The documents you send out they say something about what you are providing so you want to provide that in a professional manner".

PPC II trainee - large regional firm:

"Ensuring you have everything planned out - you know your case work is organised. Not only from a legal context it's also about case management and organisation of your file. It goes beyond legal advice”.

Solicitor - small Dublin firm:

"Having everything really above board, no problems with new files. Having everything transparent in relation to all the details passing through the office, obviously no hidden files or no concerns in relation to accounts. Dealing with your client in the most professional manner. Being as efficient as possible, dealing with your files in the most effective way possible. “

Solicitor - large regional firm:

"It's presentation in front of a client, it's discretion, making yourself available to clients, looking after files. I suppose it's in general being organised, being clear, responsive and discreet".

The literature is rich with references to professionalism as competence and efficacy in providing legal services (Hamilton, 2008; Law Society of Scotland, 2014).

In the earlier MA study, a similar category of provision of competent legal services also emerged but there was a lot more emphasis on professional knowledge. Again these findings may have been skewed by the focus on two distinct groups from either end of the spectrum that were interviewed.

The latter excerpt is an example of the move towards comprehensiveness from Category A to D. It is also referred to as a nested hierarchy as discussed above, that is, reference to aspects 
present in categories lower (ethics, client care, and then efficiency) in the hierarchy were evident in the categories higher in the hierarchy but not vice versa. The higher the category is in the hierarchy generally results in more complexity as the higher category will have some of the essential elements of the previous category supplemented by a qualitative variance in perception.

Interestingly, despite adopting the de-contextualising approach (whereby extracts from transcripts are combined for analysis as described at 3.4.1) generally each category comprised a number of interviewees. Moreover, the interview data seldom contained more than one of the categories of description set out above. This is evident only in respect of the first set of data analysis which deals with the concept of professionalism where there is a distinction between the perceptions of the Law Society Course Managers/Executives/tutors and the solicitors/trainees solicitors. The former's perception tends towards Category A while the latter tends towards Category $\mathrm{C}$ and $\mathrm{D}$. The former focus on professionalism as value and ethically based whereas the solicitors place more emphasis on the more technical, practical, client management components. This was not exclusively the case as one trainee did allude to ethics which was linked to mannerisms. Perhaps, the latter, while emphasising the more technical understanding of professionalism, assumed the value-based, ethical approach to professionalism and did not explicitly refer to this deeper perception: it was not an understanding this group were avoiding or had not considered. In retrospect, perhaps I should have facilitated a more in-depth discussion or teased out the former groups, perhaps, implied perceptions. Although, there is a balance to be achieved between an over directive interview style and accepting the interviewees' response at face value.

There were a number of key views discussed in the relevant literature that was not alluded to in the stakeholders' perception of professionalism. For example, none of the categories understood professionalism as serving the public good in terms of carrying out pro bono work and civil trusteeship and public altruism to the rule of law and justice system and improvement of the system. Yet, this perception features strongly in the literature (Shestack, 1998; Wilkins, 1999; Kronman, 2000; Parker, 2002; Montgomery, 2008; Hamilton, 2008; Maharg 2012; SRA, 2014, Law Society of Scotland, 2014; McCallum, 2014). The absence of these views amongst my stakeholders might be because of a wider trend towards a perception in terms of running a business with many recognising the shift from the traditional paradigm to a commercial model of professionalism (Kelly, 1994; Pearse, 1995; Kronman, 2000; Boon et al., 2005; Corbin, 2005). This is also recognised in the medical field: Beauchamp (2004) 
talks about a re-interpretation of professionalism in the new millennium. Yet, this understanding of professionalism was not discussed by the stakeholders. In the earlier MA study those interviewed were either tutors in the Law Society or training solicitors in very large Dublin based firms which were mainly commercial law firms. Professionalism was perceived by these firms, in the MA study, as forming part of running a successful business. The emphasis was on standards of excellence but within a commercial framework.

No stakeholder in my data alluded to professionalism incorporating continual self-reflection or the importance of balancing wealth and other principles of professionalism (Epstein, 1999; Hamilton, 2008) or the avoidance of incompatible occupations and personal publicity (CCBE 2013). Nor were the promotion of equality and diversity in running a business discussed (SRA, 2014; Law Society of Scotland, 2014).

Also of note, is the somewhat technical view of professionalism as opposed to a knowledgebased view of the concept particular in Categories B and D above. It brings Boon et al.'s (2005) concerns to mind regarding a move towards a more technical approach to teaching professionalism, with commercialisation at the forefront, where trainees are losing out on a deep learning approach to the fundamentals of professionalism. Taylor (1997) also discusses the challenge of ensuring process knowledge is protected in achieving technical skills.

\subsubsection{Structural relationship between the categories.}

The outcome space describes the structural relationship between the categories. The qualitatively different categories of description are logically related to each other in terms of structural and referential dimensions. The referential dimension (see section 3.4.2) of an experience is the overall meaning that has been assigned to the phenomenon (the professional concept) by the individual experiencing it. The structural dimension analyses how the parts are related i.e. how the phenomenon can be distinguished from its context and how the individual parts of the phenomenon relate to each other and the overall phenomenon (Gardiner and Edwards as cited in Harris, 2011; Hession, 2012;). Ashwin (2006) describes this aspect as characterising the categories in terms of what is in the foreground and background to each category.

The referential dimension (see section 3.4.2) of the stakeholder's understanding of professionalism identified four different meanings assigned to professionalism by the stakeholders. The meanings correlate to the categories of descriptions namely: values, 
behaviour, client management and competence. As each category was distinct, the referential analysis did not produce any further grouping of meaning. From a structural perspective (how the parts are related i.e. how professionalism can be distinguished from its context and how the individual parts of the phenomenon relate to each other and the overall phenomenon) perceptions ranged from what I refer to as an abstract to a tangible perspective.

Interestingly, the earlier MA study produced an outcome space with distinctively different meanings but a similar structural perspective i.e. the referential meanings, while different, were either abstract or tangible.

The resulting outcome space/summary of referential and structural aspects of each of the categories of description is presented in Table 1 below.

\section{Referential}

$\begin{array}{llll}\text { Structural } & \text { Values } & \text { Behaviour } & \text { Client management }\end{array}$

\begin{tabular}{|llll|}
\hline Abstract A & & & \\
& & & \\
Tangible & B & C & D \\
\hline
\end{tabular}

Table 1: Outcome space: Part 1 - Perception of Professionalism

Category A's understanding of professionalism is an abstract perception in comparison to Categories B, C and D which hold a more tangible or technical approach. Category A attaches a value meaning to the phenomenon which is not tangible or does not have a concrete understanding. The other categories attach meanings to the concept that are more concrete in the sense that meanings such as behaviour, client management and competence are described in a distinct and at times technical manner, for example, how one presents them self and attention to detail. This structural analysis adds richness to the data analysis. The relationship of the meanings to each other assists in determining and understanding the variance in perceptions of the stakeholders. How this form of analysis assists and adds generally to the analysis of the data is discussed in Chapter 3. 
A number of key points emerge from the discussion of the findings relating to the understanding of professionalism. The variance is reflected in the categories of description and outcome space. The key variances among the stakeholders were the larger firms' emphasis on presentation in their perception of professionalism, the divergence of views between trainee solicitors and more experienced solicitors in their perception of clients' expectations of a professional and generally, the more abstract, value-based view of professionalism among Law Society executives and tutors when compared to the more tangible or practical views of the solicitors. The somewhat technical view of professionalism, as mentioned above, and the silence around ethics and values in some of the findings is a significant variance in perception.

As noted above there were a number of understandings explored in the literature that were not reflected in the stakeholder's perceptions. An understanding of professionalism as serving the public good, in promoting equality and diversity, the commercial model of the concept or professionalism in terms of achieving a balance between the principles of professionalism and wealth accumulation were not discussed. Moreover, a solicitor's obligation to comply with the representative and regulatory bodies' code of conduct was vaguely alluded to by very few stakeholders. This aspect of professionalism is discussed in depth in the literature. There may have been an assumption that one must adhere to the code of conduct in this regard which was not vocalised in the interviews. As discussed above a more directive approach in the stakeholder's interviews might have determined if the stakeholders had considered these approaches to professionalism or perhaps the data reflects a wider trend towards a more technical view of professionalism.

There were a number of stark contrasts with the MA study: while ethics and values formed the basis of Category A, ethics in particular was alluded to across the stakeholders' understandings in the MA study (again it is important to reiterate that this study involved Law society tutors and large Dublin based firms which has had a bearing on the findings). Moreover, the stakeholders in the MA study did not allude to the management of clients in their understanding of professionalism but placed a lot more emphasis on professional knowledge.

There is clearly variation in understandings of the concept which reflects the varied discussions in the literature reviewed. The extent of diverse ideas in the literature and the relative silence about key aspects of professionalism raises an on-going question as to 
whether it is important, from a teaching point of view, for the stakeholders to come to a common understanding of professionalism and whether it is possible to define it?

\subsection{Part 2: Stakeholders' perception of how best to nurture professionalism}

This section of the analysis addresses the second limb of the research sub questions - what are the qualitatively different ways in which the stakeholders vary in their understanding of how professionalism can be instilled or fostered. The rich data collected lends itself to carrying out a phenomenographic analysis of five categorised questions. The five units of analysis are the stakeholders' understanding of the following:

1. Can everyone "pick up" professionalism?

2. Is it possible to teach professionalism explicitly?

3. Should standards of professionalism be assessed in order to instil it and by whom?

4. Is it important to define professionalism in this context?

5. What influences the instilling of professionalism?

As outlined in Part 1 (section 4.2), the categories are illustrated with excerpts from the interview transcripts which emphasise the variation between the units of analysis. Where the category is more comprehensive (higher in the hierarchy) the data transcripts may describe common features. Part 1 dealt with one unit of analysis; namely, the understanding of professionalism, whereas this part involves a more extensive form of data analysis. It outlines five units of analysis and establishes five outcome spaces.

\subsection{1 - Part 2.1. Can everyone pick up professionalism?}

This unit of analysis explores the perceptions of the stakeholders in respect of a person's ability or inability to assimilate or learn professionalism on the basis of their disposition. The topic was explored in the majority of the interviews. It involves limited data analysis but merits a separate unit because of its interesting discussion points. The unit comprises of three categories of description as follows:

- No - not everyone can pick up professionalism (Category A)

- Yes - everyone can pick up professionalism but only if they actively want to (Category B)

- Yes - everyone can pick up professionalism (Category C) 
The perceptions of the stakeholders are relatively distinct and the hierarchical ordering is somewhat evident in Category C. The perceptions in the lower categories are, to a certain extent, reflected in the higher categories i.e. there is level of comprehensiveness in Category C. Categories $\mathrm{B}$ and $\mathrm{C}$ were equally weighted with quite strong views held by the stakeholders in these categories.

\subsubsection{Category A: No - not everyone can pick up professionalism}

A small group of stakeholders thought that professionalism could not be instilled in everyone. While only a small number held this view, they ranged across the spectrum of stakeholders (Law Society executive, solicitor from a regional small firm and a PPC II trainee from a small regional firm), with the notable exception of large firm stakeholders. The following are relevant illustrative extracts:

\section{Law Society Executive:}

"I think that has to be part of the training, part of the instruction. If their moral compass is off in an area that is fraught with dilemmas then maybe they are not cut out to be a solicitor. It is not an absolute science".

Solicitor - regional small firm:

"I don't think it has anything to do with background. I think some people lack professionalism and you can't change a person - it's nothing to do with background. Some people are very professional, others aren't. “

PPC II trainee - small regional firm:

"It's someone's personality, they have their own tendencies."

This latter interviewee also expressed the contradictory view that you could teach professionalism in the Law Society but not in a solicitor's firm.

A number of commentators discuss the belief that professionalism is innate or intuitive (Braithwaite, 1990; Pearce, 2002; Steinert et al. 2005; Hamilton, 2008). Riley and Kumar's (2012) writings in particular follow a similar line of thinking to Category A. They explore the view that professionalism can only be nurtured if the individual has certain innate qualities. Similarly, Montgomery (2008) explores the arguments of a group of academics that, as values are fully formed at an early stage, education will not alter the ingrained values. 
4.3.1.2 Category B: Yes - everyone can pick up professionalism but only if they actively choose to do so.

A small number of the stakeholders were of the view that, while an individual can behave professionally and nurture professionalism, they need to make a conscious effort to do so. The following is an extract from an interview with a pre PPC I student from a large Dublin firm:

Pre PPC I trainee - large firm:

"I think when you are brought into a firm you can force yourself to adapt and take on the professional nuances - that's why you are there, you are there to provide it so if you are going to provide it in a manner that its expected of you. I don't agree that you are born that way and can't take it on. I suppose some people can refuse to take it on. Professionalism you can improve everything - drafting of document, attention to detail. Some people will have obviously more attention to detail than others. That's inherent in a person. But I definitely think you can adapt and take on professionalism nuances, just tell yourself this is what I am going to do. I am going to be better at this, this is what is expected. It's not as if it is going to go unnoticed and that will have an effect down the line. Now it's not as if you never find people's professionalism differ or in certain areas people excel."

An in-house counsel solicitor also alludes to this barrier to instilling professionalism:

Solicitor-in-house:

"Yes - there are barriers to any learning if you don't want to learn. You can lead the horse to water but you can't make it drink it. With professionalism you have to want it as with anything”

The requirement to actively want to assimilate professionalism or behave professionally is not explicitly discussed in the literature in the context of an individual's ability to behave professionally.

\subsubsection{Category C: Yes - everyone can pick up professionalism}

This category perceived the ability to assimilate professionalism or act professionally in terms of behaviour. A high proportion of the stakeholders were of the view that while some find it easier than others, everyone can assimilate professionalism and more importantly, 
behave professionally. This was mainly discussed in the context of a role-modelling approach. This is illustrated in the following extract. It is also interesting to note that there was a perception that one can be trained to behave professionally without understanding why i.e. by taking the ethics out of the picture.

\section{Law Society tutor:}

"I would like to think that it's the case [that everyone can pick up professionalism]. I think it's very unhelpful, I suppose, when people talk about ethics and values. I don't think that is the way to talk about. I think we should talk about it in terms of behaviour.... then everybody can achieve that...that some people would be more intuitive and they think they are in a situation they are not happy with while others would go further into the situation before it begins to dawn on them that there is something not quite right. You can teach the ethical situation and the guidelines set down by the Law Society here ... the students are aware enough of that.... But the attitude side, well I would like to think that people think that I have a choice in the way I can behave in a particular way. That even though I might be a complete scoundrel I can still behave in a particular way."

\section{Solicitor - Small Dublin firm:}

"I think it's in most people - they take on the responsibility when they become a solicitor. They must realise that. If you were not responsible you wouldn't be becoming a solicitor there are other professions out there where you can go about your life without having to deal with it in as serious or responsible manner. But I think when solicitors come into a role it's a necessity - it's probably built into them in a way and that's why they came into the profession. Possibly, like in any profession, some people slip through the cracks. Some people enter the profession not being as professional as others. I think that happens in all professions being medical or otherwise. But I think generally it's somewhat built into them and then it grows as you go through the profession."

These transcripts illustrate the comprehensiveness of this Category: they also allude to Categories $\mathrm{A}$ and $\mathrm{B}$ i.e. the innateness of professionalism and the choice to behave professionally.

Giving students the space to develop professionalism internally was also explored in this category: 


\section{Law Society executive 1:}

"I think it is in everybody. I don't think it's about putting it into people; it's about bringing it out of people. It's an internal piece in everybody that needs space so that it can be talked through and discussed, what is my bottom line, what is a deal breaker, what can I not do ever, what would I really be upset by, what would me feel fantastic about my work."

This extract brings to mind Brownlee's (2014) paper on developing the personal conscience and Hamilton's (2005) Four Component model. Brownlee (2014) speaks of cultivating integrity and values by gaining inner knowledge of our hearts and mind. Hamilton's (2005) model includes moral sensitivity and moral reasoning and judgement that vary depending on individual internalised beliefs. But it is important to reiterate the general ambivalence to these aspects amongst the stakeholders.

As outlined in Part 1 above and Chapter 3, the establishment or development of the outcome space involves further differentiating the categories of description in terms of structural relation of the parts and referential (meaning) dimensions. The referential dimension of the stakeholders' perceptions, in respect of whether everyone can assimilate professionalism, identified three different meanings for this group's perceptions. These meanings are similar to the category descriptors.

The resulting outcome space/summary of referential and structural aspects of each of the categories of description is presented in Table 2 below.

\section{Referential}

\begin{tabular}{|llcc|}
\cline { 2 - 4 } Structural & Not everyone can & $\begin{array}{c}\text { Yes - } \\
\text { but only if want to }\end{array}$ & Yes everyone can \\
\hline Innate & A & & \\
Control & & B & C \\
\hline
\end{tabular}

Table 2: Outcome space: Part 2.1 - Can everyone pick up professionalism?

From a structural perspective, Category A perceives that professionalism is innate: you either have it or not. To a certain extent, this is not within the control of the individual. Categories B and $\mathrm{C}$ perceive that the individual has control over their behaviour: the individual determines 
his/her behaviour and makes a decision to act professionally or nurture professionalism within themselves. These perceptions are held in the context of the teaching/instilling of professionalism. Thus, it would appear from this analysis, that the effectiveness of teaching professionalism is, to a certain extent, determined by the level of engagement of the trainee with the process of fostering professionalism.

\subsubsection{Part 2.2: Explicit teaching of professionalism - Is it possible?}

The phenomenographic process identified four qualitatively distinct categories of description of understanding or perception regarding the explicit teaching of professionalism:

- Professionalism can be taught explicitly (Category A)

- Explicit teaching of the basic principles of professionalism only (Category B)

- Implicit teaching of professionalism (Category C)

- The instilling of professionalism requires a role modelling approach (Category D)

In contrast to the analysis of Part 1 above, the perceptions of the stakeholders relating to the possibility of teaching professionalism explicitly, can be ordered hierarchically based on the level of comprehensiveness. There is more complexity and comprehensiveness in the higher categories (on an ascending scale from A to D). The higher categories (C and D), contain elements of the previous categories but also contain other qualitative variances. There is a clear nested hierarchy (as described above at section 4.1) evident in this unit of analysis whereby there is an increasing level of comprehensiveness in these four categories forming a nested hierarchy. Category D is considered more comprehensive than Category $\mathrm{C}$ and so on. Also, the interviewees in Category D are aware of the perceptions in the categories lower in the hierarchy. Describing the levels of comprehensiveness adds depth to the data analysis and helps identify the variances in perceptions more clearly. The process of describing levels of comprehensiveness in the qualitative analysis is discussed further at section 4.1.

\subsubsection{Category A: Professionalism can be taught explicitly}

This category perceived professionalism as a concept that could be taught comprehensively in an explicit or didactic manner. It was not a pervasive view among the stakeholders. What is notable is that while their role is in explicit teaching of what Eraut (1994) terms the propositional knowledge underpinning professional action (the legal theories and principles) and the process knowledge (application of the know-how), none of the Law Society executives or tutors held this view. Also, with the exception of one, no pre-PPC trainees, who 
had recently completed third-level studies of a didactic nature, thought you could teach it explicitly. The following extracts illustrate this category. The second extract presumes a very technical perception of professionalism which might have an influence on the stakeholder's view of how it can be taught explicitly i.e. explicit teaching is effective where there is a technical perception of professionalism as a concept. While professionalism is perceived by a category of stakeholders as value-based, it was not clear from the data that this view of professionalism can be explicitly taught. A number of commentators discuss the explicit teaching of professionalism in the context of values (Maharg, 2012; Nicols, 2005; Kreiger, 2005). Values are taught in an explicit approach on the PPC (Law Society, Interpersonal ImpACT programme, 2014). Yet, it was not perceived as an appropriate approach or method by Law Society executive or pre PPC students. Again, perhaps, this reflects a trend towards a technical understanding of professionalism.

Solicitor-large firm:

"I think one of the best ways we can do that is in legal education to have formalised education in this from the outset...I think you can teach it... I know that for the first few of years of traineeship the use the [Law Society] manuals - they refer to them."

Solicitor-in-house:

"Can you teach it? Absolutely. I do know some of the big firms in Dublin have a template in relation to emails: how you would address somebody, how to close off a letter yea - I do think you can teach it."

This category suggests that the Law Society should have a role in the explicit teaching of professionalism. A number of stakeholders alluded to this:

PPC II trainee - small regional firm:

"Oh yea. You always stress to keep communicating with clients, keep them up to date and keep them happy, keep the stress down and so that there is no reporting to the Law Society for misconduct. It is stressed here you have to act in a certain way with clients - treat them well. Not just keeping them up to date but treating them well and with respect." 
It is interesting to note that as a researcher I was referred to as the Law Society ("you") in the above extract despite clearly explaining to interviewees the purpose of the interview and my position as a researcher and not a Law Society employee.

\section{Law Society tutor:}

"Professionalism is part of professional development and needs to taught and dealt with explicitly -teach what you can teach, discuss reflect on, very explicitly within a very integrated training within their Law School."

Explicit teaching of professionalism is strongly advocated by a number of key commentators particularly in the medical field (Brainard \& Brislen, 2007; Cruess \& Cruess, 1997; Steinhart et al. 2005 and Hamilton, 2008 from a legal perspective). A clear understanding and explicit definition of professionalism forms an important part of these commentators' support for an explicit teaching programme. Notably, with the exception of the above extract in the context of the Law Society's role, those stakeholders who were in favour of an explicit teaching approach did not maintain that a clear understanding of the concept was important (a unit of analysis dealing with defining professionalism is dealt with below). In the MA study, it was a relatively widely held view that professionalism needed to be defined in order to be taught.

Also evident in this category was an emphasis on teaching it pervasively in an explicit manner, as illustrated in this extract:

\section{Law School tutor:}

"There should be an explicit programme, because it's a module course it should be a programme that runs through all the modules and that it should be integrated and that those practitioners coming into tutor that we are also included..... I think the principles of professionalism should then be communicated to all tutors. The Law Society should be more clear explicit on what they are trying to achieve with the students training."

Very few stakeholders discussed the pervasive approach, contrasting with those interviewed in the MA study where this view was more widely held. This may be because half of those interviewed in the MA study were tutors with an interest in curriculum design and content whereas the current study, as discussed, collected data from a wider group of stakeholders. The literature recognises the importance of the embedding of professionalism in a pervasive manner throughout the substantive areas of law (Braithwaite, 1990; Rhode, 1994; Shestack, 1996; Pearce 2002; Cruess \& Cruess, 2006; Maharg, 2012). 
The precise form of, or approach to, explicit teaching was not referred to: approaches such as group work which are described in the literature (Suchman et al., 2004; Kullgren and Lowenstien, 2004, Branch, 2010; Kahn, 2013) were not discussed, which is notable as group work forms an important part of the Law Society teaching model and was discussed in the MA study.

\subsubsection{Category B: Explicit teaching of the basic principles of professionalism only}

This category describes the perception that only the basic underlying principles of professionalism can be taught explicitly. This view was strongly held by the stakeholders in the sense that there was no place for explicit teaching with the exception of guiding principles. This is illustrated in the transcript extract below. Questions of what are the basic principles and whether they need to be agreed upon were not discussed specifically in this context. The perceptions of the stakeholders regarding the need to define professionalism is analysed at section 4.3 .4 below.

Solicitor - small regional firm:

"It's a hard thing to teach .... all you can give them is guidelines on how to treat people and how to respect their files and their problems and try to treat it in a certain manner."

PPC II trainee - large regional firm:

“I suppose it's like anything - you can give guidance on it. You don't really think much about it until you go back to the office. It's like the ethics course this year-it's not something you are conscious of until you are back in the office. I think it is difficult to teach on the books but you would get the benefit from later on in practice. Like ethics it's difficult to teach but you get the basic principles out there it's something you use in your practice later on."

The role of the Law Society in teaching the basics was also alluded to in this category:

PPC I trainee - large firm:

"I would think it would be great if the Law Society taught it and said at a basic level everyone should, you know, in a client meeting everyone should behave like this. You should you know the basic practical things as to what to do. I know in Civil Advocacy we probably did a bit in the workshop but it would be great to have a lecture on it you know on what really we should be doing." 
This transcript again illustrates the somewhat restricted technical view that some stakeholders hold of professionalism. It is interesting that the literature does not appear to distinguish between explicit teaching of the concept as a whole and the teaching of the basic principles of professionalism while the stakeholders did make this distinction. This is something to consider in any collaborative effort to move towards, perhaps, a more explicit form of inculcating professionalism.

\subsubsection{Category C: Implicit teaching only of professionalism}

This category emphasised the implicit nature of nurturing professionalism - a perception limited to Law Society executives which again is interesting in that explicit teaching of course modules is a key feature of the Law Society teaching and learning model. The interview transcripts clearly describe this category:

\section{Law Society executive 1:}

"It has to be something you work out - you have to be able to stand back because you will never be able to teach them all the situations. You almost coach it, how it would apply, the understanding of it - not in an overly directive way. Say in conveyancing transaction, there is not necessarily the right or wrong answer per se. It's to encourage them to be objective in those situations, to stand back a bit and think of the bigger picture, they get sucked into a scenario and lose judgement."

\section{Law Society executive 2:}

"It's implicit in every tutorial, for example in the course I teach, we spend a lot of time talking about taking instructions for a will. And the important distinction between taking instructions and giving advice and that the solicitor is not merely a conduit. That the solicitor brings their own knowledge and experience into play in relation to the client's wishes - that's professionalism. That's providing a valuable service for a client and again that would apply across the board for the other subjects as well"

The literature discusses experiential learning whereby students acquire knowledge in an applied authentic but safe manner (Maharg, 2006, 2007; Alexander, 2012; Riley and Kumar, 2012). Shareholders allude to this approach in this category as an implicit form of learning. In the MA study experiential learning as a tool is discussed in more depth than in this study. 
Implicit learning in the workplace is also seen as a form of experiential learning (Brennan et al. 2006).

While not as comprehensive as Maharg's (2006, 2007) Transactional Learning programme, the PPC is for the most part an applied professional practice course. The teaching and learning model involves lectures dealing with the principles followed by an application of the principles in tutorials. Pre and post tutorial exercises help consolidate and reinforce legal professional skills and legal knowledge. The PPC Skills Module is a good example of the experiential learning and the implicit learning of professionalism. For example, the client communication and advocacy skills modules involve learning in authentic settings all underpinned by principles of professionalism. Boon et al. (2005) warn against the reliance on experiential learning, arguing that it leads to a lack of understanding of the underlying concepts. It would appear that the PPC Course model addresses this concern by explaining the principle concepts in the lectures and its practice manuals. In this study's findings the Law Society executives attach a lot of importance to the applied aspect of the learning model.

The following extract describes the implicit teaching along the lines of developing a personal conscience through an implicit process, and, unusually brings in an ethical and philosophical dimension:

\section{Law Society Executive 3:}

"I am not sure you would use the word taught. It's a process...maybe that's a bit - it is a process of becoming more conscious of what I believe is in most people. Not necessarily languaged very often from the outside so it's about giving people the space and the language and opportunity to reflect very deeply on what their own perspective is and what others perspectives are and what feels like good professional practice or what feels like disturbing practice to talk about it and get a language for it. Can you teach someone to be a good-it's a very philosophical question isn't it?"

While this category does not go as far as discussing Hamilton's (2008) Four Component Model there are elements of the Model discussed here. Fostering growth in personal conscience and the notion of the inner voice (Brownlee, 2014) are also alluded to. 


\subsubsection{Category D: The instilling of professionalism requires a role modelling approach}

This category sees role modelling either as an alternative to explicit teaching or as a method of instilling professionalism together with explicit teaching. This is a very comprehensive category where this perception is prevalent across the board in that all interviewees discuss the importance of role modelling as paying a crucial part in the nurturing trainees' professionalism. However, the extent of the impact of role modelling or the specific approach to role modelling varies and is illustrated in the following transcript extracts. Trainees, firms (both large and small regional and Dublin-based firms) and Law Society executives stressed the importance of role modelling and learning in the workplace in the context of nurturing professionalism. This was a strong and widely held view:

\section{PPC II trainee - large Dublin firm:}

"Yes and no - you can give broad guidelines but you learn it on the job. One of my bosses, I basically lived in his pockets for six months and if I am wondering about something, I tend to revert back to what he would have done [R: would you have checked with him or did you just assimilate it] Yea - just picked it up. Sometimes I would bounce things off him - like 'howiya'* what do I do here. Just in terms of interacting with clients, counsel he was very much into best practice on how to conduct oneself."

*How are you?

Solicitor - large regional firm:

"So I think we learn more on the job than you think in my experience. I found that how senior solicitors deal with clients is something I would have more picked up on the job more than the Law Society."

\section{Law Society executive 2:}

"That the examples they see in the office are of professionals doing the best job they can for clients all or most of the time - that everything they do in the office is expected to meet a certain standard whether they are working for a fee or pro bono or whether it's financially useful to the firm. Everything they do is imbued with that level of professionalism because they are competing in a market where firms reach that level of professionalism."

The importance of role modelling in the instilling of professionalism is widely recognised in the workplace learning literature. Engagement of this approach in order to transfer tacit 
knowledge (as discussed at section 2.3.3) is explored by many commentators in this context (Marsick and Watkins, 1990; Evans and Rainbird (2002); Eraut \& Hirsch, 2007; SRA, 2014). While the data in this category does not explicitly refer to tacit knowledge, it is evident that the stakeholders are alluding to it. The legal and medical literature is rich with advocacy of the importance of role modelling and mentoring in fostering professionalism (Schon, 1987; Roberts et al., 2004; Coulehan, 2005; Cruess and Cruess, 2006; Riley and Kumar, 2012; Park et al., 2010; Ratanawongsa et al. 2006; Byszewski et al, 2012; Cuesta Braind et al. 2014)

The role of the legal training firm and training solicitor as a role model in this category follows, to a certain extent, the model recommended by Evans and Rainbird (2002) in the context of situated learning. The learning of professionalism is fostered in an authentic context within the culture of the profession and reflects the ways in which the practitioners provide legal services. While other elements of their model, for example, the linking of concepts and practices and explicit mentoring are alluded to in the data in my study, other elements such as reflection and collaboration of knowledge are not discussed. Moreover, the transfer of knowledge to new situations was not perceived, or at least not explicitly alluded to, by the stakeholders as forming part of the learning in the workplace/learning from a role model. The importance of the transfer of knowledge is discussed by Bowden and Marton (1998), Boud (2001) and Marton and Booth (1997). It is notable that this is not explored in the data. The ability of a trainee to transfer and apply the knowledge (and, in this context, professionalism) in new situations, particularly when qualified, is an important part of their professional development.

The data alludes to the shared and accepted way of behaving in an organisation which underpin organisational learning (Boreham and Morgan, 2004). The open plan office where large law firm partners, trainees and administration staff share a common working space, as discussed in a few of the interviews, is an example of the Boreham and Morgan model in terms of the reconstitution of power relationships. There was a sense that trainees recognise and appreciate this reconstitution. But there is no evidence in the transcripts of Rainbird et al.'s (2004) concerns that power relations and workplace agency impede the organisational learning. Again, in retrospect, perhaps these concerns should have been explored in the interviews.

The influence that Law Society executives and associate faculty as role models have on professional standards of trainees is also recognised in this category: 


\section{Law Society executive:}

"We have a role as educators in teaching professionalism by ensuring everything that we do or provide to them is done in as professional a manner as possible. That the lecturers are there on time, that tutors are on time, that the material is up to date and looks well. Of course law changes but that we get updates to them as quickly and efficiently as possible. That if they have a query that it is dealt with quickly and efficiently in a satisfactory manner. While at the same teaching them that this is the level of behaviour that we expect of them to provide for their clients in practice. Let's say every tutorial exercise we do are problem-type and based on a client coming to them with a problem, we then work through that in tutorial so we do try to get across to students from the outset that you are acting for clients, that you are providing the best level of advice and advocacy and the best professional service for clients at all times."

This perception reflects the views of Braithwaite (1990); Park et al. (2010) and Maharg (2012) who also recognise how tutors and faculty members can act as positive role models and influence professional attitudes. The Law Society stakeholders in this category concur with Suchman et al. (2004), Byszweksi et al. (2012) and Molloy (2014) in that the hidden curriculum has a powerful influence on instilling professionalism and in reinforcing the explicit teaching of the notion. This perception was not alluded to by stakeholders across the board.

Fellow trainees were also seen as having an impact as role models:

PPC I trainee - large firm:

"Yea - I think so because it's all about learning from the people and how they like kind of hold themselves. That is something you notice from the students here in Blackhall, [colloquial term for Law Society PPC Course - the Law Society is situated at Blackhall Place] they are all quite well spoken and confident. You do learn from being around them, you do, yea."

Eraut (2004) refers to this type of influence on behaviour as uncodified cultural knowledge. Engestrom (2004) and Boud \& Middleton (2003) discuss the importance of learning, taking place sideways through peers within the organisation, as an alternative to the conventional knowledge hierarchy. The acquisition of tacit knowledge (Eraut \& Hirsch, 2007) from peers is also alluded to in this category. 
The understanding that bad role models were effective in demonstrating what not to do was a prevalent perception across the range of trainees and solicitors. The Law Society executives did not allude to this feature of role modelling. Again, this aspect of role modelling is illustrated in the following extracts:

PPC I trainee - large Dublin firm:

"I think it's something, you watch people and you kind of pick up on what's acceptable and you follow other people's mannerisms. I know sometimes I have been surprised and thought; oh that's how people act. Like I wouldn't talk like that to someone in like a professional environment, then you realise that boundaries aren't really where you thought they would be. I don't think you learn that really in the Law Society as you are more being lectured to. You are not engaging that much."

Solicitor - large Dublin firm:

"Absolutely that is a really critical way and I think probably it's just so double-edged... you have a professional role model - a role model as a professional in close contact with yousolicitors' that embody a really professional approach. And on the other side if you have a training contract with the hassled and/or tired and/or cynical professional, the reverse applies and enormous damage can be done. That's a really important question to give training solicitors a sense of responsibility that they actually have when they take on someone as a trainee solicitor."

While Stern (2003), Cruess \& Cruess (2006) and Park et al. (2010) maintain that students find it difficult to distinguish between good and bad role models, both Corbin (2005) and Rhode (1994) found, in their studies on the influence of firms on individuals' values and perceptions of professionalism, that certain individuals will not conform with the firm when they recognise bad role modelling.

Notably, only one of those interviewed referred to needing some sort of a structure to the role modelling approach to assimilating professionalism:

Pre PPC I trainee - regional small firm:

"I think you would pick it up anyway but I think you would also need things pointed out to you because sometimes there would things that wouldn't be professional. And they can tell 
you after what wasn't professional. I think having the points laid out for you would be helpful as well [R: a bit of structure?] yea”

Very few of the stakeholders mentioned mentoring as a vital component in the nurturing of professionalism with only two, both Law Society executives, discussing the importance of supported mentoring. None of the firm stakeholders alluded to mentoring as a tool in helping trainees assimilate professionalism. This is in contrast with the MA study where the importance of mentoring was discussed across the board but with less emphasis on role modelling. A structured approach to either was not mentioned in the MA study.

\section{Law Society executive:}

"...so whenever they are wondering if they can do this or shouldn't do this as this would be the professional thing to do or not they feel that they will be supported. So they know they will not be pressurised into doing something less professional. They know they can question it; they will be backed up if they have their doubts. If trainees are given too much responsibility early on they can perhaps lose sight of that. It's about the support to recognise their situations very early on so they know to apply it as they go along...They are not expected and they won't know because these things are not like a conveyancing transactions. They can be more difficult and subtle. They can ask and they will get a sense or understanding of what it is and it will develop with experience. So with five years PQE if something crops up that impinges on professionalism they will see it a mile away - it will become clearer".

A Law Society tutor alluded to the general support that the Law Society can provide and the control that both the Law Society and tutor should have over this process:

"I think it's important that [trainees] are in control of these things. They can develop these abilities; they can develop, read and inform themselves about ethics. I think that in Law Society there is a great network and support for practitioners if you feel you are in a position that you are concerned about. I think if you get to the stage .... well that's success. It's trying to get the students to a position that they begin to recognise these situations... If you didn't have that [explicit learning programme] and then they were in a firm that were not a good role model for them. I think that would be barrier. It's important to have both. I think 
they only place you can really control it is here in the Law School so I think that needs to be quite strong.

None of the stakeholders from firms which are perceived as the key role models, discussed having any form of structure to the role modelling provided. This is interesting, in the sense that role modelling is perceived by these key role models as a very informal approach to assimilating professionalism that does not need any structure. This reflects Boud \& Middleton's (2003) views.

Support for the structured role modelling approach to learning is advocated by a number of commentators (Eraut, 2004; Eraut \& Hirsch, 2007; Park et al., 2010). Boreham and Morgan's (2004) model of organisational learning recognises the importance of structured dialogue for learning in the workplace. While the NY Bar association (2011), Branch (2010), Hamilton and Brabbit (2007) advise against unstructured role modelling, Boud and Middleton (2003) warns against too rigid a structure affecting informal learning opportunities.

The resulting outcome space/summary of referential and structural aspects of each of the categories of description in this part is presented in Table 3 below. The referential aspects are similar to the category descriptions in this part. These are: explicit teaching of professionalism is possible; explicit teaching of the basic principles of professionalism is possible; implicit teaching of professionalism is possible; and, instilling of professionalism requires role modelling.

\section{Referential}

\begin{tabular}{|lcccc|}
\cline { 2 - 5 } Structural & $\begin{array}{l}\text { Explicit teaching } \\
\text { is possible }\end{array}$ & $\begin{array}{c}\text { Explicit teaching } \\
\text { of basics only }\end{array}$ & $\begin{array}{c}\text { Implicit teaching } \\
\text { only }\end{array}$ & $\begin{array}{c}\text { Role-modelling } \\
\text { required }\end{array}$ \\
\hline $\begin{array}{l}\text { Directive } \\
\text { Non- }\end{array}$ & A & B & & \\
directive & & C & D \\
\hline
\end{tabular}

Table 3: Outcome space: Part 2. 2 - Explicit teaching of professionalism, is it possible?

From a structural perspective Category A and B reflect a view that professionalism can be taught explicitly and trainees can be directed to learn in this manner. Category B does limit this approach to the concept's basic principles. Category $\mathrm{C}$ and $\mathrm{D}$ perceive the teaching and 
nurturing of professionalism as a non-directive act - as an implicit form of teaching or requiring a role-model approach. The importance of the role-modelling approach is, therefore, clearly recognised in this category. This approach is discussed in depth in the literature. The stakeholders' perceptions reflect the view of Stern (2003) and Steinert et al. (2005) that role-modelling alone is not enough (the comprehensiveness of Category D illustrates this). Notably, the stakeholders do not extend this to reflect the views of these commentators and others (Branch, 2010; Park et al., 2010), that a structured approach to rolemodelling is advisable. Stakeholders did not allude to the concerns of Wilkins (1999) in relation to reliance on lawyers only as role models in the context of in-house and multidisciplinary firms.

In contrast to the above, the MA study showed there was a very wide and stark variance between the training solicitors and Law Society tutors in relation to the perception that role modelling together with explicit/implicit teaching is required. A widely held perception of large firms' solicitors, in the MA study, was that role-modelling, in the sense of leading by example, was all that was required. Again, to reiterate, those interviewed in the MA study were from both ends of the spectrum: large commercial Dublin-based firms and Law Society tutors. Moreover, stakeholders in this doctoral study recognised the role of the Law Society formal learning model (with a focus on applied learning), contrasting with the MA study where there was a clear variance of perceptions among firms and tutors about the role of the Law Society. More widely, workplace learning commentators often hold an anti-academic stance as discussed by Brennan et al. (2006), in that this form of learning is pragmatic and supports employability: something the formal learning model does not. There was stronger evidence of this stance in the large firms' perceptions in the MA study than in this study.

\subsubsection{Part 2. 3: Should standards of professionalism be assessed in order to instil it and by whom?}

This unit of analysis explores the perceptions of the stakeholders in respect to whether the assessment of professionalism standards is important. It involves limited phenomenographic data analysis. The unit comprises three categories of description as follows:

- Professionalism cannot be assessed (Category A)

- Professionalism can be assessed but the method is not clear (Category B) 
- Professionalism should be assessed (Category C)

In similar fashion to the analysis at 4.3.1, the perceptions of the stakeholders are relatively distinct and the hierarchical ordering is not clearly evident. The perceptions in the lower categories are somewhat reflected in the higher categories. There is a level of comprehensiveness in Category $\mathrm{C}$, for example. The weighting is in favour of Category $\mathrm{C}$ whereby a distinctly higher proportion of stakeholders held this view over and above the other categories.

\subsubsection{Category A: Professionalism cannot be assessed}

This category perceives professionalism as a concept that cannot be assessed due to its abstract nature. This was not a widely held view.

\section{Solicitor/tutor:}

"I think it's very hard to assess it - you can teach it. I would find it very hard to do - no. You can provide the guidelines to people but that is as much as you can do."

While, generally, the literature does not explicitly discuss professionalism as a notion that cannot be assessed, it is safe to assume that those who believe that professionalism is something that cannot be taught (as discussed in Braithwaite, 1990; Pearce, 2002; Hamilton, 2008; Riley and Kumar, 2012) would also be of the view that it cannot be assessed. Ginsberg et al. (2000) do maintain that values, which a group of this study's stakeholders perceive as underpinning professionalism, cannot be assessed.

\subsubsection{Category B: Professionalism can be assessed but the method of assessment is not clear}

The understanding in this category is that professionalism can be assessed but, due to the nature of the concept, it is difficult to determine what method of assessment is appropriate. The following extract expresses the challenge of determining how to assess it:

\section{Solicitor - large Dublin firm:}

"It's an interesting question. Can you measure, or how do you go about assessing or measuring or determining if someone is professional or not. Mmm. I think you can. I think it goes back to the importance of having a well-rounded and deep understanding of what professionalism is. The difficulty is if we equate it with kind of professional success or 
monetary success. Partners who perform financially, are they most professional de facto? I mean, by and large, there will tend to be a correlation. I think it is measurable but I haven't thought about how you would go about measuring it. I know most firms have fee earner performance reports and various other kind of criteria. Certainly there are aspects of those that go beyond the technical abilities beyond knowing the law. But I really don't have much of an answer to the question. I think it would be challenging and I would be interested in finding out how you would go about quantifying professionalism."

The challenges of assessing professionalism are recognised in the literature particularly in terms of contextualising the behaviour. Ginsberg et al. (2002) and Beauchamp (2004) discuss the challenges associated with assessing in a contrived setting i.e. how individuals may behave differently in real-life situations.

\subsubsection{Category C: Professionalism should be assessed}

This category understood professionalism as a concept that should be assessed - the most widely held view across the board. While most recognised and held the strong belief that the exam format was not appropriate, a number of suggestions were made about how to assess professionalism including a co-ordinated approach from the Law Society, the training firm and feedback from the client:

\section{Solicitor - large regional firm:}

"To a certain degree you can. To be honest I think it is evaluated by yourself, a bit by the Law Society and also by your clients. So I couldn't imagine [that] doing an exam on professionalism is very easy to do on paper - you are doing, you are acting. How you perform on paper as regards professionalism. I don't think you could do it by exam certain things you could tick the box for. You can get feedback from clients."

This view is similar to that of Argyris and Schon (1974) and Eraut (2000). They stress the importance of genuine feedback and self-reflection to ensure students take responsibility for their actions. This leads to a reconciliation between the espoused theories of the profession (the professional conscience) and the actual behaviour or actions of the individual or what Argyris and Schon (1974) call 'theories-in-use', discussed in the literature review. The transcripts in this category, while referring to feedback from employees do not suggest or go as far as an audited form of workplace learning as envisaged by the SRA (2014) or Park et 
al.'s (2010) recommendation of a model of formative feedback in an active role modelling approach.

The PPC currently adopt a closed-book exam format for the ethics/professionalism assessment. While the stakeholders in this study were of the view that the standard exam format was not appropriate, other standard forms of assessment were discussed in the data, including Multiple Choice:

PPC I trainee - large Dublin firm:

"You could do something like a Multiple Choice Questions- would you disclose this information/ how would you act blah blah and that's probably the best way of testing or an essay type answers where you are given a scenario to deal with. I don't think you could really do it in typical exam format."

Another view expressed is that professionalism should be assessed pervasively throughout the course:

Law Society executive:

"It's very difficult to assess it using open book exam. Professionalism - while it is imbued in everything we do, it is too abstract a concept to examine, although now advocacy is a PPC I subject and there is a pass/fail in that. It is examined as part of the PPCM and the lectures and tutorials are on solicitors' client and conduct relationship with colleagues and counsel and that would imply that your professionalism is being examined as part of the course and not as a stand-alone topic because it's too abstract a topic - it straddles all the professions. It goes to the very heart of what solicitors do - it goes to the very heart of things with the client."

The literature discusses the pervasive teaching of professionalism (Braithwaite, 1990; Rhode, 1994; Shestack, 1996; Pearce, 2002; Cruess \& Cruess, 2006) but it appears that only Ginsberg et al. (2000) recommends assessment of professionalism across the entire teaching programme.

An interesting suggestion was to assess trainees in relation to their standards of behaviour in tutorials while attending the PPC. This approach is not discussed in the literature although Maharg (2012) does go as far as to suggest that educators should be obliged to inform the 
professionals governing regulatory body of low scores in professional assessment. In following transcript the stakeholder supports assessing students' behaviour while on the PPC:

Law Society tutor:

"I am not sure how it could be [assessed]. Obviously they do an exam on ethics and a group project. I am not sure in terms how they are assessed on PPCI the specifics... Possibly as well though, this sounds very old fashioned, we could expect that the students are beginning to think about how they act professionally when they are here, never mind when they go into the office because we, the Law School* doesn't have control over what happens in the office but the Law school does have control over what happens in the Law School. So an expectation of how they how they approach their work, they attend their tutorials and how they deal with each other and that's very subtle. There should be an expectation of professional expectation of the students."

\section{*Law Society Education Centre is often referred to as the Law School}

The resulting outcome space/summary of referential and structural aspects of each of the categories of description in this part is presented in Table 4 below. Again the referential aspects correspond with the category descriptions in this section.

\section{Referential}

\begin{tabular}{lccc|}
\cline { 2 - 4 } Structural & Cannot be assessed & $\begin{array}{c}\text { Should be assessed } \\
\text { but how }\end{array}$ & $\begin{array}{c}\text { Should be assessed } \\
\text { and here is how }\end{array}$ \\
\hline Challenging & A & B & C \\
Non-challenging & &
\end{tabular}

Table 4: Outcome space: Part 2.3 - Should professionalism be assessed?

From a structural perspective, Category A and B view the assessment of professionalism as challenging. Category $\mathrm{C}$ views professionalism as a notion that should be and can be assessed and it does not find this task particularly challenging.

Formative assessment of professionalism, to ensure compliance with the social contract that underpins professionalism (as discussed at section 2.2.7), features strongly in both the 
medical and legal literature (Steinert et al. 2005; Stern, 2005; Cruess and Cruess, 2006; Hamilton, 2008; Maharg, 2006, 2007;) . While a co-ordinated approach was discussed in this category it did not extend to self and peer evaluation which Taylor (1997) maintains encourages both independent and interdependent learning. Stakeholders alluded to both feedback (Taylor, 1997) and context-based assessment (Poikela, 2004). The pervasive assessment of students (i.e. assessment of professionalism across all course work and training) as recommended by Ginsberg et al. (2000) was discussed. Interestingly, observation of students in authentic settings (that is, in their training offices), as an important form of the assessment process (Stern, 2005), was not discussed by the training solicitors: one would expect the 'teachers' in this setting to allude to this role. This process of observing was referred to by trainees from large firms: there was a clear sense that training firms adopted a "Big Brother" approach in that all behaviour was noticed and noted. While trainees were not interviewed in my MA study, the solicitors from the large firms that were interviewed suggested that their role included this unofficial tracking and observing of trainees' professional behaviour or lack thereof.

The SRA's interest in outcome-based assessment of professionalism and Boon et al.'s (2005) concerns with this approach, in the sense of pandering to a training culture, are pertinent in the context of this study. Currently the Law Society's PPC ethics/professionalism course and exam are underpinned by learning outcomes based on the Law Society Professional Guide of Conduct (2014). The PPC Professional module or its form of assessment was not referred to in this category. Moreover, the virtues or concerns with an outcome-based assessment were not discussed. The stakeholders do not appear to be concerned with the lack of deep learning or the distinction between formal and technical knowledge as identified by Boon et al. (2005). With the proposed review of the PPC, as required by the Legal Services Act 2015 (see section 1.2.3 for discussion of this Act), it will be interesting to see what approach to assessment will be recommended and whether these issues will be considered. This study's findings could feed into the review.

\subsubsection{Part 2. 4: Is it important to define professionalism in this context?}

The importance of defining professionalism in instilling the notion is discussed in this unit of analysis. The unit comprises three categories of description as follows:

- Professionalism needs to be defined (Category A) 
- There is no need to define professionalism (Category B)

- Professionalism is too difficult to define (Category C)

Categories $\mathrm{A}$ and $\mathrm{C}$ have similar weighting i.e. a similar number of stakeholders held the perceptions in each of these categories. Category B involved fewer stakeholders. Corresponding with the analysis at section 4.3 .1 above, the perceptions of the stakeholders are relatively distinct with a certain level of comprehensiveness in Category C.

\subsubsection{Category A: Professionalism needs to be defined}

This category describes the perception that professionalism should be defined. It might be assumed that there would be a clear overlap between this category and the perceptions of those in the category who understood that professionalism could be taught explicitly and, in particular, those who believed that the Law Society has a role in teaching the basic principles. This overlap was not evident. A separate unit of analysis was therefore useful in analysing this question.

Notably, the trainees held the view that professionalism needs to be defined more widely than other stakeholders. In the following extract, the trainee suggests that the concept be defined, not for the benefit of trainees or in the context of teaching professionalism, but for those in practice:

PPC I Trainee - large Dublin firm:

"I think it would be really good if there was a definition for it. Because some people don't pay heed to it at all. They come to a certain level in their career and they think they can talk to anyone the way they like and they don't need to abide by it. I think everyone should abide by a certain code of professionalism."

Views were mixed in this category about who should define it: the option of the Law Society or the Law Society jointly with firms was explored. Views were strongly in favour of the Law Society having a role, a view which was not so prominent in the MA study.

Solicitor/tutor - regional firm:

"I think it would be something for the Law Society to define being the governing body rather than the firms." 
Pre PPC I trainee - regional small firm:

"I would say firms have their own, maybe not standards, but their own way of going about things but a Law Society definition would be more beneficial as it would be on overall sense. Yea, definitely."

\section{Law Society tutor:}

"I think there should be an explicit understanding among all the players of what the Law School think the elements of professionalism are and that the tutors understand what professionalism and what the Law Society is trying to achieve in that regard."

Notably, there was very little discussion about the importance of defining professionalism in order to support the teaching of the concept. The question as to whether to define the concept or not was introduced in the interviews in the context of teaching professionalism yet very few stakeholders alluded to or linked it to the nurturing of professionalism in trainees. This contrasts with the literature pertaining to defining professionalism in the context of explicit teaching as discussed above at section 4.3.2 - Category A (Professionalism can be taught explicitly) and the perception of a number of stakeholders in the MA study.

How professionalism is understood is discussed in detail at section 4.2 and section 2.2. There is widespread support for defining professionalism generally (not only in the context of inculcating the concept) among professional bodies, regulatory bodies and leading academics.

\subsubsection{Category B: There is no need to define}

The perception in this category is that the inculcation of professionalism is innate (this relates to the earlier perception at section 4.3.1) and therefore a definition of professionalism is useless:

Solicitor - large regional firm:

"To my mind it is ingrained from your first day of training - in my experience it's not something that needs to be defined or probably even taught."

This was not a widely held perception. 


\subsubsection{Category C: Professionalism is too difficult to define}

This category describes the perception that, for reasons of subjectivity and the subsequent danger of defining it too narrowly, professionalism cannot be defined. The extracts also illustrate a somewhat cynical reluctance to define the concept because it will give solicitors an opportunity to "get around" the definition.

\section{Law Society executive 1:}

"The difficulty with defining it, and it's the same problem I have with the Irish Constitution, some things are value -related that can change when society changes and I can be subjective so I would be torn between defining it too greatly narrowly. It's not that's it's flexible per se but its application and understanding could change given the circumstances."

\section{Law Society executive 2:}

"My problem with defining something is that someone will try to sneak between the cracks and say 'well this falls within your definition' even though, on the face of it, is not very professional attitude. Professionalism is like the old joke of the Supreme Court about pornography - you can't define it but you know it when you see it! You know when someone is doing a good job and acting in a professional manner. Once you try and tie it down to define it you create opportunities where people who are linguistically gifted to give them wriggle room. And again the Law Society has codes of conduct and it is imbued in that and I don't think professionalism is defined in those, but standards of behaviour and conduct are defined. Students should be expected to abide by these standards from the moment they join us."

While this stakeholder recognised the importance of explicitly setting out a concept 'in black and white' for students, the view was that it is too subjective and, in any event, is not adhered to when an individual is under pressure:

\section{Law Society executive 3:}

“That's one group of people's view of professionalism. It's subjective and environmentally driven. One can do that and all of what you said can be done and it probably has a place in terms of the symbolic. It's really powerful for students to see something in black and whitethey are given value. It can't replace the difficult work of what do you think? What do you believe in? It's very different - what do you do if no-one is looking? If it's the middle of the 
night, if you are not at your desk? If you are on the golf course, if you are in the Bahamas. What do you do? Do you go in? I am a bit more fearful of putting emphasis on that as people lose it under threat."

The resulting outcome space/summary of referential and structural aspects of each of the categories of description in this part is presented in Table 5 below. Again the referential aspects are the same as the Category descriptors.

\section{Referential}

\begin{tabular}{llll}
\cline { 2 - 3 } Structural & Needs to defined & No need & Cannot be defined
\end{tabular}

\begin{tabular}{lll}
\hline Possible & A
\end{tabular}

Not possible

$\mathrm{C}$

Table 5: Outcome space: Part 2.4 - Should professionalism be defined?

From a structural perspective, Category A and B understand that it is possible to define the concept of professionalism. It is not clear if this is in the context of teaching and nurturing the notion. While Category B believes it is possible to define professionalism, it understands that there is no need to define it. Category $\mathrm{C}$, in contrast perceives professionalism as a concept that cannot be defined. This structural outcome space is of limited use in the data analysis in that it adds very little to the analysis above.

The perception outlined in Category $\mathrm{C}$ was strongly held by the Law Society executives, which is interesting in that one perhaps might assume that this group of stakeholders would advocate a clear definition of the concept in support of the explicit learning model adapted by the Society which comprises lectures on core topics followed by more applied learning in the form of tutorials. This is in contrast to the views of a number of academics as discussed at section 4.3.2 above - Category A (Professionalism can be taught explicitly) and in the literature review.

These views reflect broader debates about the difficulties with defining professionalism because it is shaped by organisations and individuals' perceptions (Eraut, 1994 and Mather et 
al., 2000). Although stakeholders do not specifically refer to defining professionalism as a means of controlling knowledge (Martimianakis et al. 2009) both are alluded to in the context of defining how professionalism is perceived i.e. the trainee fits in with the firm's view of professionalism.

\subsubsection{Part 2.5: What influences the instilling of professionalism?}

Influences on the instilling of professionalism are discussed in this unit of analysis. The categories of description have similar weighting i.e. a similar number of stakeholders held the perceptions in each of these categories. Category A and B involved fewer stakeholders. The unit comprises four categories of description as follows:

- The existence of barriers influences the learning of professionalism (Category A)

- Positive learning experience influences the instilling of professionalism (Category B)

- The instilling of professionalism is influenced by the culture of firm (Category C)

- Professionalism is influenced by an individual's background and /or personality (Category D)

While the perceptions of the stakeholders are relatively distinct in Category A and B, there is a level of comprehensiveness in Category $\mathrm{C}$ and $\mathrm{D}$, i.e. many of those with Category D perceptions also held the understanding evident in Category $\mathrm{C}$.

\subsubsection{Category A: The existence of barriers influences the learning professionalism}

In this category, a few stakeholders understood that certain barriers influence the learning of professionalism. Barriers included students not wanting to nurture professionalism. This is also discussed earlier at section 4.3.1.2 (Can everyone pick up professionalism?) Category B - everyone can pick up professionalism when they make a decision to do so. Other barriers were not having a good role model, an explicit learning programme and difficulty with application of the knowledge. These are illustrated in the transcripts below:

PPC II trainee - large regional firm:

"In terms of barriers it's very difficult to learn from a book and then apply in real circumstances. It can be hard to adapt or apply in real circumstances.", 


\section{Law Society tutor:}

"If you didn't have that [explicit learning programme] and then they were in a firm that were not a good role model for them I think that would be barrier [to learning professionalism]. It's important to have both. I think the only place you can really control it is here in the Law School so I think that needs to be quite strong."

As pointed out above in section 4.3.1.2, the requirement to actively want to assimilate professionalism or behave professionally is not explicitly discussed in the literature in relation to an individual's ability to behave professionally or as a barrier to assimilating professionalism. The analysis of the literature in the context of the data collected pertaining to good role models and an explicit learning approach is dealt with in section 4.3.1.2. While not specifically discussed in the context of barriers to nurturing professionalism, a lack of a good role model and an explicit teaching approach to foster professionalism is discussed throughout the relevant literature.

4.3.5.2 Category B: Positive learning experience influences the instilling of professionalism This category views previous learning/teaching experiences and current learning experiences as influencing the nurturing of professionalism. The attitude of the tutor or training solicitor has a strong effect on the trainee's learning experience:

PPC I trainee - large firm:

"Whereas if I am encouraged and someone is, like, welcoming of me following them trying to learn things, then I will learn anything. I think it is all about the attitude of the person that is teaching."

PPC II trainee - large regional firm:

"In terms of personality or [their] approach, I think how the tutor or lecture approaches the subject will impact on how maybe enthusiastic [they are] about the area or how open I am to take on board what they are saying. As to how they deliver it but I think you have your own way of learning. In terms of their approach, it does have an impact, everyone takes on board different ways of doing things."

Other stakeholders referred to the influence that previous learning has had on their role as tutor and instilling professionalism: 
Solicitor/tutor - small regional firm:

"I would definitely think previous learning influences my role so as I would recall those teachers that were excellent and how they taught. In particular those we were scared of yes, we might have learnt but not in a positive way while those teachers who struck up a good relationship with us and encouraged us to ask questions, certainly we learnt so much moreit made us challenge and think about what we were learning."

The literature discusses past learning experiences not in terms of the effect it has on the inculcation of professionalism specifically but in terms of professional development and students' learning outcomes. This is reflected in the data. Taylor (1997) maintains that learners' experience is a core component of personal knowledge which in turn influences professional development. Prosser \& Trigwell (1999) study the relationship between students and teachers' prior experiences of learning situations and learning outcomes.

\subsubsection{Category C: The instilling of Professionalism is influenced by the culture of the firm}

This category perceived the culture of the training firm and training environment to have a strong influence on the instilling of professionalism. This was not a very widely held belief as a distinct perception, with four stakeholders across the sample's spectrum holding this view. But the influence of the culture of the firm is implied in the context of the role of the firm in role-modelling. The category is described in the following extract:

\section{Law Society executive:}

"My sense is, I think people can be heavily influenced by the environment - so if the environment is very conducive to ethical practice and that is supported, then that is very influential.... if the environment is really good or if the environment is contrary to that. So if the environment is set up being very clear on boundaries and ethics and personal deal breakers is actually problematic for people, then that has an influence as well, it can prevent people acting on their own."

The environment alluded to in the above transcript could also relate to the teaching institution's environment and the influence of the hidden curriculum as discussed above in section 4.3.2. 
The discussion regarding the influence of the firm is also relevant to the discussion on role modelling as outlined above in section 4.3.2.4. The literature outlines a number of key studies that analyse the influence of legal training firms on trainees' sense of professionalism (Nelson \& Trubeck, 1992; Rhode, 1994; Mather et al. 2001; Corbin, 2005). Eraut (2004) and Boreham and Morgan (2004) recognise the influence that workplace cultural knowledge has on behaviour. The latter explore the ways in which the shared and accepted way of behaving in the workplace, based on certain practices, affects learning. In my study, the stakeholders did not discuss this influence in terms of a structured form of learning, perhaps because as Eraut (2004) maintains one is not aware of the influence of the workplace culture. Yet, while not a widely held perception, at least not explicitly, the interviewees in this study were clearly aware of this influence. Boreham and Morgan (2004) also describe structured dialogue in the workplace as having an effect on the organisational learning (see section 2.3.5). While stakeholders did not allude to structured dialogue, unstructured dialogue, in terms of a set of cultural practices or a common world is implied in this category. It is interesting to note that this category of description was not a very widely held perception of the trainees and firms, particularly from large firms. In the MA study there was a distinct understanding from the solicitors in large firms that the firms had a strong influence on the behaviour of the trainees to the point that there was a suggestion that trainees were indoctrinated in the culture of the firm. As mentioned above, trainees were not interviewed in the MA study.

\subsubsection{Category D: Professionalism is influenced by an individual's background and /or personality}

This category understands professionalism to be strongly influenced by one's upbringing and personality. It is a strongly, and relatively widely held view and understanding in this part six stakeholders alluded to this influence. Of those, only one stakeholder also held the view that professionalism was not something that could be instilled in everyone yet one would expect there to be more of an overlap of views here. Notably, just one of the Law Society executives held this view that professionalism was strongly influenced by upbringing and personality. This category is illustrated in the following extracts from PPC II students, the LS executive:

PPC II trainee - regional small firm:

"I think you could but on the basis of the principles [of a solicitor's firm] I have worked under I feel like if they are doing it wrong I would avoid doing that [R: and is this something 
you recognise yourself]. I would yea - think it's just my upbringing, the manners instilled in me by my parents. [R: you have general 'cop on'*. You know what's wrong or right?] Yea I think so [R: Do you think it is something you teach someone if they haven't had a great upbringing in that regard] I am not so sure you can teach it. It's someone's personality, they have their own tendencies."

*common sense

PPC II trainee- large Dublin firm:

"I think some people fundamentally; I wouldn't trust them with my car keys, does ring true with some people. I think most people can pick up degrees of it. Someone's attitude and 'cop on'* some people will be a bit of an eejit no matter what you teach them or where you put them. Yea I'd say a bit of 'cop on' is the foundation of it all whether that comes from birth or the environment.

\section{Law Society executive:}

"It's family, friendship ..It's everywhere in life. It is not just learnt there. But if you come from a background where it's given value then that's a much greater vaccine. Then you can take that young person and put them in that environment where that's not recognised or valued and it's much harder to shake it and if you take that person where they haven't had that kind of modelling early enough then they can become very infatuated by the other way of being. They can think it's a very valid alternative and a very lucrative alternative say...that gets me up the ladder faster. It's easier depending on our own start in life."

As outlined in the literature review (section 2.3.2), Eraut (1994) describes personal knowledge in very wide terms ranging from tacit knowledge to emotions. While this category does describe the powerful influence of personal knowledge on the teaching of professionalism in broad terms, the category does not extend beyond attitudes, values, personal understandings, background and, to a certain extent, tacit knowledge. The influence this category has on workplace cultural knowledge is described by Eraut \& Hirsh (2007) also, although Eraut's (2004) advice to maintain control of this form of influence is not discussed in the data. 
The resulting outcome space/summary of referential and structural aspects of each of the categories of description in this part is presented in Table 6 below. Again the referential aspects are similar to the Category descriptions:

\section{Referential}

Structural Barriers Learning Experience Culture of firm Individual personality

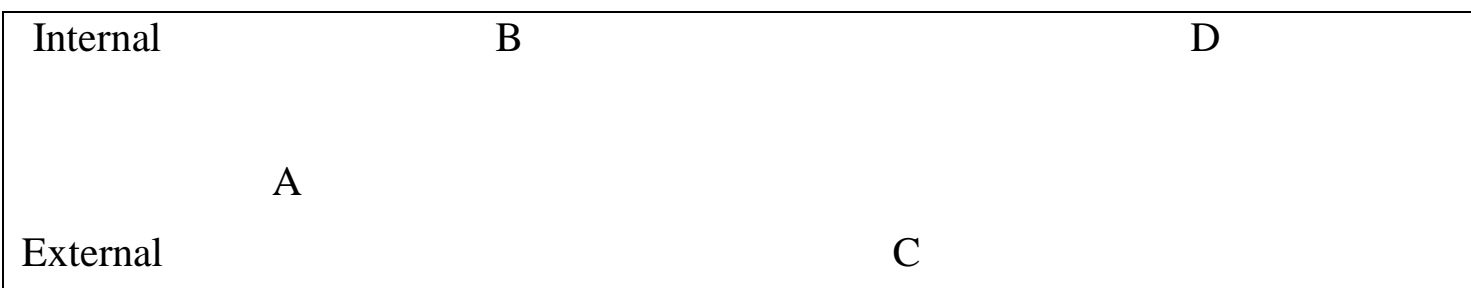

Table 6: Outcome space: Part 2.5 - Influences on teaching professionalism

From a structural perspective, Categories B and D represent the internal influences on the instilling or teaching of professionalism. Internalised learning experience, backgrounds and personalities of the individual all exert an influence. Category $\mathrm{C}$ represents the influence of external culture on this process. Category A has internal and external elements to it: barriers can include a disinclination to nurture professionalism internally, and external barriers can include lack of good role models and the learning structure.

\subsection{Findings and discussion - summary of key points}

An analysis of the variance in the perceptions of the stakeholders is an important exercise at this stage.

\subsubsection{What is professionalism: variance in perceptions,}

Part 1 (section 4.2) highlights a clear variance in relation to how professionalism as a concept is understood. An ethics and value-based understanding of professionalism was found to be a more prevalent amongst Law Society executives and tutors. While larger firms' trainees and solicitors perceived professionalism as more behaviour based, mainly in the sense of presentation and manners. More experienced practitioners understood professionalism in terms of managing clients. Trainees viewed it as a simple obligation to be available and at the behest of clients. As mentioned above, perhaps this reflects a wider trend towards a more 
technical view of professionalism or perhaps a deeper perception of professionalism was not vocalised in the interviews.

\subsubsection{Variance in perceptions in relation to one's ability to assimilate professionalism}

The unit of analysis exploring stakeholders' perception in relation to one's ability to assimilate professionalism established three views; ranging from an understanding that not everyone can assimilate it to a view that everyone could assimilate the notion. This unit revealed a certain amount of variance among the stakeholders: the former view was held by stakeholders other than those from large firms (trainees and solicitors) with one exception. This would be expected: the large firms advocate a learn-by-example approach while the view that: if one makes a decision to behave professionally they can; was mainly held by those from large firms. The view that everyone can assimilate professionalism was held by a high proportion of stakeholders across the board in relation to the role modelling approach but it was mainly Law Society executives who discussed it a general sense. There was also the perception, held by a few stakeholders, that one must actively want to assimilate professionalism or behave professionally. While this is not explicitly discussed in the literature, in the context of an individual's ability to behave professionally, it echoes somewhat Argyris and Schon (1974) view that professionals hold theories about how the professional world should be but often their actions contradict this.

\subsubsection{Variance in perceptions in relation to the explicit and implicit teaching of professionalism}

Analysis at section 4.3.2 (explicit teaching of professionalism - is it possible?) revealed a lot of common ground and there were also distinct variations among stakeholders. Most notably, Law Society executives and pre-PPC students did not understand professionalism as a concept that could be taught explicitly, despite the learning model adopted in the Law Society. This was a view held by a number of stakeholders from firms, trainees and Law Society tutors. The perception that explicit teaching has a place in nurturing only the basic principles was held by stakeholders across the board with the exception of the Law Society executives, yet it was a widely held view that the Law Society should have a role in the teaching and nurturing of the concept. The Law Society executives held a stronger perception about the implicit teaching of professionalism, both in the Law Society and in the firms, and about the importance of applied learning which would be expected. While there was little or no variance in the perception that role modelling was the best approach to instilling 
professionalism (with structured role modelling not identified as a view), the Law Society Executives held some notable perceptions that contrasted strongly with the other stakeholders. They discussed the powerful influence of the hidden curriculum and a few discussed the importance of the structured mentoring approach - these aspects were not referred to by other stakeholders.

\subsubsection{Variance in views on the assessment of professionalism}

The analysis of the assessment of professionalism at section 4.3.3 (Should standards of professionalism be assessed in order to instil it and assessed by whom?) above showed that a few of the small firm PPC II students and solicitors, together with a number of the Law Society executives, perceived professionalism as a concept that cannot be assessed. This contrasted with the perception of the large firms. There was variation between suggested methods of assessment across the stakeholders. The variation of stakeholders' perception regarding defining professionalism in the context of teaching the concept was analysed at section 4.3.4 (Is it important to define professionalism?) There was one key variation: trainees held a stronger view in favour of defining professionalism while Law Society executives in particular perceived it as too difficult to define.

\subsubsection{Influences on nurturing professionalism: variances in perceptions}

The various influences on instilling professionalism were discussed at section 4.3.5 above (What influences the instilling of professionalism?). Four distinct categories were identified with no clear variance among stakeholders' perceptions: while some categories of influences were not widely alluded to there was no particular emphasis placed by any group of stakeholders on any one influence. These influences do not appear to relate, to any great extent, to the delimiters and enhancers to informal and incidental learning described by Marsick \& Watkins (1990) and discussed at section 2.3.1 or to the factors required for an expansive learning environment (Fuller \& Unwin, 2002) discussed at section 2.3.10.

There is clearly variation among the stakeholders in their perceptions on what professionalism is and how to instil or teach it. The variance is nowhere near as stark as that found in the MA study where the perceptions of the large firms and the Law Society executives/tutors were very varied particularly as regards the Law Society's role in instilling professionalism in large firm trainees. As discussed earlier, the MA study was limited to collecting data from two ends of the spectrum of stakeholders - large firm training solicitors 
and Law Society tutors/executives. In this regard, it was clearly important to hear the voice of student and the solicitors from the mid, small and regional firms to get a more accurate view of the perceptions of all those involved in the provision of professional legal education.

\subsubsection{Divergence between the data and the literature}

As discussed at section 2.4.13, a number of key areas explored in the literature emerged in the findings while others were not anticipated. While the variance is not as stark as the MA study, the findings do identify a number of key areas of diverging perceptions. Moreover and perhaps significantly, there are views discussed in the literature that were not considered by the interviewees in this study. For example, the data reveals a certain lack of a link between the fundamental principles of professionalism and practice. The workplace learning in the training office is not linked to the explicit and implicit learning programmes in the Law Society. Eraut (2004) and Eraut and Hirsch (2007) explore the importance of linking theory and practice in making learning effective by transferring knowledge to a new situation. They maintain that the process is not automatic. Their suggestion to implement an integrated programme to link the theory and practice is echoed by other commentators as discussed at section 2.3. The ability to transfer knowledge to a new situation is vital in a newly qualified solicitor's role. A narrative approach as suggested by Coulehan (2005), could also be used to bridge the gap between the explicit teaching of professionalism and the tacit informal approach to instilling professionalism. A collaborative effort by all stakeholders is, in my view, important to link practice and the core principles of the concept.

The literature widely discusses the importance of structure, support for workplace learning and role modelling in general (Cruess \& Cruess, 2006, Branch, 2010). Many advocate systematic training of role models which, in relation to my study's implications, could include training firms and Law Society executives and tutors. Yet, there is a notable lack of evidence of this in the data findings. Others advocate the need for a clear consensus among role models as to the definition of professionalism and the standards expected of trainees. There is variance among the stakeholders on this point.

The findings also show a distinct variance in how to assess professionalism. An audited form of workplace learning, as envisaged by the SRA (2014) was not considered by the stakeholders. Moreover, the data revealed a lack of interest in the importance of genuine feedback in the training firms. 
As discussed in the literature review, the PPC traineeship programme is structured in the sense that trainees are required to carry out various tasks in the workplace in the core areas of practice. The training solicitor is obliged to ensure that trainees are given the opportunity to complete the tasks in the training $\log$ and this is overseen by the Law Society Training executive who makes office visits to ensure compliance and discuss any issues with trainees. This type of structure was not referred to in the data and there appeared to be a lack of awareness of it amongst some stakeholders of this structure. This would indicate a need to communicate approaches so that all stakeholders are aware of structures. More importantly, this identifies a need for "buy in" and collaboration from the stakeholders to the process. Although many of the tasks are underpinned by professionalism and professional standards, this type of structure lends itself to professional knowledge. It is not a structured role modelling approach. Moreover, the data does not allude to mentoring or any formal structured mentoring programme based on the Kohlberg four components of moral action as suggested by Hamilton and Brabbit (2007), for example. The interviewees do not go as a far as Shulman's (2005) suggested three pronged approach to the process of preparing students for professional careers - surface learning, deep structure and a moral tacit structure. The Law Society pilot supervision programme was not alluded to.

There is variance among stakeholders at each of the parts analysed above. A consideration of the variances and a bridging of these variances should be considered in developing a stakeholder-led collaborative programme. A common understanding of what professionalism entails among stakeholders is a consideration in a collaborative programme and strongly advocated by a number of commentators (Cruess and Cruess, 1997; Whitcomb, 2002; Steinhart et al. 2005; Brainard and Brislen, 2007 and Hamilton, 2008) 


\section{Chapter 5}

\section{CONCLUSION}

\subsection{Introduction}

As I argued at the beginning of this thesis, a profound sense of crisis pervades debates about professionalism in Ireland's legal system. It is in this context that this study's research question is raised: Is their variance in key stakeholders' perceptions on how best to instil or teach professionalism and what are the implications of any variance for professional legal education in Ireland? The perceptions of those involved in the instilling, teaching and learning of professionalism are important in this vulnerable era for legal professionals in light of the crisis in professionalism discussed in Chapter 1.

In order to address the three-fold research question that was posed in Chapter 1, this thesis comprises a phenomenographic study of the variance in perceptions among the key stakeholders in legal professional education in Ireland, in this chapter I outline the conclusions from this qualitative study, together with my evaluation of its strengths and limitations. In drawing conclusions, I will elaborate how the findings address these research questions and thus indicate original research and contribute to the knowledge in this area. I discuss the implications for professional education and training with suggestions for further research projects. I also consider the contribution to academic understanding of workplace learning and the significance of this work.

\subsection{Qualitative analysis - concluding remarks}

5.2.1 How do the stakeholders perceive and understand professionalism as a concept and is there variance in their perceptions (Part 1)

Four qualitatively different ways in which the stakeholders understand the notion of professionalism emerged and informed an analysis of the data; professionalism is valuebased, behaviour-based, involves management of clients/interaction with peers, and, is based on competence and efficiency. From a structural perspective (this dimension analyses how the phenomenon can be distinguished from its context and how the individual parts of the phenomenon relate to each other and the overall phenomenon - see section 4.2.5), the first category reflects an abstract perception of the concept while the remaining categories represent a more tangible perception of professionalism. The range of perceptions amongst my sample of interviewees is somewhat limited and does not reflect the extent of 
understanding explored in the literature reviewed in Chapter 2. While a group of stakeholders did describe professionalism in terms of values and autonomy, this perception did not extend, at least explicitly, to professionalism in terms of serving the public good, in promoting equality and diversity or in terms of achieving a balance between the principles of professionalism and wealth accumulation. As outlined in Chapter 4, these characteristics were not alluded to in the data. Moreover, an understanding of professionalism as a concept based on a commercial model or in terms of compliance with an obligation to a code of conduct did not feature in the data.

The structural analysis of the understanding of professionalism of large firm training solicitors and Law Society tutors, in the MA study (as described in section 3.2) was similar, with emphasis placed on the tangible perceptions. However, there were clear differences in perceptions: professionalism as a value-based concept was a more widely held understanding in the MA study. Moreover, there was more emphasis placed on professional knowledge as a key characteristic of professionalism in the MA study. The makeup of the stakeholders is different in this study: there were more Law Society tutors interviewed in the MA study and this may explain the latter finding.

While the perception of professionalism in terms of values was alluded to by a number of stakeholders, this perception was not a widespread understanding. The Law Society executives placed a lot more emphasis on this perception. There appears to be a move to a more technical view of professionalism in this study. This is an interesting finding and begs the question: why? It is difficult to pinpoint the reason. It may be due to capturing the perceptions of a wider range of stakeholders or a cultural shift. Perhaps the 'crisis of accountability' or tick-box culture that O'Neill (2002) refers to has led to reduced horizons on the part of the stakeholders and a restricted perception of professionalism. Those who held a more in-depth or broader understanding of the concept, for the most part, stemmed from a non-practising background i.e. Law Society executives and tutors. Those in practice (both solicitors and trainee solicitors) are immersed in a climate of accountability when compared to those involved in education - this, perhaps, explains the variance in perception. Yet very few of the stakeholders vocalised an understanding of professionalism as adhering to a code of conduct. Taylor (1997) and Boon et al.'s (2005) concerns are worthy of consideration in this context. They express concern with the move towards a more technical approach to teaching professionalism, where trainees are losing out on a deep learning approach to the 
fundamentals of professionalism. Generally, the PPC Course model addresses Boon et al.'s (2005) concerns regarding the lack of understanding of underlying concepts in experiential learning by explaining the principle concepts in the lectures and its practice manuals. Yet, trainees still hold a very technical view of professionalism. It may not only be the influence of their training firm - it may also be a lack of exploration of the underlying principles in the context of teaching professionalism.

What implications does this variance have for professional legal education? This wide variance of understanding is a concern for those involved in the instilling of professionalism. This indicates that stakeholders are teaching or instilling professionalism without a common understanding of the concept. Trainee solicitors are therefore exposed to a narrow or broad perception of professionalism dependent, it would appear, on whether they are learning in the workplace (i.e. in practice) or in the Law Society. There are many commentators (Cruess \& Cruess, 1997; Whitcomb, 2002; Steinhart et al. 2005; Brainard \& Brislen, 2007 and Hamilton, 2008) who strongly advocate an agreed cognitive base as to what professionalism entails both for practitioners and for the purposes of teaching. Others warn against a checklist of behaviours (Eraut, 1994; Martimianakis et al., 2009). Maharg (2012) argues that the development of professional legal education should involve a shared understanding of what the concept means. While the difficulty with coming to an agreement on what professionalism entails is widely recognised in the literature (Mather et al. 2001; Hazard \& Dondi, 2004), the findings in this study indicate a clear need for a co-ordinated approach by stakeholders to agree on the key characteristics of professionalism. This will, hopefully, open up the discussion on what we understand professionalism to mean, explore the underlying values of the concept and keep a check on the move towards a technical narrow perception.

In the context of the implications for a trainee's learning experience and development, another finding worthy of a concluding comment, is the variance between the trainees' and the solicitors' view of what is expected of them in terms of a service to clients. This tension between being available for a client at all times and managing a client's expectations needs to be addressed by developing the trainees' client management skills.

5.2.2 What are the qualitatively different ways in which the stakeholders vary in their understanding of how professionalism can be fostered (Part 2)

The second limb of the research question (what are the qualitatively different ways in which the stakeholders vary in their understanding of how professionalism can be "passed on"?) 
explored five units of analysis, as outlined in detail in Chapter 4, with a number of distinct variances emerging in the perceptions' of the stakeholders. While these variances in experience and understanding reflect, for the most part, the views expressed by researchers and academics in the legal and medical field, this study add depth to this understanding in this particular context. The importance of role-modelling in instilling professionalism both in the workplace and in the teaching institution, for example, was a widely held view (see section 2.4.4). Engestrom's (2004) discussion of learning taking place horizontally underpinned by his social activity theory and the concept of situated learning (Eraut \& Rainbird, 2002; Eraut, 2004) (see section 2.3.6) are alluded to in the data. Trainees, in particular, recognised the importance of a community of learning (Lave \& Wagner, 1991) and learning from their peers.

Despite this, there are findings that did emerge from the data analysis which are at odds with the literature. The structural analysis of the varying meanings about whether everyone can learn or pick up professionalism ranges from an innate understanding to one of control i.e. the individual controls the fostering of professionalism. This range of understanding does not appear to reflect the literature reviewed. While not a widely held view, it is somewhat unsettling, that stakeholders (trainees in particular) hold the perception that there is a choice as to whether to engage with professionalism or not. While this issue is not discussed explicitly in the literature it does, somewhat, as previously mentioned, echo Argyris and Schon (1974) argument that espoused theories do not accurately reflect the actions of the professional. Notably, the stakeholders did not allude to a structured form of role modelling. A number of commentators (Eraut, 2004; Branch, 2010; New York Bar Association, 2011; Park et al. 2010) strongly advise structuring role-modelling. It would be useful to have a discussion with stakeholders, particularly solicitors' firms, in relation to introducing structure to role modelling and its effectiveness in fostering professionalism. As discussed in section 2.4.4, the pilot Law Society Supervision Programme could form the basis of structured role modelling system.

The phenomenographic analysis did reveal a number of somewhat surprising categories of variance among stakeholders. The understanding that explicit teaching of professionalism was possible and explicit teaching of the basic key principles (with the Law Society having an important role) emerged as two of the categories. Neither of these views was held by the Law Society Executives, which is interesting, because as noted in section 4.3.2, this group of 
stakeholders is involved in teaching both the propositional and process knowledge. This group placed a lot more emphasis on the implicit learning of professionalism, contrasting with the view held by the tutors in the MA study. From a structural perspective, the Law Society Executives perceive the fostering of professionalism as a non-directive act. This finding would suggest that there is a need to raise awareness or for this group to gain a better understanding of their role in, not only applied and technical skills teaching but also the explicit teaching of the underlying theory underpinning professionalism i.e. the process knowledge. As discussed above, in relation to how professionalism is understood, the stakeholders did not appear to be concerned about or aware of a lack of deep learning or the distinction between formal and technical knowledge of professionalism, as identified by Boon et al. (2005). The coming together of theory and knowledge, as explored by leading workplace learning commentators (Evans et al, 2011; Eraut, 2004) does not emerge in the data as much as one would expect. Certainly, the three dimensions of teaching professionals, to include surface, deep and tacit learning as outlined by Shulman (2005) in discussing signature pedagogies is not reflected across the board. Again, this reveals, perhaps, a lack of understanding of training firms' role in transferring the tacit knowledge in terms of a moral dimension comprising a set of professional attitudes, values and beliefs.

It is also interesting to note that the Law Society's role in teaching the basic principles of professionalism was recognised by the solicitors' firms: this contrasts with the findings of the MA study where the large firms did not allude to the Law Society having a role in fostering professionalism. This demonstrates a development in awareness of the Law Society role in this context that, it would appear, the Law Society executives are losing sight of; again, this illustrates a need to raise awareness of their role. Alternatively, this finding may be a result of a broader spectrum of stakeholders interviewed.

In terms of assessment of professionalism, it was surprising that solicitors' firms did not allude to informal assessment in the workplace while, in contrast, the trainees were clearly aware of the observation of their behaviour. No audited form of workplace learning was alluded to as explored by the SRA (2014). Moreover, the merits or limitations of the PPC outcome-based Professional module or its form of assessment i.e. a closed book exam, were not discussed in this category. Again, a co-ordinated approach to address the qualitatively different perceptions as to how to assess professionalism is clearly needed. Perhaps, the Law Society pilot Supervision Programme could also be adopted for assessing the notion with a move away from the exam format. This is of particular importance in light of the report to be 
carried out on the Law Society's educational programme, pursuant to the Legal Services Regulation Act 2015 (see section 1.2.3) for a discussion on this legislation). The report's objective is to analyse the effectiveness of the current system of legal professional education in Ireland and to consider opening the market to other providers.

There is wide variation among stakeholders as to whether professionalism should be defined at all. What is surprising is the extent to which the Law Society executives perceive professionalism as a notion that cannot be defined, particularly, as discussed in section 4.3.4, considering their role in explicit (and applied) teaching. Certainly, the key commentators in favour of explicit teaching of professionalism also advocate a clear definition of the concept. Again, this is a variance that needs to be addressed: should professionalism be defined in a collaborative effort among stakeholders to develop an integrated programme of teaching and assessment. The shaping of professionalism by the individual's set of values and moral sensitivity, culture characteristics of the legal practices and jurisdictions in coming to a common understanding must be considered (Mather et al., 2001, Hazard \& Dondi, 2004) and renders this a difficult, maybe impossible, exercise.

The stakeholders perceived both internal and external influences on instilling professionalism with no distinct variance or emphasis on any particular influence by one group of stakeholders. The influences were as expected and reflected the literature reviewed: barriers such as a bad role model negatively impinge on the fostering of professionalism; positive learning experiences influence both the educators and the students; and both the culture of the firm and the individual's background and personality exert a strong influence. The range of influences did not explicitly extend to the factors that promote an expansive learning environment described by Fuller and Unwin (2002). These factors, which include, development of knowledge and skills through participation in a community of practice and opportunities for learning on and off the job are implicitly considered by stakeholders in the context of role-modelling. Notably, a number of the interviewees recognised the influence of the firm's culture. This contradicts Eraut's (2004) view that people are unaware of the influence of the workplace culture.

While there were varying perceptions among stakeholders as to how to foster professionalism, the extent of the variance was not as wide or stark as that found in the MA study which explored the two ends of the spectrum of those involved in instilling professionalism (the perceptions of large Dublin based training firms' and Law Society 
tutors' of their role in transferring or teaching professionalism). One of the reasons for undertaking a doctoral level study was to test this stark variance in perceptions with a wider pool of stakeholders. The pool was extended by adding more variance in terms of the location and size of the firm and hearing the voice of the student and the Law Society executives. While this reason for engaging in this study is justified, there are variances that need addressing or at least to open up a discussion, among the stakeholders, about these issues.

\subsection{General implications for professional legal education in Ireland and workplace}

\section{learning}

In concluding, it is very evident that the qualitatively different ways in which the stakeholders understand professionalism and how they understand the ways in which the fostering or teaching of professionalism occurs, has significant implications for professional legal education in Ireland and the profession. Specific implications are alluded to in the context of the phenomenographic analysis as discussed above. The variance in understanding reveals a lack of connection between the theory and practice i.e. a gap between the theory underpinning professionalism and the technical understanding of it. A gap in understanding also exists between the explicit teaching and assessment of professionalism and the implicit fostering of the notion. This lack of connection, together with the sometimes stark variances in perceptions among stakeholders, portrays a disjointed effort by those responsible for instilling professionalism in trainee solicitors. It illustrates a lack of communication and coordination among stakeholders that needs to be addressed. While a number of commentators advocate a common understanding among stakeholders of what professionalism entails (Cruess and Cruess, 1997; Whitcomb, 2002; Steinhart et al. 2005; Brainard and Brislen, 2007 and Hamilton, 2008), Evans et al. (2011) go further and supports this study's finding. They suggest facilitating the relationship between the providers and users of different kinds of knowledge in education and the workplace by dialogue at local level. This dialogue should involve all stakeholders if "the wider purposes of WBL and those who engage in it are to be served" (p.161). This study would strongly suggest that this dialogue needs to be facilitated among professional legal education stakeholders.

I believe that a number of this study's findings add significantly to the workplace learning debate as discussed in section 5.2 with some warranting specific mention in this regard. For instance, some stakeholders perceived professionalism as a concept that could either be taken on board or not taken on board as a matter of choice. This sense of control over the transfer of 
workplace knowledge or there being a choice whether to adopt it is worthy of discussion among stakeholders. Is this sense of choice a matter of concern and, if so, can or should it be addressed? The stakeholders' limited concern or consideration of a lack of deep learning in the workplace informs the workplace learning discussion and justifies Boon et al.'s (2005) disquiets. Assessment in the workplace was not alluded to by stakeholders: this needs to be considered, particularly by the training firms. Again, this is an interesting finding in the context of workplace learning.

I strongly believe that the implications of this study need to be considered by stakeholders in legal professional education in Ireland and the recommendation to open up a dialogue among these stakeholders initiated. I would envisage taking a lead role, with the approval of the Law Society Director of Education, in the process of stakeholders' engagement with the concerns identified by this study's findings. I would suggest that the dialogue takes the form of a panel forum with round table small group sessions followed by open floor and plenary discussions. This forum would be open to all stakeholders, both Dublin and regional based. The roundtable discussions should be structured and facilitated to ensure they are focused and effective. The primary objective will be to promote dialogue and raise awareness of the concerns discussed in this study. This forum should hopefully lead to a collaborative effort to address the concerns and issues identified and ultimately lead to an integrated programme based on a common and deeper understanding of professionalism.

\subsection{Strengths, weaknesses and limitations}

The principal strength of this study is the voice given to the full breadth of stakeholders in legal professionalism education in Ireland, in particular the trainee solicitors, smaller regional firms and Law Society executives. The earlier MA study did not indicate the wider stakeholders' perceptions of professionalism and or clearly how best to foster it. Moreover, this study adds to the wider literature by adding an Irish legal focus. The phenomenographic analysis was found to be particularly suited to the study. This methodology is especially suited to analysing variation in perceptions about education which form the basis of this study's research question. It successfully revealed a number of variations in understandings that need addressing with a view to developing a co-ordinated and ultimately a more effective form of teaching and instilling professionalism.

There may have been a weakness in the methods adopted in the study. The cultural norms of solicitors in particular perhaps contribute to a norm of professional reticence, where 
individuals are wary of answering questions outside their comfort zone. Although the data collected was informative and thought-provoking, the in-depth interviews recommended by the methodology did not materialise in all cases. Other constraints came perhaps from perceptions about my position. Although I made clear that I was a researcher and not as a Law Society employee testing their level of professionalism, at times there was a hesitancy. As noted above, the open-question approach perhaps needed to be more directive in some cases in order to ensure the data related to the research questions: for example, the linking of a definition for professionalism with the teaching of professionalism was not naturally alluded to. As outlined in my Findings and Discussion Chapter, the discussion with the stakeholders could have been teased out at times, particularly where an understanding or perception which is explored (sometimes widely) in the relevant literature was not alluded to. Solicitors are trained to provide advice to clients in a succinct manner and this training permeated their approach to the interviews. Perhaps, being more mindful and having more of an awareness of this facet of a solicitors' identity while interviewing would have resulted in more in-depth interviews in some cases. On the other hand, I was aware of the importance of striking a balance between teasing out an issue and leading the interview a particular way (see discussion about bracketing in section 3.3). Nevertheless, despite these barriers, the interviews did result in rich data which led to, on analysis, informative and significant findings.

The limitations of the methodology in general are discussed in depth in Chapter 3 (section 3.5. 1). I believe I addressed the critics concerns about the focus on the group experiences by discussing the individual's perceptions where this added to the analysis of the data. Moreover, an understanding of professionalism as a concept was a key interview question and aimed to address the concerns about a lack of common understanding of the phenomenon. The non-generality of the phenomenographic analysis is a limitation but it is possible to apply the analysis to a similar group where characteristics of those interviewed are outlined, as was the case in this study.

\subsection{Significance/Contribution to knowledge and practice}

I have aimed for the study to provide a deep qualitative contribution to the debate on how best to foster professionalism, not in-depth only in professional legal education but also other forms of professional education. Potentially, the study also contributes and adds insights to the debates on workplace learning and knowledge transfer. In particular, it revealed 
qualitative difference ways in which stakeholders understand professionalism and how to teach it - variances that need to be addressed.

There are also potential methodological contributions. This study's research questions have not previously been analysed in a phenomenographic manner. This methodology adds depth to the qualitative analysis of the data by focusing on the educationally critical variance in perceptions. Moreover, professionalism and the teaching of the concept have not been researched in the context of legal professional education in Ireland.

I have found the outcome to be thought-provoking and the study's findings and conclusions are worthy of consideration by the stakeholders and the legal profession particularly in preparing for the effect of the Legal Services Regulation Act, 2015 which will result in opening up competition in the provision of professional legal education in this jurisdiction (see section 1.2.3).

\subsection{Concluding remarks}

In an era of anxiety surrounding the implications of the demise of the value of professionalism, its commercialisation and a general crisis of trust (see discussion in section 1.2/2.2.3), it is important now more than ever to agree on strategies regarding instilling professionalism in students and the standards of professionalism that they are expected to maintain throughout their legal careers.

The aim of this study was to determine the different ways in which the stakeholders understand professionalism and how fostering or teaching of professionalism occurs. Analyses of the data collected to address this study's research questions indicate that a coordinated approach to fostering professionalism is required to address the variation in understanding shown. To this end I would recommend critical engagement with the complexities of professionalism and the approach to nurturing this professionalism by the stakeholders. I would further recommend open discussion among the stakeholders to address the various deeper questions, such as trust and over-compliance, which have been raised throughout this study. A collaborative approach ensuring all stakeholders have a voice, led by the Law Society or other independent body, should lead to stakeholders developing an integrated programme to ensure professionalism is fostered, developed and maintained to an agreed standard. Ultimately, this should raise professional standards and would be a positive step towards addressing the concerns of the profession. 


\subsection{Implications for future research and publication}

This thesis provides a robust platform for future research and will be of interest to researchers, practitioners (legal and otherwise) and educators particularly in the professional field. The findings uncovered provide useful direction and foundation for research within a number of areas as outlined below:

1. Developing an integrated programme to foster professionalism in Ireland: a comparative study of other jurisdictions.

2. Measuring the effectiveness of a co-ordinated approach to fostering professionalism in terms of knowledge transfer and application in practice and ultimately an improved level of professionalism.

3. Exploring how the stakeholders in legal professional education perceive teaching: technical competence or knowledge?

4. Crisis of Trust? - the stakeholders' perceptions and implications for professional legal education.

I intend to publish and present my findings in a number of legal education journals (the Law Teacher, for example) and at various educational conference in Ireland/EU. The Legal Services Regulation Act 2015 (see section 1.2.3) will inevitably result in profound changes to professional legal education in Ireland - this study will therefore be of particular interest in this context. 


\section{REFERENCES}

American Bar Association's (ABA) Model Rules of Professional Conduct (1983). Retrieved 20 August 2014 from:

http://www.americanbar.org/groups/professional_responsibility/publications/model_rules_of _professional_conduct.html

Akerlind, G. (2002). Principles and practise in phenomenographic research. Proceedings of the International Symposium on Current Issues in Phenomenography. Canberra: University of Canberra.

Akerlind, G. (2003). Growing and developing as a university teacher - variation in meaning. Studies in Higher Education. 28 (4), 375-390.

Akerlind, G. (2005). Variation and commonality in phenomenographic research methods. Higher Education Research \& Development, 24(4), 321-334.

Akerlind, G. (2010). Growing and developing as a university teacher - variation in meaning. Studies in Higher Education 28(4), 375-390.

Alexander C. (2012). Learning to be lawyers: professional identity and the law school curriculum. Maryland Law Review. Vol .70:462.

Argyris, C. \& Schon D (1974). Theory in practice: increasing professional effectiveness. Jossey Bass.

Ashwin, P. (2006). Variation in academics accounts of tutorials. Studies in Higher Education, 31(6), 651-665.

Ashworth, P. \& Lucas, U. (2000). Achieving empathy and engagement: A practical approach to the design, conduct and reporting of phenomenographic research. Studies in Higher Education, 25(3), 295-308.

Bailey, M. (2011). Policy, professionalism, professionality and the development of HR practitioners in the UK. Journal of European Industrial Training, 35 (5), 487-501.

Bartlett, F., Mortensen, R. \& Tranter, K. (2011) Alternative perspectives on lawyers and legal ethics - re-imagining the profession. Routledge, London and NY. 
Beauchamp, G. (2004). The challenge of teaching professionalism. Annals Academy of Medicine, 33(6), $679-705$.

Beckett, D. \& Gough, J. (2004). Perceptions of professional identity: a story from paediatrics. Studies in Continuing Education. 26(2), 195 - 208

BERA. (2014). Revised ethical guidelines for educational research. Retrieved 27 June, 2014 from http://www.bera.ac.uk/publications/resources?tid=All.

Boon, A., Flood, J. \& Webb, J. (2005). Postmodern professions? The fragmentation of legal education and the legal profession. Journal of Law and Society, 32(3), 473-492.

Boreham, N. \& Morgan, C. (2004). A sociocultural analysis of organisational learning. Oxford Review of Education. 30(3), 307-325.

Boud, D., Solomon, N. \& Symes, C. (2001). New practices for new times. In Boud \& Solomon (Eds.). Work based learning - a new higher education. SRHE and OUP, Buckingham.

Boud, D. (2001). Knowledge of work: Issues of learning. In Boud \& Solomon (Eds.). Work based learning - a new higher education. SRHE and OUP, Buckingham

Boud, D. \& Middleton, H. (2003), Learning from others at work: communities of practice and informal learning. Journal of workplace learning. 15 (5).

Bowden, J. A. (2005). Phenomenographic team research process. In Bowden \& Green (Eds.), Doing Developmental Phenomenography (pp. 11-31). RMIT University Press, Melbourne.

Bowden, J. and Walsh E. (2000), Phenomenography. RMIT, Melbourne

Bowden, J. and Marton, F (1998). The university of learning. Kogan Page, London.

Braithwaite, W. T. (1990). Hearts and minds. ABA Journal, 76(9), 70.

Brainard, A. \& Brislen, H. (2007). Viewpoint: learning professionalism: a view from the trenches. Academic Medicine. 82(11), 1010-1014.

Branch, W.T. (2010). The road to professionalism: reflective practice and reflective learning. Patient Education and Counselling, 80, 327-332. 
Brennan, J. and Little, B (1996). A Review of work based learning in Higher Education. London, DfEE and Qsc (CHERI).

Brennan, J., Little, B, Connor, H. de Weert, E., Delve, S., Harris, J., Josselyn, B., Ratcliffe, N. and Scesa, A. (2006). Towards a strategy for workplace learning: Report to HEFCE by CHERI and KPMG. Higher Education Funding Council for England, Bristol, UK. Retrieved on 8 August 2015 from: http://oro.open.ac.uk/6437/1/towardsastrategyrd09_06.pdf

Brownlee, K. (2014), President of Ireland Ethics Initiate speech, Law Society of Ireland.

Bryman, A. (2008). Social Research Methods (Third ed.). Oxford University Press, Oxford.

Byszweksi, A., Hendleman, W., McGuinty, C. \& Moineau, G. (2012). Wanted: role models medical students' perceptions of professionalism. BMC Med Educ, 15(12), 115.

Council of the Bars and Law Societies of the European Union CCBE Code of Conduct (2013). Retrieved 20 August 2014 from:

http://www.ccbe.eu/fileadmin/user_upload/NTCdocument/EN_CCBE_CoCpdf1_138297305 7.pdf

Corbin, L. (2005). How "firm" are lawyers' perceptions of professionalism? Legal Ethics, $8(2)$.

Cope, C. (2002) Ensuring validity and reliability in phenomenographic research using the analytical framework of a structure of awareness method. Retrieved 15 November 2015 from http://ironbark.xtelco.com.au/staff/cope/QRJ\%20paper.pdf

Coquillette, D.R. (1994). Professionalism: The deep theory. North Carolina Law Review. 72, 1271-1277.

Coulehan, J. (2005). Today's Professionalism: Engaging the mind but not the heart. Acad Med. 80:892-898.

Crotty, M. (1998). The Foundations of Social Research. Sage Publications, London.

Cruess, S.R. \& Cruess, R.L. (1997). Professionalism must be taught. British Medical Journal. $72,941-952$. 
Cruess, R. L. \& Cruess, S. R. (2006). Teaching professionalism: general principles. Medical Teacher, 28(3), 205-208.

Cuesta Briand, B., Auret, K., Johnson, P., Playford, D. (2014). 'A world of difference': a qualitative study of medical students views on professionalism and the 'good doctor'. BMC Medical Education. 14, 77.

Dolin, J. (2007). Opportunity lost: How Law School disappoints law students, the public and the legal profession. Retrieved August 2014 from: http://works.bepress.com/jason_dolin/1

Dowling, J. (2015). A Professional Supervision Programme for Irish Trainee Solicitors: A Pilot Investigation. Draft report

Ellstrom, PE. (2011). Informal learning at work - conditions, processes and logics. In Malloch, Cairns, Evans and O'Connor (Eds). The SAGE handbook of workplace learning. SAGE, London

Engestrom, Y. (2004). The new generation of expertise - seven theses. In Rainbird, Fuller and Munro (Eds). Workplace learning in context. Routledge, London.

Engestrom, Y. \& Karosuo, H. (2007). From workplace learning to inter-organizational learning and back - contribution to activity theory. Journal of Workplace Learning. 19(6)

Entwistle, N. (1997). Introduction: Phenomenography in higher education. Higher Education Research \& Development, 16(2), 127-134.

Epstein, R. (1999). Mindful practice. Journal of the American Medical Association. Retrieved 10 September 2015: from:

file:///C:/Users/rachael/Downloads/Epstein\%201999\%20Mindful\%20practice.pdf

Eraut, M (1994). Developing professional knowledge and competence. Routledge, London.

Eraut, M. (2000) Non-formal learning, implicit learning and tacit knowledge in professional work in Coffield F. (ed.) The Necessity of Informal Learning, ESRC Learning Society Programme. Policy Press, Bristol.

Eraut, M (2004). Transfer of knowledge between education and the workplace. Open Universidad, Netherlands. Retrieved 11 August 2014 from: http://www.ou.nl/Docs/Expertise/OTEC/Publicaties/els\%20boshuizen/deel3.pdf. 
Eruat, M. \& Hirsch, W. (2007). The significance of workplace learning for individuals, groups and organisations. Skope Monograph 6, Oxford, UK. Retrieved 8 August 2014 from: http://www.skope.ox.ac.uk/sites/default/files/Monogrpah\%209.pdf

Eraut, M. (2012). Developing a broader approach to professional learning. In McKee A. \& Eraut, M (Eds). Learning Trajectories, Innovation and Identity for Professional Development. Springer.

Evans, K. and Rainbird, H. (2002). The significance of workplace learning. In Evans, Hodkinson and Unwin (Eds). Working to Learn. Kogan Page, London

Evans, K. (2002). The challenges of 'making learning visible' problems and issues in recognizing tacit skills and key competences. In Evans Hodkinson and Unwin (Eds). Working to Learn. Kogan Page, London

Evans, K., Kersh, N and Sakamoto, A (2004). Learner biographies. In Rainbird, Fuller and Munro (Eds). Workplace Learning in context. London, Routledge.

Evans, K., Guile, D. \& Harris, J. (2011). Rethinking Work-based-learning: for education professionals and professionals who educate. In Malloch, Cairns, Evans and O'Connor (Eds). The SAGE Handbook of Workplace Learning. SAGE, London

Evans, L. (2007). Professionalism, Professionality and the development of education professionals. Paper presented at the ILL/CRPE $2^{\text {nd }}$ Conference.

Evans, L. (2008). Professionalism, professionality and the development of education professionals. British Journal of Educational Studies. 56(1), 20-38.

Evetts, J. (2003). The sociological analysis of professionalism. Int Sociololgy 18

Freidson, E. (2001). Professionalism the Third Logic. Polity, London.

Dept. of Finance, (2010). EU/IMF Programme of Financial Support for Ireland.

Fuller, A and Unwin L (2002). Developing pedagogies for the contemporary workplace. In Evans, Hodkinson and Unwin (Eds). Working to Learn. Kogan Page, London

Fuller, A and Unwin, L (2011). Workplace learning and the organization. In Malloch, Cairns, Evans and O'Connor (Eds). The SAGE Handbook of Workplace Learning. SAGE, London 
Ginsberg,S., Regehr, G. and Lingard, L. (2002) Understanding students' reasoning in professionally challenging situations. Retrieved 15 August, 2014 from http://www.ncbi.nlm.nih.gov/pmc/articles/PMC1494956/

Hager, P (2011). Theories of workplace learning, In Malloch, Cairns, Evans \& O'Connor (Eds.). The SAGE handbook of workplace learning. SAGE, London.

Hamilton, N. \& Brabbit, L. (2007). Fostering professionalism through mentoring. Journal of Legal Education, 2007. U of St. Thomas Legal Studies Research Paper No. 06-17.

Hamilton, N. (2008). Assessing professionalism: measuring progress in the formation of an ethical professional identity. University of St Thomas Law Journal, 5, 470-510.

Harris, R. (2011). Phenomenographic perspectives on the structure of conceptions: The origins, purposes, strengths, and limitations of the what/how and referential/structural frameworks. Education Research Review, 6, 109-124.

Hazard, G. \& Dondi, A. (2004). Legal Ethics - a comparative study. Stanford University Press, California.

Hession, R. (2012). A Phenomenographic study on teaching professionalism - how tutors and training solicitors in legal professional education perceive their role. MA thesis - MA in Higher Education Professional Legal Education and Skills.

Hession, R. (2013). Should education researchers explicitly reveal their position? - a personal life history study. EdD Assignment

Hogan, D. (1996). The Legal Profession in Ireland 1789-1922. Incorporated Law Society of Ireland, Dublin.

Kreiger, L. (2005). The inseparability of professionalism and personal satisfaction: perspectives on values, integrity and happiness. Clinical law review. Vol. 11:425.

Illeris, K (2003). Workplace learning and learning theory. Journal of Workplace learning. 15(4).

Ireland, J., Tambyah, M., Neofa, Z. \& Harding, T. (2008). The tale of four researchers: trials and triumphs from the phenomenographic research specialization. Presented at the Australian Assocation for Research in Education 2008 International Education Conference: 
Changing Climates: Education for Sustainable Futures. Queensland University of Technology: Brisbane.

Kahn, P. (2013). The informal curriculum: a case study on tutor reflexivity, corporate agency and medical professionalism. Teaching in Higher Education. 18(6), 631-642.

Kelly, M.J. (1994). Lives of lawyers; Journeys in the organizations of practice. University of Michigan Press, Michigan.

Kullgren, J. \& Lowenstein, J. (2003). Can you teach professionalism?.... and if you can, how? Virtual Mentor, 5(12), 1-3.

Kronman, A.T. (1999). Professionalism. Faculty Scholarship Series. Paper 1048. Retrieved 10 March 2016 from:

http://digitalcommons.law.yale.edu/fss_papers/1048

Kronman, A. T. (2000). The Law as a profession. In Rhode (Ed.), Ethics in Practice: Lawyers' Roles, Responsibilities and Regulation (pp. 29-39). Oxford University Press, Oxford.

Kvale, S. (1996). InterViews: An introduction to qualitative research interviewing. Thousand Oaks, SAGE, California.

Law Society of Scotland PEAT 2 outcomes. Retrieved 12 August 2014 from: https://www.lawscot.org.uk/media/225803/peat\%202\%20outcomes.pdf

Law Society of Ireland (2013). A Guide to Professional Conduct of Solicitors in Ireland (3rd ed.). Law Society of Ireland, Dublin.

Law Society of Ireland (2014). Interpersonal ImpACT programme. Law Society of Ireland, Dublin.

Limberg (2014). Phenomenography. Retrieved 25 June, 2014 from: http://srmo.sagepub.com.eresources.shef.ac.uk/view/sage-encyc-qualitative-researchmethods/n316.xml

Maharg, P. (2006). On the Edge: ICT and the transformation of professional legal learning. Web Journal of Current Legal Issues, 3. 
Maharg, P. (2007). Transforming Legal Education: Learning and Teaching the Law in the early Twenty-first Century. Ashgate, Hampshire.

Maharg, P. (2012). 'Associated Life': Democratic professionalism and the moral imagination. In Bankowski \& Del Mar (Eds.), The Moral Imagination and Legal Life. Beyond Text in Legal Education (Vol. 2). Ashgate Publishing, Aldershot.

Mann, L. (2009). Critical features of Phenomenography. Retrieved 10 August 2015 from http://aaee-scholar.pbworks.com/w/page/1177079/Research\%20Method\%20\%20Phenomenography.

Marsick, V. \& Watkins, K. (1990). Informal and incidental learning in the workplace. Routledge, London.

Martimianakis, M. A., J. M. Maniate, and B. D. Hodges. (2009). Sociological Interpretations of Professionalism. Medical Education 43 (9): 82983.

Martin, E., Trigwell, K., Prosser, M. \& Ramsden, P. (2003). Variation in the Experience of Leadership of Teaching in Higher Education. Studies in Higher Education, 28(3), 247.

Marton, F. (1986). Phenomenography - a research approach to investigating different understandings of reality. Journal of Thought, 21, 28-49.

Marton, F. \& Booth, S. (1997). Learning and Awareness. Lawrence Erlbaum, Mahhaw, NJ.

Mather, L., McEwen, C. \& Maiman, R. (2001). Divorce lawyers at work - varieties of professionalism in practice. OUP.

May, T. (2001) Social Research: Issues, methods and process. $3^{\text {rd }}$ edition. Open University Press, Maidenhead.

McCallum, C. (2014). Professionalism in the practice of law. Retrieved 5 April 2015: http://www.ibanet.org/Article/Detail.aspx?ArticleUid=56bbc140-9a8e-4b28-b35d$\underline{43912 b a 98676}$

McKenzie, J. (2002). Variation and relevance structures for university teachers' learning: Bringing about change in ways of experiencing teaching. Paper presented at the Annual Conference of the Higher Education Research and Development Society of Australasia. Perth. 
Molloy (2014). Corruption in the Gárda Síochana. The Irish Times 16 November 2014.

Montgomery, E. J. (2008). Incorporating emotional intelligence concepts into legal education - strengthening the professionalism of law students, University of Toledo Law Review, 39, 323-352.

Nagler, A., Andolsek, K., Rudd, M., Sloane, R., Musick, D., and Basnight, L. (2014). The professionalism disconnect: do entering residents identify yet participate in unprofessional behaviors? BMC Medical Education, 14:60.

Nelson, R.I. \& Trubeck, D.M. (1992). Introduction: new problems and new paradigms in studies of legal professionalism. In Nelson, Trubeck \& Rayman (Eds). Lawyers ideals/lawyers practices: transformations in the American legal profession. Cornell University, Ithaca NY.

Nichols, N. C. (2005). Modelling Professionalism: The Process from a Clinical Perspective. Widener Law Journal, 14(2), 441-448.

Niikko, A. (2003). Education - a joint task for parents, kindergarten teachers and kindergarden student teachers. International Journal of Early Years Education. 12 (3), 259274

New York Bar Association (2011). Report of the taskforce on the future of the legal profession. Retrieved 22 September 2011 from http://www.nysba.org/AM/Template.cfm?Section=Home\&ContentID=48353\&Template=/C $\underline{\text { M/ContentDisplay.cfm }}$

O’Neill, O. (2002). A Question of Trust - the BBC Reith Lectures 2002. Cambridge University Press.

Oxford dictionary.com. Retrieved 10 September 2015 from http://www.oxforddictionaries.com

Park, J., Woodrow, S., Reznick, R., Beales, J. and MacRae, H. (2010). Observation, reflection and reinforcement:surgery faculty members' and residents' perceptions of how they learned professionalism. Academic Medicine. 85(1), $134-139$.

Parker, C. (2002). Regulation of the ethics of Australian legal practice: autonomy and responsiveness. UNSW Law Journal. 25 9(3). 
Parker M. (2006). Assessing professionalism: theory and practice. Med Teach, 28(5):399403.

Pearce, R (1995). Professionalism Paradigm Shift: Why Discarding Professional Ideology Will Improve the Conduct and Reputation of the Bar. 70 N.Y.U. L. Rev. 1229

Pearce, R. (2002). Legal Ethics must be at the Heart of the Law School Curriculum. Journal of Legal Professionalism, 26(159), 160-163.

Phillips, F. (2004). Ethics of the Legal Profession. Cavendish Publishing, London.

Pillow, W. (2010). Confession, catharsis, or cure? Rethinking the uses of reflexivity as methodological power in qualitative research. International Journal of Qualitative Studies in Education. 16(2) 175-196.

Prosser, M., \& Trigwell, K. (1999). Understanding learning and teaching: The experience in higher education. McGraw-Hill Education, UK.

Prosser, M. \& Trigwell, K. (1999). Relational perspectives on higher education teaching and learning in the sciences. Studies in Science Education, 33 (31-60).

Rainbird, H., Fuller, A and Munro, A (eds) (2004). Workplace learning in context. London: Routledge.

Ratanawongsa, N., Bolen, S., Howell, E., Kern, D., Sisson, S. \& Larriviere, D. (2006). Residents perceptions of professionalism in training and practice: barriers, promoters and duty hour requirements. J Gen Intern Med, 21, 758-763.

Research Ethics, General Principles and Statements (Version 6), University of Sheffield.

Retrieved 5 April 2014 from: https://www.shef.ac.uk/ris/other/gov-

ethics/ethicspolicy/general-principles.

Riley, S. and Kumar, N. (2012). Teaching medical professionalism. Clinical Medicine, 12 (1), 9-11.

Rhode, D.I. (1985). Ethical perspectives on legal practice. Stanford Law Review, 37 (589), 614.

Rhode, D.I. (1994). Professional responsibility: ethics by the pervasive method. Little Brown, Boston MA. 
Roberts, LW., Green Hammond, KA., Geppert, CM., \& Warner, TD (2004), The positive role of professionalism and ethics training in medical education: a comparison of medical students and resident perspectives. Acad Psychiatry, 28(3): $17-82$.

Sandberg, J. (1994). Human competence at work: An interpretivist approach. Bas, Goteborg University, Sweden.

Schon, D. (1987), Educating the reflective practitioner: towards a new design for teaching and learning in the professions. Jossey Bass: San Francisco.

Shestack, J. J. (1998). Pervasive professionalism must be part of legal education. $A B A$ Journal, 84(3), 6.

Shreeve, A. (2010). A phenomenographic study of the relationship between professional practice and teaching your practice to others. Studies in Higher Education, 35(6), 691-703

Shulman, L. (2005). Signature pedagogies in the professions. Dardalus, Summer 2005.

Sikes, P. (2004). Methodology, procedures and ethical concerns. In Opie (Ed.). Doing educational research: a guide for first-time researchers (pp.15-33). Sage Publications Ltd., London.

Silver, M. (2005). Commitment and responsibility: modelling and teaching professionalism pervasively. Widener Law Journal, 14.

Solicitors Regulation Authority (SRA) Training Regulations 2014. Retrieved August 2014 from: http://www.sra.org.uk/solicitors/handbook/trainingregs2014/content.page

Solicitors Regulation Authority /MMG Report (2014). Developing competence statements for solicitors. Retrieved 24 August 2014: https://www.sra.org.uk/sra/consultations/competencestatement.page.

Stamouli, I. \& Huggard, M. (2007). Phenomenography as a tool for understanding our students. Paper presented at International Symposium for Engineering Education. Dublin City University.

Steinert, Y., Cruess, S., Cruess, R. \& Snell, L. (2005). Faculty development for teaching and evaluating professionalism: from programme design to curriculum change. Medical Education, 39, 127-136. 
Stempel, J.W. (1999). Embracing descent: the bankruptcy of a business paradigm for conceptualizing and regulating the legal profession. Florida State University Law Review 27.

Stern, D. (2003). Can professionalism be taught? Virtual Mentor, 5(12), 1-3.

Suchman, A., Williamson, P., Litzelman, D., Frankel, R. \& Mossbarger, T. (2004). Towards an informal curriculum that teaches professionalism - transforming the social environment of a medical school. J Gen Intern Med, 19 501-504.

Svensson, L. (1997). Theoretical Foundations of Phenomenography. Higher Education Research \& Development. 16(2), 159-171.

Swick, HM.,Szenas P., Danoff D., Whitcomb ME (1999). Teaching professionalism in undergraduate medical education. JAMA. 282:830-32.

Taylor, I. (1997). Developing learning in professional education: Partnerships for practice. McGraw-Hill Education (UK).

Tutty, J., Sheard, J. \& Avram, C. (2008). Teaching in the current higher education environment: perceptions of IT academics. Computer Science Education, 18(3), 171-185.

Wear, D. \& Kuczewsji, MG. (2004). The professionalism movement: can we pause it? Retrieved 10 April, 2015 from http://www.ncbi.nlm.nih.gov/pubmed/15186664

Whitcomb, M. (2002). Fostering and evaluating professionalism in medical education. Academic Medicine, 77, 473-474.

Wilkins, D. (1999). Beyond "Bleached Out" Professionalism - Defining Professionalism for Real Professionals. In D. Rhode (Ed.), Ethics in Practice - Lawyers Roles Responsibilities and Regulation (pp. 208-235). Oxford, Oxford. 


\section{Appendix i}

\section{Sample interview questions}

Tutor/training firms/Course Managers questions

- What do you understand your role as a tutor/ training solicitor/Course Manager to be?

- "Professionalism" - What does it mean to you?

- Should there be a standard definition of professionalism and if so who should define professionalism?

- What you think is the best approach to ensure trainee solicitors assimilate professionalism? (and can apply it)

- To what extent do you adopt this approach as tutor/training solicitor?

- Can you explicitly teach professionalism?

- Does professionalism need to be defined to be taught?

- What do you think are the barriers to/promoters of learning professionalism?

- Does how you were taught influence your teaching/mentoring style?

- What influences the learning of professionalism?

- Who has a role in instilling/teaching and/or assessing professionalism?

\section{Trainees questions}

- What do you think the role of the tutor/ training solicitor is?

- "Professionalism" - What does it mean to you?

- Should there be a standard definition of professionalism and if so who should define professionalism?

- Can you learn professionalism?

- How do you best learn professionalism?

- Does professionalism need to be defined to be taught? 
- What influences your learning of professionalism?

- Do you think the tutor's/training firm's style of teaching impacts on your learning?

- What do you think are the barriers to/promoters of learning professionalism?

- Should it be assessed and if so, how?

- Do you think you should have an input into how professionalism is taught and/or assessed? 


\title{
Appendix ii
}

\section{British Educational Research Association BERA}

\section{ETHICAL GUIDELINES FOR EDUCATIONAL RESEARCH}

\author{
September 2011
}

\section{PREAMBLE}

1 The 2004 revision of the Association's Ethical Guidelines (for Educational Research) built on the 1992 statement to recognize the academic tensions that a multi-disciplinary community generates when dealing with the complex research issues that characterize education contexts and to include the field of action research. This 2011 version refines and strengthens the Association's position on the rights of researchers in commissioned research contexts. A small number of updating revisions have also been made.

$2 \mathrm{It}$ is intended that deliberation on these guidelines, and compliance where appropriate, will be a binding responsibility on all members of the Association in their research activities. Although they can only be advisory for others engaged in carrying out, sponsoring or using educational research, it is the hope of the Association that they will attract widespread consultation and adherence. In the particular case of groups of educational researchers (e.g. in university departments or private agencies), the Association recommends the setting up of local ethics committees that endorse and employ these guidelines in support of their own work.

3 The underpinning aim of the guidelines is to enable educational researchers to weigh up all aspects of the process of conducting educational research within any given context (from student research projects to large-scale funded projects) and to reach an ethically acceptable position in which their actions are considered justifiable and sound. For the vast majority of educational research activity this basic tenet may be non-problematic but dilemmas will arise for others and these guidelines will provide a basis for deliberation and perhaps resolution or compromise.

\section{Aspirations of Educational Researchers}

4 Educational researchers aim to extend knowledge and understanding in all areas of educational activity and from all perspectives including learners, educators, policymakers and the public. The Association recognizes that the community of educational researchers is multi-disciplinary and that within the paradigms and methodologies espoused by the various disciplines, and often variously by their sub-disciplines, a variety of concepts may be problematic. Examples among these are the concepts of 'data', 'reliability', 'validity', 'subjectivity' and 'objectivity'. Debates abound, for example, on the relativity or otherwise of 'truth' and 'reality' and such debates are symptomatic of a community undertaking critical analysis of its basic tenets and enjoying the enhancement of its intellectual capital through the creative tension it produces.

5 The Association therefore recognizes the legitimacy of the diverse educational research philosophies, theories and methodologies that exist and seeks to ensure that its guidelines do not selectively judge or constrain, directly or indirectly, the methodological distinctions or the research processes that emanate from them. These guidelines, then, are offered as set of principles and 
advice that will be subject to continuing review as our knowledge, understanding and practice of educational research continues to evolve.

\section{Principles Underpinning the Guidelines}

6 The Association considers that all educational research should be conducted within an ethic of respect for: • The Person $\bullet$ Knowledge $\bullet$ Democratic Values $\bullet$ The Quality of Educational Research • Academic Freedom

\section{Ethical Guidelines for Educational Research}

7 In guiding researchers on their conduct within this framework the Association sets out its guidelines under the following headings: $\bullet$ Responsibilities to Participants $\bullet$ Responsibilities to Sponsors of Research • Responsibilities to the Community of Educational Researchers • Responsibilities to Educational Professionals, Policy Makers and the General Public

\section{GUIDELINES Responsibilities to Participants}

8 The participants in research may be the active or passive subjects of such processes as observation, experiment, auto/biographical reflection, survey or test. They may be collaborators or colleagues in the research process or they may simply be part of the context e.g. where students are part of the context but not the subjects of a teacher's research into his or her own professional practice.

9 The Association considers that educational researchers should operate within an ethic of respect for any persons involved in the research they are undertaking. Individuals should be treated fairly, sensitively, with dignity, and within an ethic of respect and freedom from prejudice regardless of age, gender, sexuality, race, ethnicity, class, nationality, cultural identity, partnership status, faith, disability, political belief or any other significant difference. This ethic of respect should apply to both the researchers themselves and any individuals participating in the research either directly or indirectly. Adherence to this ethic of respect implies the following responsibilities on the part of researchers. Voluntary Informed Consent

10 The Association takes voluntary informed consent to be the condition in which participants understand and agree to their participation without any duress, prior to the research getting underway.

11 Researchers must take the steps necessary to ensure that all participants in the research understand the process in which they are to be engaged, including why their participation is necessary, how it will be used and how and to whom it will be reported. Social networking and other on-line activities, including their video-based environments, present challenges for consideration of consent issues and the participants must be clearly informed that their participation and interactions are being monitored and analysed for research.

12 Researchers engaged in action research must consider the extent to which their own reflective research impinges on others, for example in the case of the dual role of teacher and researcher and the impact on students and colleagues. Dual roles may also introduce explicit tensions in areas such as confidentiality and must be addressed accordingly. 
13 Educational research undertaken by UK researchers outside of the UK must adhere to the same ethical standards as research in the UK. Appropriate consent should be sought from local authorities in cultures that adopt a collective approach to consent (e.g. community or religious leaders or local government officials) but cultural sensitivity should not extend to excluding the individuals concerned from making their own informed decision to take part in the research. Any additional regulations and cultural sensitivities of the host jurisdiction must also be

observed, for example if participants wish to be accompanied in data collection activities such as interviews. Especially sensitive ethical issues arise when researching particular communities which are marginalised because of their age, culture, race, gender, sexuality, socio-economic standing or religion. Ethical issues also arise when researching in sensitive situations influenced by contexts of cultural difference and which impact on educational experiences. Where the overseas research involves children or vulnerable adults, the researchers must comply with the child protection clearance procedures of the UK. Where the researchers (e.g. for data collection) are recruited in the overseas context itself, in which UK-style protection clearance is not available, a letter or other formal endorsement of the good character of each researcher should be obtained from a person in authority in the jurisdiction concerned (e.g. school principal). Openness and Disclosure

14 The securing of participants' voluntary informed consent, before research gets underway, is considered the norm for the conduct of research. Researchers must therefore avoid deception or subterfuge unless their research design specifically requires it to ensure that the appropriate data is collected or that the welfare of the researchers is not put in jeopardy. Decisions to use nondisclosure or subterfuge in research must be the subject of full deliberation and subsequent disclosure in reporting. The Association recommends that approval for any course of action involving deception should be obtained from a local or institutional ethics committee. In any event, if it possible to do so, researchers must seek consent on a post- hoc basis in cases where it was not desirable to seek it before undertaking the research. Right to Withdraw

15 Researchers must recognize the right of any participant to withdraw from the research for any or no reason, and at any time, and they must inform them of this right. In all such circumstances researchers must examine their own actions to assess whether they have contributed to the decision to withdraw and whether a change of approach might persuade the participants to re-engage. In most cases the appropriate course of action will be for the researchers to accept the participants' decision to withdraw. Decisions to persuade them to re-engage must be taken with care.

Researchers must not use coercion or duress of any form to persuade participants to re-engage with the work. In cases where participants are required by a contractual obligation to participate e.g. when mandated as part of their employment to facilitate an evaluation study, researchers may, however, have proper recourse to a third party (e.g. the employing authority) to request compliance with a contract. Children, Vulnerable Young People and Vulnerable Adults

16 The Association requires researchers to comply with Articles 3 and 12 of the United Nations Convention on the Rights of the Child. Article 3 requires that in all actions concerning children, the best interests of the child must be the primary consideration. Article 12 requires that children who are capable of forming their own views should be granted the right to express their views freely in all matters affecting them, commensurate with their age and maturity. Children should therefore be facilitated to give fully informed consent. 
17 The Association considers that the spirit of Articles 3 and 12 above should also apply in research contexts involving young people and vulnerable adults.

18 In the case of participants whose age, intellectual capability or other vulnerable circumstance may limit the extent to which they can be expected to understand or agree voluntarily to undertake their role, researchers must fully explore alternative ways in which they can be enabled to make authentic responses. In such circumstances, researchers must also seek the collaboration and approval of those who act in guardianship (e.g. parents) or as 'responsible others' (i.e. those who have responsibility for the welfare and well-being of the participants e.g. social workers).

19 Researchers must ensure that they themselves, and any collaborators or research assistants and students under their supervision, comply with legal requirements in relation to working with school children or vulnerable young people and adults.

20 Researchers must recognize that participants may experience distress or discomfort in the research process and must take all necessary steps to reduce the sense of intrusion and to put them at their ease. They must desist immediately from any actions, ensuing from the research process, that cause emotional or other harm.

21 Researchers must recognize concerns relating to the 'bureaucratic burden' of much research, especially survey research, and must seek to minimize the impact of their research on the normal working and workloads of participants. Incentives

22 Researchers' use of incentives to encourage participation must be commensurate with good sense and must avoid choices which in themselves have undesirable effects (e.g. the health aspects of offering cigarettes to young offenders or sweets to school-children). They must also acknowledge that the use of incentives in the design and reporting of the research may be problematic; for example where their use has the potential to create a bias in sampling or in participant responses. Detriment Arising from Participation in Research

23 Researchers must make known to the participants (or their guardians or responsible others) any predictable detriment arising from the process or findings of the research. Any unexpected detriment to participants, which arises during the research, must be brought immediately to their attention or to the attention of their guardians or responsible others as appropriate.

24 Researchers must take steps to minimize the effects of designs that advantage or are perceived to advantage one group of participants over others e.g. in an experimental or quasi-experimental study in which the treatment is viewed as a desirable intervention and which by definition is not available to the control or comparison group respectively. Privacy

25 The confidential and anonymous treatment of participants' data is considered the norm for the conduct of research. Researchers must recognize the participants' entitlement to privacy and must accord them their rights to confidentiality and anonymity, unless they or their guardians or responsible others, specifically and willingly waive that right. In such circumstances it is in the researchers' interests to have such a waiver in writing. Conversely, researchers must also recognize participants' rights to be identified with any publication of their original works or other inputs, if they so wish. In some contexts it will be the expectation of participants to be so identified. 
26 Researchers must comply with the legal requirements in relation to the storage and use of personal data as set down by the Data Protection Act (1998) and any subsequent similar acts. In essence people are entitled to know how and why their personal data is being stored, to what uses it is being put and to whom it may be made available. Researchers must have

participants' permission to disclose personal information to third parties and are required to ensure that such parties are permitted to have access to the information. They are also required independently to confirm the identity of such persons and must keep a record of any disclosures. Disclosure may be written, electronic, verbal or any visual means.

27 The Data Protection Act also confers the right to private citizens to have access to any personal data that is stored in relation to them. Researchers seeking to exploit legal exclusions to these rights must have a clear justification for so doing.

28 Researchers must ensure that data is kept securely and that the form of any publication, including publication on the Internet, does not directly or indirectly lead to a breach of agreed confidentiality and anonymity. Disclosure

29 Researchers who judge that the effect of the agreements they have made with participants, on confidentiality and anonymity, will allow the continuation of illegal behaviour, which has come to light in the course of the research, must carefully consider making disclosure to the appropriate authorities. If the behaviour is likely to be harmful to the participants or to others, the researchers must also consider disclosure. Insofar as it does not undermine or obviate the disclosure, researchers must apprise the participants or their guardians or responsible others of their intentions and reasons for disclosure.

30 At all times the decision to override agreements on confidentiality and anonymity must be taken after careful and thorough deliberation. In such circumstances it is in the researchers' interests to make contemporaneous notes on decisions and the reasoning behind them, in case a misconduct complaint or other serious consequence arises.

31 The Association considers it good practice for researchers to debrief participants at the conclusion of the research and to provide them with copies of any reports or other publications arising from their participation. Where the scale of the research makes such a consideration impractical, alternative means such as a website should be used to ensure participants are informed of the outcomes.

\section{Responsibilities to Sponsors of Research}

$32 \mathrm{~A}$ sponsor of research is considered to be any person or body that funds research (e.g. a research charity or government body) or facilitates it by allowing and enabling access to data and participants (e.g. an examinations body).

33 The Association expects researchers to bring its Ethical Guidelines to the attention of all sponsors of research.

34 Written agreements are considered the norm for funded or commissioned research. Such agreements should wherever possible and especially in the case of publicly funded research take 
into account the need of a democratic citizenry to be informed by the results of these enquiries. They should minimally cover the purpose of the research, the research methods to be used, any conditions of access to data or participants, ownership of data, the researchers' right to publish, requirements for reporting and dissemination, deadlines for completion of the work and the accounting for the use of funds. In recognition of the dynamics of research, agreements should also include provision for negotiating changes sought by either the researchers or the sponsors.

35 Researchers must fulfil their responsibilities to sponsors to the highest possible standards. It is in the researchers' interest that respective responsibilities and entitlements should be agreed with the sponsors at the outset of the research. Where the sponsor acts essentially as a host or facilitator for research, researchers must, out of courtesy, inform them of the work they propose to undertake e.g. a group of teachers engaging in a process of action research as part of curriculum renewal should inform the school management of their intentions.

36 In negotiating sponsored research, researchers must provide honest and complete details of their competence and capacity to undertake the research that is proposed. Researchers will normally take a disinterested approach to research design, analysis and interpretation and where they feel they must take other than a disinterested position this should be made clear and amenable to scrutiny. Methods

37 Researchers must employ methods that are fit for the purpose of the research they are undertaking. Those researchers who prefer or promote specific methods, theories or philosophies of research must have knowledge of alternative approaches sufficient to assure sponsors that they have considered these and that the research needs are being properly addressed. Sponsors should be offered a full, honest and amenable justification on the final choice of methods.

38 Researchers must, within the context and boundaries of their chosen methods, theories and philosophies of research, communicate the extent to which their data collection and analysis techniques, and the inferences to be drawn from their findings, are reliable, valid and generalizable. Publication

39 The Association recommends that all members should make themselves familiar with the BERA research writing guidelines: Good Practice on Educational Research Writing.

40 The right of researchers independently to publish the findings of their research under their own names is considered the norm for sponsored research, and this right should not be lightly waived or unreasonably denied. This right is linked to the obligation on researchers to ensure that their findings are placed in the public domain and within reasonable reach of educational practitioners and policy makers, parents, pupils and the wider public.

41 Researchers must avoid agreeing to any sponsor's conditions that could lead to serious contravention of any aspect of these guidelines or that undermine the integrity of the research by imposing unjustifiable conditions on the methods to be used or the reporting of outcomes. Attempts by sponsors or funding agencies to use any questionable influence should be reported to the Association.

42 Researchers have the right to dissociate themselves publicly from accounts of the research that they conducted, the subsequent presentation of which they consider misleading or unduly selective. 
Sponsors enjoy a similar right. It is in the interests of researchers and sponsors alike to prevent this situation arising by agreements on publication or, if necessary, through arbitration.

\section{Responsibilities to the Community of Educational Researchers}

43 The community of educational researchers is considered to mean all those engaged in educational research including academics, professionals (from private or public bodies), teachers and students. Misconduct

44 All educational researchers must protect the integrity and reputation of educational research by ensuring they conduct their research to the highest standards.

Researchers must therefore not bring research into disrepute by, for example: • Falsifying research evidence or findings; • 'Sensationalizing' findings in a manner that sacrifices intellectual capital for maximum public exposure; $\bullet$ Distorting findings by selectively publishing some aspects and not others; • Criticizing other researchers in a defamatory or unprofessional manner; • Exploiting the conditions of work and roles of contract research staff; • Undertaking work for which they are perceived to have a conflict of interest or where self- interest or commercial gain might be perceived to compromise the objectivity of the research; • Undertaking work for which they are not competent; - Using work carried out with co-researchers as the basis of individual outputs without the agreement of the co-researchers concerned; • Using research for fraudulent or illegal purposes.

45 Where researchers become aware of examples of malpractice or potential malpractice they must present their concerns, in the first instance, to the researchers involved. With due consideration to the important principle of the public's right to know, researchers should avoid bringing the community into disrepute through public accusations or allegations.

46 Subject to any limitations imposed by agreements to protect confidentiality and anonymity, researchers must make their data and methods amenable to reasonable external scrutiny. The assessment of the quality of the evidence supporting any inferences is an especially important feature of any research and must be open to scrutiny. Where sponsors initiate the request for scrutiny, and disclosure of aspects of the data may be injurious to participants, researchers should consider assuring the sponsor of the integrity of the work through the scrutiny of a mutually acceptable third-party, who is also bound by the non-disclosure agreements.

47 Researchers must accord due respect to all methodologies and related methods. They must contribute to the community spirit of critical analysis and constructive criticism that generates improvement in practice and enhancement of knowledge. Authorship

48 The authorship of publications is considered to comprise a list of everyone who has made a substantive and identifiable contribution to their generation. Examples of substantive contributions include: contributing generative ideas, conceptual schema or analytic categories; writing first drafts or substantial portions; significant rewriting or editing; contributing significantly to relevant literature reviewing; and contributing to data collection, to its analysis and to judgements and interpretations made in relation to it. 
49 Academic status or other indicator of seniority must not determine first authorship; rather the order of authorship should reflect the relative leadership and contributions made by the researchers concerned.

\section{Responsibilities to Educational Professionals, Policy Makers and the General Public}

50 Researchers have a responsibility to seek to make public the results of their research for the benefit of educational professionals, policy makers and a wider public understanding of educational policy and practice, subject only to the provisos indicated in previous paragraphs.

51 Educational researchers must endeavour to communicate their findings, and the practical significance of their research, in a clear, straightforward fashion and in language judged appropriate to the intended audience. 


\section{Appendix iii}

\section{Participant Consent Form}

Title of Research Project: Professionalism - can you teach it?

Name of Researcher: Rachael Hession

\section{Participant Identification Number for this project: \\ Please initial box}

1. I confirm that I have read and understand the information sheet dated linsert date] explaining the above research project and I have had the opportunity to ask questions about the project.

2. I understand that my participation is voluntary and that I am free to withdraw at any time without giving any reason and without there being any negative consequences. In addition, should I not wish to answer any particular question or questions, I am free to decline.

3. I understand that my responses will be kept strictly confidential. I give permission for members of the research team to have access to my anonymised responses. I understand that my name will not be linked with the research materials, and I will not be identified or identifiable in the report or reports that result from the research.

4. I agree for the data collected from me to be used in future research

5. I agree to take part in the above research project.

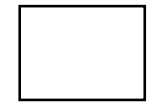

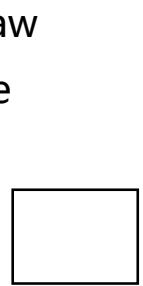

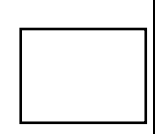

Name of Participant

Date

Signature 


\section{Lead Researcher \\ Date \\ Signature}

To be signed and dated in presence of the participant

Copies:

Once this has been signed by all parties the participant should receive a copy of the signed and dated participant consent form, the letter/pre-written script/information sheet and any other written information provided to the participants. A copy of the signed and dated consent form should be placed in the project's main record (e.g. a site file), which must be kept in a secure location. 


\section{Appendix iv}

\section{INFORMATION SHEET}

\section{Research Project Title:}

Professionalism - can you teach it?

\section{Invitation paragraph}

You are being invited to take part in a Doctorate research project. Before you decide it is important for you to understand why the research is being done and what it will involve. Please take time to read the following information carefully and discuss it with others if you wish. Ask me if there is anything that is not clear or if you would like more information. Take time to decide whether or not you wish to take part.

\section{What is the project's purpose?}

The aim of this three year research project is to study the views of those involved in legal professional education as regards how to teach professionalism. Ultimately, I hope the findings of this project will contribute to an improvement in the standard of professionalism of the newly qualified solicitor.

\section{Why have I been chosen?}

A varied group of participants is required for this project. You have been chosen on the basis of the size/location of the firm you are a training solicitor/trainee with (not relevant to Course Managers, your gender, stage of traineeship (trainees only). 14 to 18 participants will be interviewed.

\section{Do I have to take part?}

Taking part in the research is entirely voluntary and refusal to agree to participate will involve no penalty or loss of benefits to which you are otherwise entitled. You may discontinue participation at any time without penalty or loss of benefits to which you are otherwise entitled.

\section{What will happen to me if I take part?}

Agreement to participate will involve one interview of no longer than one hour. I may need to ask you a few follow questions to clarify a point. I will ask you to answer the questions as comprehensively and freely as possible.

\section{When and where will interviews take place?}

The location and time of the interviews will be by agreement with each participant e.g. options to hold interviews at your place of work, at the Law Society or another location at a time that suits you.

\section{Will my taking part in this project be kept confidential?}


All the information that I collect about you during the course of the research will be kept strictly confidential. You will not be able to be identified in any reports or publications.

\section{The researchers position/funding the research?}

While the researcher is an employee of the Law Society of Ireland she is carrying out this project in her personal capacity as part of a Doctorate in Education (EdD) with the University of Sheffield. The Law Society is funding the Doctorate fees as this project contributes to my role in Education.

\section{Who has ethically reviewed the project?}

This project has been ethically approved via the University of Sheffield's - School of Education ethics review procedure. The University's Research Ethics Committee monitors the application and delivery of the University's Ethics Review Procedure across the University.

\section{Will I be recorded, and how will the recorded media be used?}

The audio and/or video recordings of the interview will be used only for analysis and for illustration in conference presentations and lectures. No other use will be made of them without your written permission, and no one outside the project will be allowed access to the original recordings (with the exception of a typist if required). Recordings will be password protected.

12. Will I be contacted to clarify the transcript of my interview? How can I find out about the findings?

The researcher may contact you if she requires clarification or to annotate the interview transcript within two weeks of the interview. Contact will be made by phone initially to agree on the details of a meeting to discuss clarifications.

Should you wish to find out more about the findings of the study feel free to contact the researcher (contact details below) to discuss same or to make the findings available to you. The researcher expects the findings to be finalised by April 2016.

\section{Who do I contact if I have cause for complaint?}

Please contact the researcher's supervisor, Professor Kathryn Ecclestone k.ecclestone@sheffield.ac.uk or the Chair of the Ethics panel: Dan Goodley: d.goodley@sheffield.ac.uk. Thereafter you may contact the University registrar: registrar@sheffield.ac.uk.

\section{What are the advantages/disadvantages of taking part?}

This study aims to provide useful educational insights into the teaching of professionalism and ultimately the improvement of the standard of professionalism of the solicitor's profession. Your input will contribute to this overall objective. The disadvantage is that the 
interview will take time out of your working day/freetime (approx. $30 \mathrm{~min}$ ) and will involve an effort on your behalf to engage with the researcher's questions and discussion.

Please complete and sign the Consent Form attached if you are happy to be involved in this project

Thank you for taking part in the project

Researcher: Rachael Hession, Law Society of Ireland, (01) 8815707 
The

University

Of

Sheffield.

Downloaded: 28/02/2017

Approved: 16/06/2015

Rachael Hession

Registration number: 120120013

School of Education

Programme: EdD

Dear Rachael

PROJECT TITLE: Professionalism - can you teach it?

APPLICATION: Reference Number 002793

On behalf of the University ethics reviewers who reviewed your project, I am pleased to inform you that on $16 / 06 / 2015$ the above-named project was approved on ethics grounds, on the basis that you will adhere to the following documentation that you submitted for ethics review:

- University research ethics application form 002793 (dated 02/06/2015).

- Participant information sheet 006486 version 4 (02/06/2015).

- Participant consent form 005275 version $1(12 / 02 / 2015)$.

- Participant consent form 005054 version 1 (03/02/2015).

If during the course of the project you need to deviate significantly from the above-approved documentation please inform me since written approval will be required.

Yours sincerely

David Hyatt

Ethics Administrator

School of Education 